\title{
Re-examination of the vascular plants on Hongdo Island, Korea
}

\author{
Young-Jong JANG, Jong-Soo PARK ${ }^{1}$, Jin-Sil LEE ${ }^{2}$, Ji-Yeon LEE $^{3}$ and Byoung-Hee CHOI* \\ Department of Biological Sciences, Inha University, Incheon 22212, Korea \\ ${ }^{1}$ Plant Resources Division, Honam National Institute of Biological Resources, Mokpo 58762, Korea \\ ${ }^{2}$ Yeonsu High School, Incheon 21930, Korea \\ ${ }^{3}$ National Institute of Biological Resources, Incheon 22689, Korea
}

(Received 2 June 2021; Revised 9 August 2021; Accepted 6 September 2021)

\begin{abstract}
This study was carried out to survey the flora of Hongdo Island in Sinan-gun, Jeollanam-do, South Korea. Specimens collected from previous Hongdo flora studies were reexamined using a relevant biodiversity database, and field surveys were carried out 22 times from April of 2003 to October of 2020. Based on the specimens collected during both previous studies and this study, the identified vascular plants of Hongdo consisted of 472 taxa comprising 102 families, 296 genera, 425 species, 6 subspecies, and 41 varieties. Among them, 111 taxa are newly recorded in this study, and 6 taxa are described in detail in terms of their morphological characteristics and habitat. Also, 29 taxa were reviewed or re-identified with corresponding taxonomic annotations. In Korea, Hongdo represents the northern distributional limit of the 4 taxa of Goodyera biflora, Damnacanthus major, Calanthe aristulifera, and Hemerocallis hongdoensis. Moreover, Hosta yingeri and Saussurea polylepis are endemic to Hongdo and nearby islands in Korea. Distribution maps of these species were prepared. Protected species designated by the Ministry of Environment were 7 taxa consisting of 2 taxa of level I, specifically Sedirea japonica and Neofinetia falcata, and 5 taxa of level II, which were Cymbidium macrorhizon, Woodwardia japonica, Dendrobium moniliforme, Calanthe aristulifera, and Bulbophyllum inconspicuum. Red list plants as designated by the National Institute of Biological Resources numbered 11 taxa. Naturalized plants numbered 40 taxa.
\end{abstract}

Keywords: Hongdo Island flora, vascular plants, voucher specimens, biodiversity database

홍도는 전라남도 신안군 흑산면에 속하며, 목포에서 서 쪽으로 $113 \mathrm{~km}$, 흑산도에서 $22 \mathrm{~km}$ 떨어진 면적 $6.47 \mathrm{~km}^{2}$ 섬 이다(동경 $125^{\circ} 10^{\prime}-125^{\circ} 13^{\prime}$, 북위 $34^{\circ} 39^{\prime}-34^{\circ} 44^{\prime}$ ). 홍도의 지 형은 북동쪽의 깃대봉 $(368 \mathrm{~m})$ 과 남서쪽의 양산봉 $(231 \mathrm{~m})$ 을 중심으로 능선이 북동-남서향으로 뻗어있으며, 능선을 중심으로 북서사면과 동남사면이 배사구조를 띤다(Kim, 1986). 해안지역은 홍도항과 해수욕장 일대를 제외하면 급경사의 해식애가 발달하였다(Kwon et al., 2018). 지질은 중생대 백악기 때 형성된 지층으로 홍도층과 유문암 및 응회암층이 주를 이루고, 토양은 사암과 규암이 풍화작용 을 받아 형성된 풍화토로 주로 이루어져 있으며, 하천발 달이 미약한 관계로 하천충적토의 분포는 아주 미약하다 (Hong and $\mathrm{Yu}, 1997)$. 기후는 온난다습한 해양성 기후로, 연 평균 기온 $14.1^{\circ} \mathrm{C}$, 최고기온 $22.6^{\circ} \mathrm{C}$, 최저기온 $8.2^{\circ} \mathrm{C}$ 으로, 우 리나라 연평균 기온 $13.2^{\circ} \mathrm{C}$ 와 비교했을 때, $0.9^{\circ} \mathrm{C}$ 높으며, 연 중 가장 높은 8 월의 경우 $33.1^{\circ} \mathrm{C}$, 최저기온은 1 월에 $-1.8^{\circ} \mathrm{C}$ 이
다(Korea Meteorological Administration, 2020). 연강수량은 $1,187.2 \mathrm{~mm}$ 로 우리나라 연 강수량 $(1,587.9 \mathrm{~mm})$ 에 비해 적으 며, 연평균 습도는 $80.17 \%$ 로 우리나라 평균습도 $69.33 \%$ 보 다 높은 편이다. 특히, 배사구조를 띤 지형으로 인해 산정 에 운해가 자주 낀 모습을 볼 수 있다(Lee and Lee, 1959). 평 균 풍속은 $5.38 \mathrm{~m} / \mathrm{s}$ 로 우리나라 평균 풍속인 $1.88 \mathrm{~m} / \mathrm{s}$ 보다 매우 높은데, 이는 섬의 지리적 특징이 반영된 것으로 보이 며, 겨울철 강한 북서풍의 영향을 받는다(Kim et al., 2018).

홍도는 필리핀 북방에서 발생한 쿠로시오(Kuroshio) 난 류의 영향을 받는 중국, 대만, 일본, 제주 및 한반도의 식물 상과 연관되어 상록활엽수와 같은 남방계 식물의 분포에 중요한 지리학적 위치에 있다(Kim, 1996). 또한, 홍도 및 흑산도를 포함하는 다도해지역은 제 4 빙하기의 해수면이 약 80-140 m 정도가 하강함으로써 빙하기 동안 육지화하 였다가 최후 간빙기인 7,000년 전에 해수면이 상승하면서 현재의 모습을 형성하였는데(Hong and Yu, 1997), 일부 종

\footnotetext{
*Author for correspondence: bhchoi@inha.ac.kr
} 
은 섬의 국지적인 자연환경에서 분화 및 적응하여 특산종 으로 발달한 것으로 보인다(Kang and Chung, 2000). 이와 같이 홍도 식물상은 남방계식물 또는 홍도 및 그 인근도 서에만 제한적으로 분포하는 종 등으로 구성되어 식물지 리학적으로 중요하다.

홍도의 식물상에 관한 선행연구는 1920년 T. Ishidoya의 보고 이후로 Jeollanam-do Education Association (1940), Lee and Lee (1959), Lee and Kim (1968), Lee and Kim (1978), Choi (1980), Kim (1986, 1987), Lee (1999), Park (2003), Lee (2014), Kwon et al. (2018) 등 최근까지 많은 연구가 이루어 졌다. 그러나 대부분의 연구는 증거표본을 통한 분류학적 검토보다는 식생 등 생태학적 보고가 주를 이루고 있다.

기존 증거표본을 비교·검토하는 것은 정확한 자생식물 상을 파악하는 데 매우 중요하다. 그러나 기존 홍도 식물 상 보고문헌들은 대부분 표본정보를 기록하지 않아 표본 의 존재 여부를 확인할 수 없으며, 일본인 연구자에 의해 수집된 홍도 표본은 도쿄대 표본관(TI)에 소장되어 있는 등 국내와 해외의 표본관에 증거표본들이 흩어져 있어 검 토에 어려움이 있다. 최근 생물다양성 정보학(biodiversity informatics)의 발전과 더불어 세계의 주요 표본관과 박물 관들은 표본 정보를 디지털화하여 데이터베이스로 만들 어 제공하고 있으며, GBIF (Global Biodiversity Information Facility, http://www.gbif.org), iDiGBio (Integrated Digitized Biocollections, https://www.idigbio.org)은 전 세계 일차종발생 정보와 같은 생물다양성데이터를 공개 액세스로 제공하고 있다. 국내에서도 국립수목원의 국가생물종지식정보시스 템(http://www.nature.go.kr), 국립생물자원관의 한반도의 생 물다양성 포털(https://species.nibr.go.kr), 국립중앙과학관의 국가자연사연구종합정보시스템(https://www.naris.go.kr) 등에 서 표본정보를 디지털화하여 제공하고 있다. 또한, Lee (2012, http://www.nature.go.kr/kbi/vbng/clssc/KBI_2005_080100.do)는 도 쿄대학(TI), 교토대학(KYO), 일본국립과학박물관(TNS) 에 소장되어 있는 한국산 식물표본의 화상자료를 $\mathrm{DB}$ 형 태로 제작하여 국가생물종지식정보시스템을 통하여 공 개하였으며, 국립수목원에서는 도쿄대 표본관(TI)에 소장 된 한국표본 사진을 PDF파일로 제공하고 있다(Im et al., 2017, 2018). 이러한 생물다양성 데이터베이스를 통해 과 거 채집된 표본의 존재 여부를 확인할 수 있게 되었으며, 해외의 표본관에 수장된 표본도 검토할 수 있게 되었다.

본 연구에서는 생물다양성 데이터베이스를 통해 과거 홍도 식물상 연구에서 채집된 국내외 표본을 확인하고 본 인들의 현지조사를 통해 채집한 증거표본과 종합하여 홍 도의 관속식물상을 재검토하고 목록을 작성하였다. 이 목 록과 증거표본을 바탕으로 새로이 분포가 확인된 분류군, 분류학적 재검토 및 재동정된 분류군, 분포가 특이한 분 류군 등에 대한 분류학적 견해를 기술하고, 법정보호종 및 희귀식물과 귀화식물을 정리하였다.

\section{재료 및 방법}

\section{과거 홍도에서 채집된 표본 검토}

과거 홍도에서 채집된 표본은 Nakai의 朝鮮森林植物篇 (Flora Sylvatica Koreana), 植物學雜誌(The Botanical Magazine of Tokyo), 植物研究杂隹誌(The Journal of Japanese Botany) 등에 채집장소 또는 번호가 기재된 기록(Chang and Chang, 2010)과 GBIF (http://www.gbif.org)의 T. B. Lee Herbarium Vascular Plant Collection (Kim, 2020), T. B. Lee Herbarium Vascular Plant Collection Phase II (Kim and Chang, 2020), Flora of the Korean Peninsula Phase II (Chang, 2020) 와 국가생물종지식정보시스템(http://www.nature.go.kr)에 서 확인하였다. 문헌과 데이터베이스에 기록된 표본을 검 토한 결과, Toshio Miwa (三輪利雄)가 1916년 7월 15일에 서 22일에 채집한 표본 10점과 Tsutomu Ishidoya (石戸谷勉) 와 정태현이 1919년 8월 29일에서 30일에 채집한 표본 78 점, 이창복이 1959년 8월 19일부터 22일, 1964년 11월 16일 에서 17일, 1967년 7월 30일부터 8월 3일에 채집한 표본 334점이 확인되었다. 표본 관찰은 국가생물종지식정보시 스템과 Specimens Collected from Korea at the Herbarium of the University of Tokyo (Im et al., 2017, 2018)을 통해 사진 으로 확인하였다.

\section{홍도 현지조사}

현지조사는 2003년 4월부터 2020년 10월까지 총 22회에 걸쳐 실시하였다. 조사범위는 홍도 1 구-당산숲-전망대-송 전탑-양산봉, 양산봉-방구여, 양산봉-남단, 양산봉-남서쪽 사면(지피미골), 1구-한국전력-견산-깃대봉-설풍여골, 1 구-깃대봉-2구-등대-대풍리 등으로 이루어졌으며, 홍도 전역의 도보를 통해 접근 가능한 지역을 조사하였다(Fig. 1, Table 1).

수집된 표본은 건조표본으로 제작하여 인하대학교 생 명과학과 표본실(IUI)에 수장하였으며, 일부 표본은 국립 호남권생물자원관 수장고(HIBR)에 소장되었다. 분류군 의 동정은 국내외 식물지와 도감을 이용하였으며, 세부 분류군의 동정은 종속지와 국내외 학술지에 발표된 논문 을 참고하였다.

\section{홍도의 관속식물 목록 작성}

양치식물은 PPG I (The Pteridophyte Phylogeny Group, 2016), 나자식물은 Christenhusz et al. (2011), 피자식물은 APG IV (The Angiosperm Phylogeny Group et al., 2016)의 분류체계에 따라 과를 배열하였으며, 과 이하의 범주는 알파벳 순으로 배열하였다. 학명과 국명은 한국속식물지 (Flora of Korean Editorial Committee, 2018)에 준하였으나, 일 부 분류군의 학명은 The Plant List (http://www.theplantlist.org), The International Plant Names Index (http://www.ipni.org), Tropicos (https://www.tropicos.org) 등을 참고하여 정리하였 


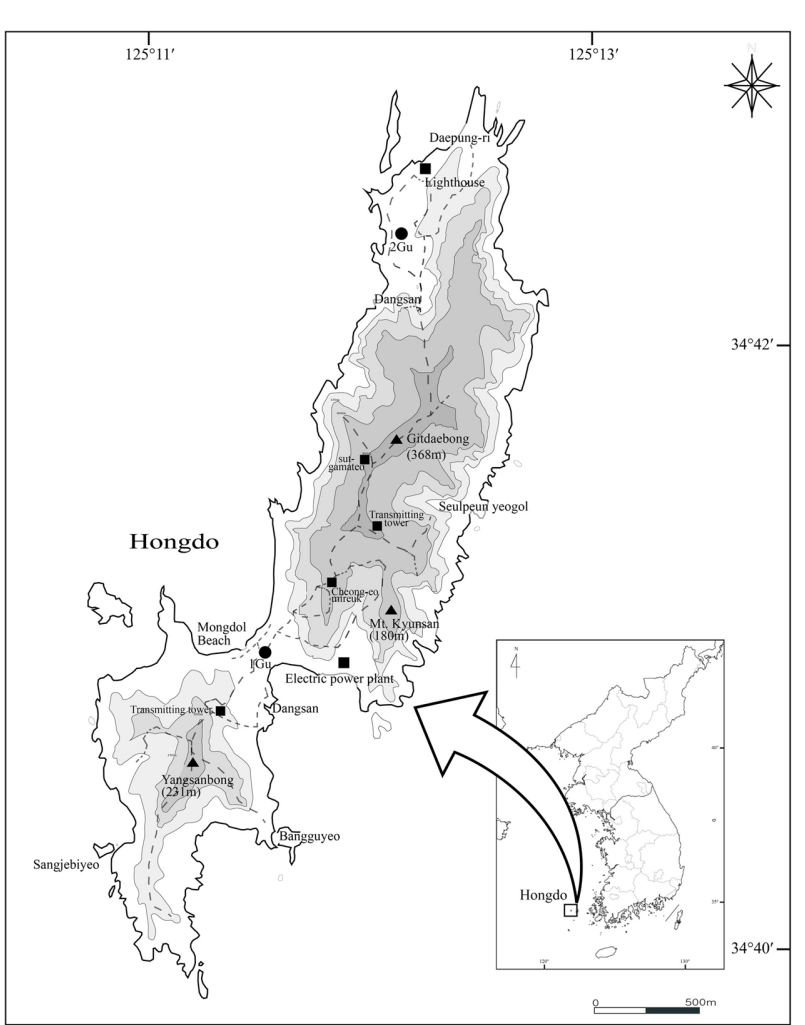

Fig. 1. Map of major surveyed routes on Hongdo Island.

다. 증거표본은 목록의 간소화를 위해 본인들에 의해 조 사된 표본 중 분류군당 1 장만 기록하였으며, 기존 표본은 문헌과 데이터베이스를 통해 확인된 표본 중 사진을 통해 관찰된 표본을 기록하였다.

현지조사와 증거표본을 바탕으로 홍도식물상에 새로 이 추가된 분류군을 기재하고, 오동정 및 분류학적 재검 토가 필요한 분류군에 대한 분류학적 주석을 기술하였다. 한편 분포의 특이성을 보이는 분류군은 국가생물종지식 정보시스템 (http://www.nature.go.kr), 한반도 관속식물 분 포도(Oh et al., 2016), GBIF (http://www.gbif.org), Science Museum Net (http://science-net.kahaku.go.jp), the Chinese Virtual Herbarium (http://www.cvh.ac.cn)에서 분포 자료를 수 집하였다. 아울러 표본을 기준으로 작성된 홍도산 관속식 물 목록을 바탕으로 한반도 특산식물(Chung et al., 2017), 법 정보호종 및 희귀식물(National Institute of Biological Resources, 2012; Ministry of Environment, 2017), 식물구계 학적 특정식물종(National Institute of Ecology, 2018), 귀화 식물(Kang et al., 2020)을 파악하였다.

\section{결과 및 고찰}

\section{홍도 식물상 개관}

홍도는 특이한 암석상 및 경관, 풍부한 동·식물상과 희
귀한 생물자원이 풍부하여 천연보호구역(천연기념물 제 170호) 및 다도해 해상국립공원으로 지정되어 보호·관리 되고 있다(Cultural Heritage Administration, 2012). 홍도는 식물구계학적으로 남해안아구에 속하며(Lee and Yim, 1978), 구실잣밤나무가 우점종으로 후박나무, 붉가시나무, 동백나무 등의 난대성 상록활엽수림이 넓게 분포하고 있 다. 홍도의 지형을 산림지대, 초원지대, 경작지, 해안으로 구분하여, 각 지형별 주요 식물군락과 구성종을 기재하면 다음과 같다.

\section{1. 산림지대}

홍도의 산림지대는 주로 구실잣밤나무 군락, 동백나무 군락, 후박나무 군락 및 소나무와 소사나무 군락 등으로 이루어져 있다. 구실잣밤나무 군락은 홍도에서 가장 넓은 면적을 점유하고 있는 대표적인 군락으로 북동, 남서, 남 동향 계곡부에 주로 분포한다(Lee et al., 2013). 교목층 및 아교목층에는 후박나무, 황칠나무, 동백나무 등이, 관목 층에는 보리밥나무, 광나무, 모새나무, 남오미자 등이, 초 본층에는 홍지네고사리, 멀꿀, 마삭줄, 소엽맥문동, 자금 우 등 상록성 식물들이 주로 우점하였다.

동백나무 군락은 깃대봉 남서, 북동사면과 능선부분 건 조한 곳에 주로 나타나는데, 아교목층과 관목층에는 예덕 나무, 광나무, 보리밥나무 등이, 초본층에는 둥근잎천남 성, 맥문동, 보춘화, 애기나리, 맥문아재비 등이 주요 구성 종이었다.

붉가시나무 군락은 능선부나 전석지 등에 분포한다. 아 교목층에는 황칠나무, 후박나무, 구실잣밤나무 등이, 관 목층에는 광나무, 다정큼나무, 사철나무 등이, 초본층에 는 가는쇠고사리, 비늘고사리, 남산제비꽃, 새끼노루귀, 콩짜개덩굴 등이 주로 나타났다.

후박나무 군락은 모든 사면에 고르게 분포하였으며, 주 로 깃대봉 북서사면 상부와 중부의 토양 수분이 높은 지 역과 2구 마을 뒷사면에 우점한다(Lee et al., 2013). 아교목 층과 관목층에는 동백나무, 광나무, 천선과나무, 보리밥 나무 등이, 초목층에는 도깨비고비, 송악, 마삭줄, 큰천남 성 등이 주로 출현하였다.

소나무와 소사나무 군락은 남서사면과 북서사면의 암벽 주변이나 정상부 및 능선부 토양이 척박한 지역에 주로 나 타났다(Kim, 1987; Lee et al., 2013). 아교목층에는 구실잣밤 나무, 쇠물푸레, 소나무 등이, 관목층에는 보리밥나무, 모 새나무, 사철나무 등이, 초본층에는 넉줄고사리, 부처손, 참취, 흑산도비비추, 나나벌이난초 등이 주로 출현하였다.

\section{2. 초원지대}

초원은 1 구 남서쪽 사면과 2 구 등대 건너편 사면인 대풍 리에 나타났다. 1 구 남서쪽 사면에는 홍도원추리가 초본 층의 주요우점종이다. 그밖에 네잎갈퀴, 갈퀴덩굴, 도깨 비고비, 송악, 솔새 등의 초본이 주로 출현하였다. 대풍리 
Table 1. Investigation dates and routes of Hongdo flora in this study.

\begin{tabular}{|c|c|c|}
\hline No. & Date & Investigation routes \\
\hline \multirow[t]{2}{*}{1} & 4 Apr 2003 & 1gu $\rightarrow$ Yangsanbong \\
\hline & 5 Apr 2003 & $1 \mathrm{gu} \rightarrow$ Gitdaebong $\rightarrow 2 \mathrm{gu}, 1 \mathrm{gu} \rightarrow$ Electric power plant \\
\hline \multirow[t]{3}{*}{2} & 9 May 2003 & $1 \mathrm{gu} \rightarrow$ Yangsanbong \\
\hline & 10 May 2003 & $1 \mathrm{gu} \rightarrow$ Yangsanbong, $1 \mathrm{gu} \rightarrow$ Gitdaebong \\
\hline & 11 May 2003 & $1 \mathrm{gu} \rightarrow$ Electric power plant \\
\hline \multirow[t]{2}{*}{3} & 21 May 2003 & $1 \mathrm{gu} \rightarrow$ Electric power plant \\
\hline & 22 May 2003 & $1 \mathrm{gu} \rightarrow$ Yangsanbong $\rightarrow$ South slope \\
\hline \multirow[t]{3}{*}{4} & 13 Jun 2003 & $1 \mathrm{gu} \rightarrow$ Electric power plant, $1 \mathrm{gu} \rightarrow$ Yangsanbong $\rightarrow$ South slope \\
\hline & 14 Jun 2003 & Mongdol beach, $1 \mathrm{gu} \rightarrow$ Gitdaebong $\rightarrow 2 \mathrm{gu}$ \\
\hline & 15 Jun 2003 & 1 gu $\rightarrow$ Transmitting tower $\rightarrow$ Yangsanbong $\rightarrow$ Bangguyeo $\rightarrow$ Yangsanbong $\rightarrow$ South slope \\
\hline \multirow[t]{3}{*}{5} & $12 \mathrm{Jul} 2003$ & Mongdol beach, $1 \mathrm{gu} \rightarrow$ Electric power plant \\
\hline & $13 \mathrm{Jul} 2003$ & $1 \mathrm{gu} \rightarrow$ Yangsanbong \\
\hline & $14 \mathrm{Jul} 2003$ & $1 \mathrm{gu} \rightarrow$ Gitdaebong $\rightarrow$ gu seashore $\rightarrow$ Lighthouse \\
\hline \multirow[t]{3}{*}{6} & 21 Aug 2003 & $1 \mathrm{gu} \rightarrow$ Electric power plant \\
\hline & 22 Aug 2003 & Mongdol beach, 1gu $\rightarrow$ Yangsanbong $\rightarrow$ Southwest slope \\
\hline & 23 Aug 2003 & 1 gu $\rightarrow$ Gitdaebong $\rightarrow$ 2gu seashore $\rightarrow$ Lighthouse, 1 gu $\rightarrow$ Transmitting tower $\rightarrow$ Yangsanbong \\
\hline \multirow[t]{2}{*}{7} & 24 Oct 2003 & 2 gu seashore $\rightarrow$ Lighthouse $\rightarrow 2 \mathrm{gu} \rightarrow$ Gitdaebong $\rightarrow 1 \mathrm{gu}$ \\
\hline & 25 Oct 2003 & $1 \mathrm{gu} \rightarrow$ Transmitting tower $\rightarrow$ Yangsanbong, $1 \mathrm{gu} \rightarrow$ Electric power plant \\
\hline 8 & 16 Apr 2005 & $1 \mathrm{gu} \rightarrow$ Gitdaebong \\
\hline \multirow[t]{2}{*}{9} & 13 Mar 2006 & $1 \mathrm{gu} \rightarrow$ Electric power plant \\
\hline & 14 Mar 2006 & $1 \mathrm{gu} \rightarrow$ Gitdaebong \\
\hline \multirow[t]{2}{*}{10} & 20 Mar 2009 & $1 \mathrm{gu} \rightarrow$ Gitdaebong \\
\hline & 21 Mar 2009 & $1 \mathrm{gu} \rightarrow$ Yangsanbong \\
\hline \multirow[t]{4}{*}{11} & 28 Jul 2019 & $1 \mathrm{gu} \rightarrow$ Electric power plant \\
\hline & 29 Jul 2019 & $1 \mathrm{gu} \rightarrow$ Gitdaebong $\rightarrow$ 2gu seashore $\rightarrow$ Lighthouse \\
\hline & 30 Jul 2019 & 1gu $\rightarrow$ Dangsan $\rightarrow$ Transmitting tower $\rightarrow$ Yangsanbong $\rightarrow$ Transmitting tower $\rightarrow 1$ gu \\
\hline & 31 Jul 2019 & $1 \mathrm{gu} \rightarrow$ Cheong-eo Mireuk $\rightarrow$ Graves around Cheong-eo Mireuk \\
\hline \multirow[t]{3}{*}{12} & 26 Sep 2019 & 1gu $\rightarrow$ Dangsan $\rightarrow$ Transmitting tower $\rightarrow$ Yangsanbong $\rightarrow$ Transmitting tower $\rightarrow 1$ gu \\
\hline & 27 Sep 2019 & $1 \mathrm{gu} \rightarrow$ Gitdaebong $\rightarrow 2$ gu seashore $\rightarrow$ Lighthouse $\rightarrow$ ggu $\rightarrow$ Daepung-ri \\
\hline & 28 Sep 2019 & $1 \mathrm{gu} \rightarrow$ Cheong-eo Mireuk $\rightarrow$ Graves around Cheong-eo Mireuk \\
\hline \multirow[t]{3}{*}{13} & 1 Nov 2019 & 1 gu $\rightarrow$ Dangsan $\rightarrow$ Transmitting tower $\rightarrow$ Yangsanbong $\rightarrow$ Transmitting tower $\rightarrow 1$ gu \\
\hline & 2 Nov 2019 & $2 \mathrm{gu} \rightarrow$ Gitdaebong $\rightarrow 1 \mathrm{gu} \rightarrow$ Electric power plant \\
\hline & 3 Nov 2019 & $1 \mathrm{gu} \rightarrow$ Transmitting tower $\rightarrow$ Yangsanbong $\rightarrow$ Bangguyeo \\
\hline \multirow[t]{3}{*}{14} & 9 Jan 2020 & $1 \mathrm{gu} \rightarrow$ Electric power plant \\
\hline & 10 Jan 2020 & $1 \mathrm{gu} \rightarrow$ Gitdaebong $\rightarrow 2 \mathrm{gu}, 1 \mathrm{gu} \rightarrow$ Gitdaebong southwest slope \\
\hline & 11 Jan 2020 & $1 \mathrm{gu} \rightarrow$ Transmitting tower $\rightarrow$ Yangsanbong $\rightarrow$ South slope \\
\hline \multirow[t]{4}{*}{15} & 16 Mar 2020 & Mongdol beach, $1 \mathrm{gu} \rightarrow$ Cheong-eo Mireuk \\
\hline & 17 Mar 2020 & $1 \mathrm{gu} \rightarrow$ Gitdaebong $\rightarrow 2$ gu seashore $\rightarrow$ Lighthouse $\rightarrow 2 \mathrm{gu}$ \\
\hline & 18 Mar 2020 & 1gu $\rightarrow$ Dangsan $\rightarrow$ Transmitting tower $\rightarrow$ Yangsanbong $\rightarrow$ Southwest slope $\rightarrow$ Yangsanbong $\rightarrow$ Transmitting tower $\rightarrow$ 1gu \\
\hline & 19 Mar 2020 & $\begin{array}{l}\text { 1gu } \rightarrow \text { Electric power plant } \rightarrow \text { Kyunsan } \rightarrow \text { Gitdaebong southwest slope } \rightarrow \text { Transmitting tower } \rightarrow \text { Seulpung yeogol } \\
\rightarrow \text { Transmitting tower } \rightarrow \text { Cheong-eo Mireuk } \rightarrow \text { gu }\end{array}$ \\
\hline \multirow[t]{3}{*}{16} & 21 Apr 2020 & $1 \mathrm{gu} \rightarrow$ Gitdaebong $\rightarrow$ ggu seashore $\rightarrow$ Lighthouse $\rightarrow$ ggu \\
\hline & 22 Apr 2020 & $\begin{array}{l}1 \text { gu } \rightarrow \text { Electric power plant } \rightarrow \text { Kyunsan } \rightarrow \text { Gitdaebong southwest slope } \rightarrow \text { Transmitting tower } \rightarrow \text { Seulpung yeogol } \\
\rightarrow \text { Transmitting tower } \rightarrow \text { Cheong-eo Mireuk } \rightarrow 1 \text { gu }\end{array}$ \\
\hline & 23 Apr 2020 & 1gu $\rightarrow$ Dangsan $\rightarrow$ Transmitting tower $\rightarrow$ Yangsanbong $\rightarrow$ Bangguyeo $\rightarrow$ Yangsanbong $\rightarrow$ Transmitting tower $\rightarrow 1$ gu \\
\hline \multirow[t]{3}{*}{17} & 11 May 2020 & Mongdol beach, 1gu $\rightarrow$ Electric power plant $\rightarrow$ Kyunsan $\rightarrow$ Gitdaebong southwest slope $\rightarrow$ Cheong-eo Mireuk $\rightarrow 1$ gu \\
\hline & 12 May 2020 & 2 gu seashore $\rightarrow$ Lighthouse $\rightarrow 2 \mathrm{gu} \rightarrow$ Daepung-ri $\rightarrow 2 \mathrm{gu} \rightarrow$ Gitdaebong $\rightarrow 1 \mathrm{gu}$ \\
\hline & 13 May 2020 & 1 gu $\rightarrow$ Cheong-eo Mireuk $\rightarrow$ Transmitting tower $\rightarrow$ Seulpung yeogol \\
\hline \multirow[t]{3}{*}{18} & 1 Jun 2020 & 1 gu $\rightarrow$ Electric power plant $\rightarrow$ Kyunsan $\rightarrow$ Gitdaebong southwest slope $\rightarrow$ Cheong-eo Mireuk $\rightarrow$ gu \\
\hline & 2 Jun 2020 & $1 \mathrm{gu} \rightarrow$ Cheong-eo Mireuk $\rightarrow$ Graves around Cheong-eo Mireuk \\
\hline & 3 Jun 2020 & $1 \mathrm{gu} \rightarrow$ Cheong-eo Mireuk $\rightarrow$ Transmitting tower $\rightarrow$ Seulpung yeogol \\
\hline \multirow[t]{4}{*}{19} & $1 \mathrm{Jul} 2020$ & $1 \mathrm{gu} \rightarrow$ Electric power plant $\rightarrow$ Kyunsan \\
\hline & 2 Jul 2020 & 2 gu seashore $\rightarrow$ Lighthouse $\rightarrow 2 \mathrm{gu} \rightarrow$ Gitdaebong $\rightarrow 1 \mathrm{gu}$ \\
\hline & 3 Jul 2020 & 1gu $\rightarrow$ Dangsan $\rightarrow$ Transmitting tower $\rightarrow$ Yangsanbong $\rightarrow$ South slope $\rightarrow$ Southwest slope $\rightarrow$ Yangsanbong $\rightarrow$ 1gu \\
\hline & 4 Jul 2020 & $1 \mathrm{gu} \rightarrow$ Cheong-eo Mireuk $\rightarrow$ Transmitting tower $\rightarrow$ Seulpung yeogol \\
\hline \multirow[t]{2}{*}{20} & 17 Aug 2020 & Mongdol beach \\
\hline & 18 Aug 2020 & $\begin{array}{l}\text { 1gu } \rightarrow \text { Cheong-eo Mireuk } \rightarrow \text { Transmitting tower } \rightarrow \text { Seulpung yeogol } \rightarrow \text { Transmitting tower } \rightarrow \text { Sutgamateo } \rightarrow \\
\text { Gitdaebong ridge } \rightarrow \text { Sutgamateo } \rightarrow \text { Cheong-eo Mireuk } \rightarrow 1 \text { gu }\end{array}$ \\
\hline
\end{tabular}


Table 1. Continued.

\begin{tabular}{|c|c|c|}
\hline No. & Date & Investigation routes \\
\hline \multirow{5}{*}{21} & 19 Aug 2020 & 1gu $\rightarrow$ Dangsan $\rightarrow$ Transmitting tower $\rightarrow$ Yangsanbong $\rightarrow$ Transmitting tower $\rightarrow 1$ gu \\
\hline & 16 Sep 2020 & $1 \mathrm{gu} \rightarrow$ Electric power plant $\rightarrow$ Kyunsan $\rightarrow$ Gitdaebong southwest slope $\rightarrow$ Cheong-eo Mireuk $\rightarrow$ 1gu \\
\hline & 17 Sep 2020 & 2gu seashore $\rightarrow$ Lighthouse $\rightarrow 2 \mathrm{gu} \rightarrow$ Gitdaebong $\rightarrow 1$ gu \\
\hline & 18 Sep 2020 & $\begin{array}{l}1 \mathrm{gu} \rightarrow \text { Electric power plant } \rightarrow \text { Kyunsan } \rightarrow \text { Gitdaebong southwest slope } \rightarrow \text { Cheong-eo Mireuk } \rightarrow \text { Graves around } \\
\text { Cheong-eo Mireuk } \rightarrow \text { Cheong-eo Mireuk } \rightarrow 1 \mathrm{gu}\end{array}$ \\
\hline & & $1 \mathrm{gu} \rightarrow$ Transmitting tower $\rightarrow$ Yangsanbong \\
\hline \multirow{4}{*}{22} & 19 Sep 2020 & $2 \mathrm{gu} \rightarrow$ Graves around $2 \mathrm{gu}$ \\
\hline & 27 Oct 2020 & Mongdol beach \\
\hline & 28 Oct 2020 & 1gu $\rightarrow$ Dangsan $\rightarrow$ Transmitting tower $\rightarrow$ Yangsanbong $\rightarrow$ Southwest slope $\rightarrow$ Yangsanbong $\rightarrow$ Transmitting tower $\rightarrow$ 1gu \\
\hline & 29 Oct 2020 & $1 \mathrm{gu} \rightarrow$ Cheong-eo Mireuk $\rightarrow$ Transmitting tower $\rightarrow$ Sutgamateo $\rightarrow$ Gitdaebong west slope \\
\hline
\end{tabular}

는 밀사초가 우점하였으며 억새, 비짜루, 새, 오이풀 등의 초본이 주로 관찰되었다.

\section{3. 경작지대}

경작지대는 홍도 1 구와 2 구 마을 부근에 위치한다. 1 구 지역 경작지 주변에는 음나무, 두릅나무, 꾸지뽕나무, 때 죽나무와 같은 낙엽성 관목이 많았으며, 초본층에는 모시 풀, 짚신나물, 장딸기가 주로 출현하였다. 2구 지역 경작 지 주변에는 관목으로 후박나무, 보리밥나무, 닥나무, 산 뽕나무, 으아리, 좀깨잎나무가, 초본층에는 장딸기, 네잎 갈퀴, 마삭줄, 미국자리공, 개망초가 주로 나타났다. 1구 에서 양산봉으로 향하는 초입과 깃대봉에서 2 구로 향하 는 북서쪽 사면은 휴경지와 과거 산불로 인하여 식생이 파괴된 지역으로 계요등, 머루, 까마귀머루, 칡과 같은 낙 엽성 덩굴식물이 주로 자란다(Lee and Kim, 1968).

\section{4. 해안지대}

해안 식물은 1 구 몽돌해수욕장과 2 구 지역에서 조사되 었다. 1 구 몽돌해수욕장은 주로 자갈, 2 구 해안가는 갯바 위로 구성되었는데, 이들 지역에서는 도깨비고비, 갯까치 수염, 번행초, 갯완두, 갯메꽃, 순비기나무 등이 해안식물 이 출현하였다.

\section{홍도산 관속식물목록 검토}

기존에 보고된 식물상 목록은 증거표본이 제시되지 않 거나 분포 혹은 실체가 불명확한 분류군이 포함되어 있다. 기존 홍도식물상 연구는 목본 49과 78속 105 종을 보고한 T. Ishidoya (1920)를 시작으로, Lee and Lee (1959)는 93과 190속 251종을, Lee and Kim (1968)은 83과 204속 256종 13 변종 1품좀 4잡종 총 274분류군을 보고하였다. 이후 Choi (1980)는 77과 224종을, Kim (1986)은 104과 265속 342종 45변종 3품종으로 390분류군을, Lee (2014)는 93과 259속 355 종 3 아종 53 변종 5품종으로 총 416분류군을 보고하였 다. 이 중 $\mathrm{Kim}$ (1987)은 자신의 조사 목록과 기존 보고 목 록(Lee and Lee, 1959; Lee and Kim, 1968)을 종합하여 110 과 336속 4잡종 545분류군을 제시하였다. 또한, Lee (2014)
는 홍도 식생연구에서 자신이 조사한 목록과 기존 보고 목록(Lee and Lee, 1959; Lee and Kim, 1968; Kim, 1986, 1987)과 비교하여 재배식물, 이명으로 처리된 분류군, 오 동정 가능성이 있는 분류군을 제시하는 등 종합적인 검토 를 시도하여 117 과 356속 503종 3아종 2잡종 90변종 8품종 총 606 분류군을 제시하였다. 최근의 자료에서는 Kwon et al. (2018)은 자연자원조사에서 93과 237속 299종 3아종 28 변종으로 총 330 분류군을 보고하였다. 하지만 대부분은 증거표본이 제시되지 않은 목록만의 기록으로 정확한 동 정과 실제 분포 여부를 확인하기 어렵다.

이번 조사와 기존 보고 목록(Lee and Lee, 1959; Lee and Kim, 1968; Kim, 1986, 1987; Lee, 2014)을 종합한 결과, 홍 도산으로 기록된 식물은 총 729분류군이었다(Appendix 1). 그러나 기존 문헌에 홍도산으로 보고된 식물 중 북방 계요소인 산미나리아재비, 어리곤달비, 분취, 개밀아재비, 골잎원추리, 나비난초 등은 북한 지역 또는 남한의 일부 고산지역에 분포하는 북방계 식물로 남해안 아구인 홍도 에 분포하기는 힘들다. 또한 갯제비쑥, 말오줌나무 등은 국내에서 울릉도에만 분포하는 분류군이기 때문에 오동 정으로 추정되어진다. 이밖에 기존표본 재동정 결과 문헌 에 기록된 식물 중 31 분류군은 오동정으로 밝혀졌으며, 18 분류군은 다른 식물의 이명으로 처리되었거나 비합법 명이었다. 또한, 재배식물로 21 분류군이 검토되었다. 이 처럼 오동정, 이명과 비합법명, 재배식물인 77 분류군을 제외한 652분류군이 홍도산 관속식물로 판단되나, 기존 문헌에 제시된 목록 중 상당수는 증거표본이 없거나 오동 정된 분류군으로 보인다. 한편으로 이전 문헌에서 보고된 바위고사리, 늦고사리삼, 함박이, 가시복분자딸기, 겨울 딸기, 무엽란, 콩짜개란 등 일부 분류군은 홍도에서 생육 이 예상되나 표본 및 현장조사에서 확인되지 않았다.

본 연구는 기존의 표본과 본인들에 의해 조사된 표본을 기초로 목록을 작성하였으며, 최근까지의 학명 정리를 반 영하여 분류군을 정리하였다. 홍도에서 과거에 채집된 $\mathrm{T}$. Miwa (15-22 Jul 1916), T. Ishidoya (29-30 Aug 1919), 이창 복(19-22 Aug 1959, 16-17 Nov 1964, 30 Jul-3 Aug 1967, 15 Aug 1980, 3 May 1986) 표본과 본 조사에서 채집한 표본 
을 종합한 결과, 홍도의 관속식물 102 과 296속 425종 6아 종 41변종으로 총 472분류군을 확인하였다.

\section{홍도 식물상에 새로이 추가된 분류군}

기존 홍도 식물상 문헌(Lee and Lee, 1959; Lee and Kim, 1968; Kim, 1986, 1987; Lee, 2014)에서는 보고되지 않았으 나, 이번 조사에서 새로이 분포가 확인된 식물은 111 분류 군이며, 이들은 관속식물목록의 국명 앞에 별표(ネ)로 표 시하였다(Appendix 1). 홍도 식물상에 대한 선행 연구가 비교적 많음에도 불구하고, 상당히 많은 분류군들이 신규 로 기록되었다. 이는 본 연구가 2003년부터 2020년까지 22 회에 걸쳐 다양한 경로 및 시기에 조사를 수행한 점과 과 거 연구자의 오동정 및 분류학 연구에 따른 재검토, 신종 과 미기록종, 새로운 귀화식물의 유입이 작용한 것으로 보인다. 홍도 식물상에 새로이 추가된 111 분류군 중 특이 식물들은 다음과 같다.

1. Woodwardia japonica (L. f.) Sm. 새깃아재비(Fig. 2A) Woodiwardia속 중 유일하게 한반도에 분포하는 새깃아 재비는 멸종위기 II급으로 지정된 희귀식물로 제주도와 남부지역 숲에 분포가 알려져 있다. 홍도산은 포자낭군이 선형으로 주맥과 평행한 점에서 새깃아재비로 동정된다. 이번 조사를 통해 새로이 분포가 확인되었으며, 깃대봉 구실잣밤나무림 무덤가 인근 초지에서 탐라사다리고사 리, 호자덩굴과 함께 자라고 있다.

2. Thelypteris angustifrons (Miq.) Ching 탐라사다리고사 리(Fig. 2B)

홍도에서 조사된 식물은 포막이 말굽 모양으로, 우편 기 부의 내측 열편이 인접한 열편과 서로 독립적이고 길이가 더 긴 점에서 탐라사다리고사리로 동정된다. 생육지도 사 다리고사리[T. glanduligera (Kunze) Ching]는 양산봉 남단 과 깃대봉 설풍여골 계곡부의 구실잣밤나무림 음지에서 생육하는 반면, 탐라사다리고사리는 깃대봉 구실잣밤나 무림 무덤가와 등산로의 반양지에서 생육하였다. 탐라사 다리고사리는 제주도와 남부지역 숲에 분포하는 것으로 알려져 왔으나, 이번에 홍도에서도 분포가 확인되었다.

3. Cyrtomium devexiscapulae (Koidz.) Koidz. \& Ching 긴 잎도깨비쇠고비(Fig. 2C)

홍도에서 채집된 Cyrtomium속 식물 중 우편은 혁질이며 광택이 있고 가장자리는 밋밋하거나 얕은 물결모양인 점 에서 도깨비고비[C. falcatum (L. f.) C. Presl]와 형태적으로 유사하나, 우편 기부에 귀가 발달하지 않고 쐐기모양이며, 포막 전체가 검은색을 띠고, 잎자루 비늘조각은 중앙은 짙은 갈색, 가장자리는 옅은 갈색인 점에서 긴잎도깨비쇠 고비로 동정된다. 또한, 생육지도 도깨비고비가 홍도 전 역의 해안가 인근의 숲 가장자리에 널리 생육하는 반면,
긴잎도깨비쇠고비는 깃대봉 구실잣밤나무림의 어둡고 습한 곳에서 소수개체가 생육하는 차이를 보인다. 긴잎도 깨비쇠고비는 제주도와 남부지역 바닷가 저지대에 분포 하며, 홍도에서는 처음 보고된다.

\section{Dryopteris caudipinna Nakai 가는홍지네고사리(Fig. 2D)}

기존 보고에서는 홍지네고사리[D. erythrosora (D. C. Eaton) Kuntze]만 홍도산으로 보고되었는데, 형태적인 유 사성으로 인해 가는홍지네고사리를 홍지네고사리로 오 동정했을 가능성이 높다. 홍도에서 채집된 Dryopteris속 식물 중 최하부 우편의 하부 첫번째 소우편이 다음 소우 편에 비해 작고 우축에 주머니모양 비늘조각이 있는 점에 서 홍지네고사리와 형태가 유사하나, 소우편이 선상피침 형 또는 선형으로 좁고 중열 내지 심열하며, 포막이 회백 색인 점에서 가는홍지네고사리로 동정된다. 가는홍지네 고사리는 홍지네고사리와 같이 홍도 전역의 구실잣밤나 무림과 후박나무림의 습기있는 지역에 생육하였다.

5. Calanthe aristulifera Rchb. f. 신안새우난초(Fig. 2E) 신안새우난초는 Hong et al. (2009)에 의해 미기록종으로 신안군 흑산면에서 보고되었으며, 멸종위기 II급으로 지 정된 희귀식물이다. 홍도산은 입술꽃잎은 연한 홍색으로 얕게 갈라지고, 거가 $15 \mathrm{~mm}$ 이상인 점에서 신안새우난초 로 동정된다. 이번 조사에서 홍도에서 분포가 확인되었으 며, 깃대봉 구실잣밤나무림의 그늘지고 습한 곳에 소수의 개체가 생육하였다.

6. Melampyrum koreanum K. J. Kim \& S. M. Yun 긴꽃며 느리밥풀(Fig. 2F)

기존 보고에서는 꽃며느리밥풀(M. roseum Maxim.)만 보 고되었으나(Lee and Lee, 1959; Lee, 2014), 기존 표본(T. B. Lee $2904 \mathrm{SNUA}$ )과 현지조사한 표본을 관찰한 결과, 화관 길이는 18-(25)-30 mm이고 포의 거치가 1-3쌍인 점에서 긴꽃며느리밥풀이 확인되었다. 긴꽃며느리밥풀은 경상 남도 소매물도에만 분포가 알려져 있었으나(Kim and Yun, 2012), 이번 조사에서 홍도에서 분포가 확인되어 식물지 리학적으로 흥미롭다. 그러나 홍도산 개체 내에서 화관 길이의 다양한 변이가 나타났다. 이러한 관찰에 기초하면, 홍도에서 긴꽃며느리밥풀만 분포하는지, 꽃며느리밥풀 이 함께 분포하는지, 또는 긴꽃며느리밥풀이 꽃며느리밥 풀의 형태적 변이형 중 일부인지 검토가 필요하다. 홍도 에서는 1 구 한국전력 가는 길 소사나무-구실잣밤나무림 경사면과 양산봉 전망대에서 송전탑 가는 소사나무-소나 무림 길목, 깃대봉 능선 소사나무림 등에 생육하였다.

\section{분류학적 재검토 및 재동정된 분류군}

과거에 채집된 것과 이번 표본을 관찰한 결과 다수의 분 류군이 오동정되어 기존 문헌 등에 기록된 것으로 판단된 
다. 이 중 새끼노루귀, 낚시제비꽃, 왜제비꽃, 벚나무, 목포 용둥굴레 등은 봄철에 개화하는 식물들로서 과거 조사가 주로 여름철에만 이루어진 점에서 오동정된 것으로 보인 다. 진고사리, 개족도리풀. 좀풍게나무, 섬모시풀, 홍도까 치수염, 큰뀡의비름, 좀땅비싸리, 청비수리, 네잎갈퀴나 물, 좀담배풀 등은 근연식물과의 형태의 유사성에 의한 오동정으로 판단된다. 또한, 낫쇠고사리, 산족제비고사리, 섬향나무, 꼬마은난초, 하늘산제비란, 흑산도비비추, 홍 도원추리, 진달래 등은 최근의 분류학적 연구를 반영하여 재검토하였다.

\section{Deparia japonica (Thunb.) M. Kato 진고사리}

기존 홍도식물상에 좀진고사리[Athyrium conilii (Franch. \& Sav.) Tagawa) ( $=D$. conilii (Franch. \& Sav.) M. Kato) $]$ 가 보고되었으나(Lee and Kim, 1968), 기존 표본(T. B. Lee s.n. SNUA:82612)과 현지조사 표본을 관찰한 결과, 홍도산은 포막에 털이 없고, 포막이 선형으로 좁아 서로 겹쳐지지 않는 점에서 진고사리로 동정된다. 깃대봉 후박나무림의 계곡부 주변에서 소수 개체가 생육하였다.

2. Arachniodes simplicior (Makino) Ohwi 낫쇠고사리(고 리쇠고사리)

기존 홍도식물상에는 쇠고사리[Rumohra amabilis (Blume) Ching)A. amabilis (Blume) Tindale (=A. amabilis (Blume) Tindale)] (Lee and Kim, 1968) 또는 쇠고사리와 낫 쇠고사리(Lee, 2014)가 보고되었다. 하지만 기존 표본(T. B. Lee 4314 SNUA; T. B. Lee s.n. SNUA)에 쇠고사리로 동정된 것과 현지조사 표본을 관찰한 결과, 이들은 모두 낫쇠고 사리로 확인되었다. 홍도산은 2회 우상복엽으로, 잎몸의 끝부분에 뚜렷한 정우편이 있으며, 최종열편의 기부는 거 의 대칭이거나 약하게 비대칭이며, 최종열편의 자루는 거 의 없고, 포자낭군은 최종열편의 가장자리 근처 또는 중 륵과 가장자리의 중간에 달리는 점에서 낫쇠고사리로 동 정된다.

3. Dryopteris bissetiana (Baker) C. Chr. 산족제비고사리 기존 홍도식물상에는 족제비고사리[D. varia (L.) Kunze] 가 보고되었다(Lee and Lee, 1959; Lee and Kim, 1968; Lee, 2014). 하지만 기존 표본(Ishidoya, T. \& T. H. Chung 3315 TI; T. B. Lee s.n. SNUA:81866)과 현지조사 표본을 관찰한 결 과 이는 산족제비고사리로 확인되었다. 홍도산은 우축에 기부가 주머니 모양인 비늘조각이 있고, 잎몸은 상부를 향 하여 점차적으로 좁아지며, 최종열편이 전연 내지 둔거치연 인 점에서 산족제비고사리로 동정된다.

4. Juniperus chinensis var. procumbens Siebold ex Endl. 섬향나무(Fig. 2G)

Juniperus procumbens (Siebold ex Endl.) Siebold ex Miq.
섬향나무는 향나무(J. chinensis L.)와 달리 누워 자라며, 잎은 대다수가 침엽으로, 성숙한 식물체에는 인엽이 드물 거나 부분적으로 있으며, 해안가에 자라는 점으로 구분한 다(Sun, 2018). 기존 표본(T. B. Lee $332 \mathrm{SNUA}$ )과 현지조사 표본을 관찰한 결과, 홍도산은 잎이 침엽과 인엽이 섞여 있거나 인엽이 다수로 눈향나무(var. sargentii A. Henry)와 구분하기 어렵다. 홍도산은 하부 일부분에 침엽이 있는 점에서 눈향나무의 해안형으로 보는 의견도 있다(Lee, 2000). 하지만 섬향나무는 대흑산도를 비롯한 남부지방의 해안가 및 섬에 주로 분포하며, 어릴 적에는 인엽과 침엽 이 같이 자라는 점( $\mathrm{Kim}$ and $\mathrm{Kim}, 2018)$ 에서 홍도산은 섬향 나무로 판단된다. 섬향나무는 별개의 종으로 보거나(Sun, 2018), 향나무의 종내분류군으로 보기도 한다(Chang et al., 2011). 본 논문에서는 향나무의 변종으로 취급한 Chang et al. (2011)의 의견에 따랐다.

\section{Asarum maculatum Nakai 개족도리풀(Fig. 2H)}

기존 홍도식물상에서 족도리풀(A. sieboldii Miq.) (Lee and Lee, 1959; Lee and Kim, 1968)과 개족도리풀(Lee, 2014) 이 보고되었다. 홍도에 생육하는 개족도리풀은 잎에 무늬 가 없는 특징을 보여(Yun et al., 2012), 족도리풀과 혼동이 될 수 있다. 개족도리풀은 잎 표면에만 짧은 털이 약간 있 는 데 반해, 잎의 양면과 엽병에 모두 털이 있는 족도리풀 과 구별된다(Oh, 2008). 기존 표본(21 Aug. 1959, T. B. Lee s.n. SNUA:80160)과 현지조사 표본을 관찰한 결과, 홍도산 은 모두 잎 상면에만 짧은 털이 있는 점 등에서 개족도리 풀로 동정된다.

6. Veratrum maackii var. parviflorum (Maxim. ex Miq.) $\mathrm{H}$. Hara 파란여로

기존 홍도식물상에서 여로(V. nigrum var. japonicum Baker)가 보고되어 있으나(Lee, 2014), 홍도산은 화피편이 무모이고 잎의 길이/너비 비가 9-12이며, 소화경이 짧고 $(8-10 \mathrm{~mm})$, 꽃색이 녹백색에서 녹색으로 변하는 점에서 여로가 아닌 파란여로로 동정된다. 깃대봉 능선 가까운 초지에 생육하였다.

7. Cephalanthera subaphylla Miyabe \& Kudô 꼬마은난초 (Fig. 2I)

Cephalanthera erecta f. subaphylla (Miyabe \& Kudô) M. Hiroe 홍도산은 근연종인 은난초[C. erecta (Thunb.) Lindl.]에 비해 전체가 작으며, 줄기잎은 1장 내지 2장이고, 가장 밑 에 달리는 잎은 줄기 중간 이상에 붙으며, 꽃받침과 곁꽃 잎의 끝이 둘로 갈라지는 점에서 꼬마은난초로 동정된다. 기존 홍도식물상에서는 보고되지 않았으며, Lee and Choi (2006)에 의해 홍도 분포가 알려졌다. 홍도에서는 깃대봉 동백나무림에서 산박하, 반디지치, 참취와 함께 생육하였 다. 꼬마은난초는 은난초의 종내분류군 f. subaphylla으로 


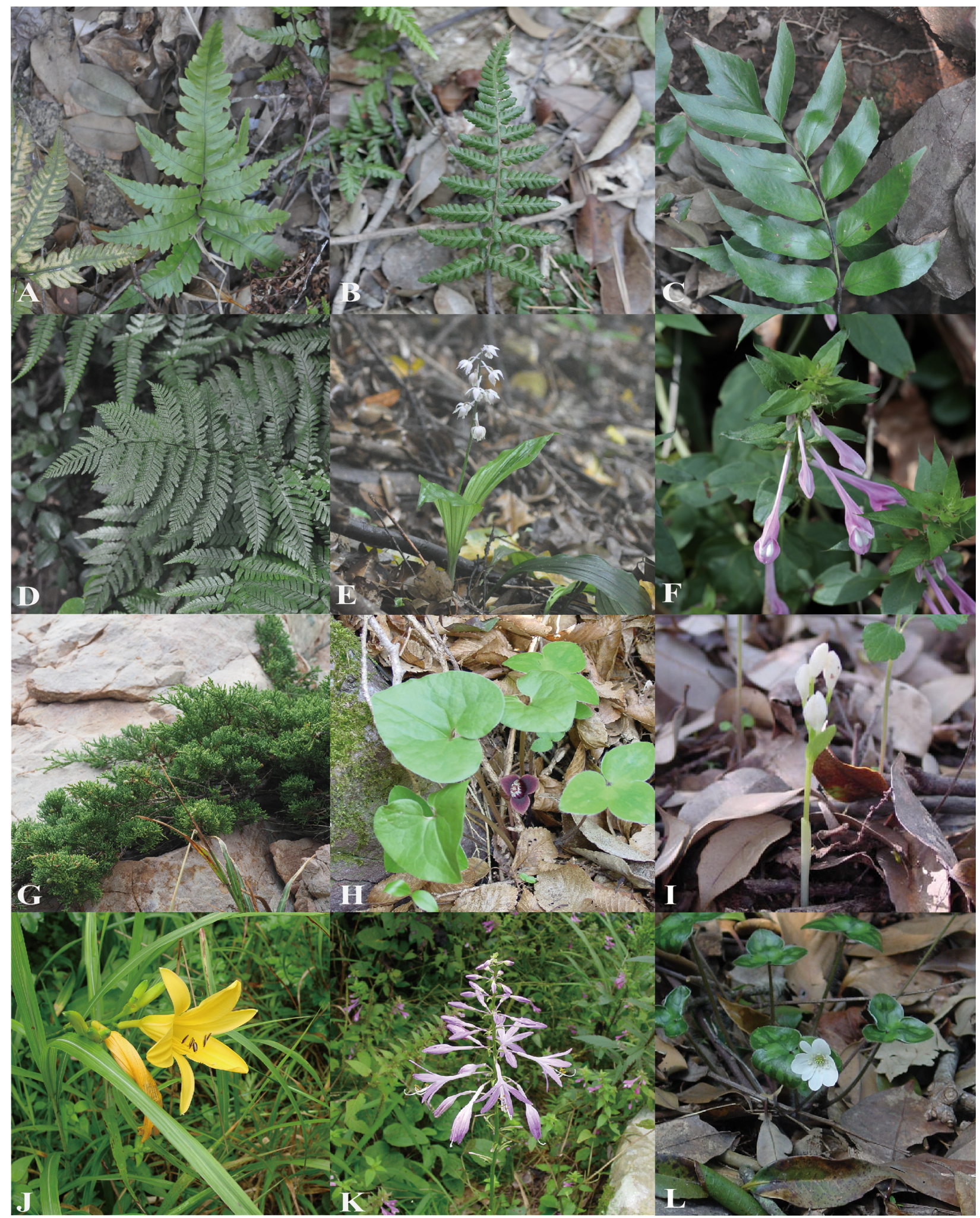

Fig. 2. Some remarkable taxa on Hongdo Island. A. Woodwardia japonica. B. Thelypteris angustifrons. C. Cyrtomium devexiscapulae. D. Dryopteris caudipinna. E. Calanthe aristulifera. F. Melampyrum koreanum. G. Juniperus chinensis var. procumbens. H. Asarum maculatum. I. Cephalanthera subaphylla. J. Hemerocallis hongdoensis. K. Hosta yingeri. L. Hepatica insularis. M. Crepidiastrum $\times$ muratagenii. $\mathbf{N}$. Rubus sumatranus. O. Saussurea polylepis. P. Goodyera biflora. Q. Damnacanthus major. R. Sedirea japonica. S. Cymbidium macrorhizon. T. Dendrobium moniliforme. U. Bulbophyllum inconspicuum. V. Calanthe insularis. W. Calanthe sieboldii. X. Lysimachia pentapetala. 


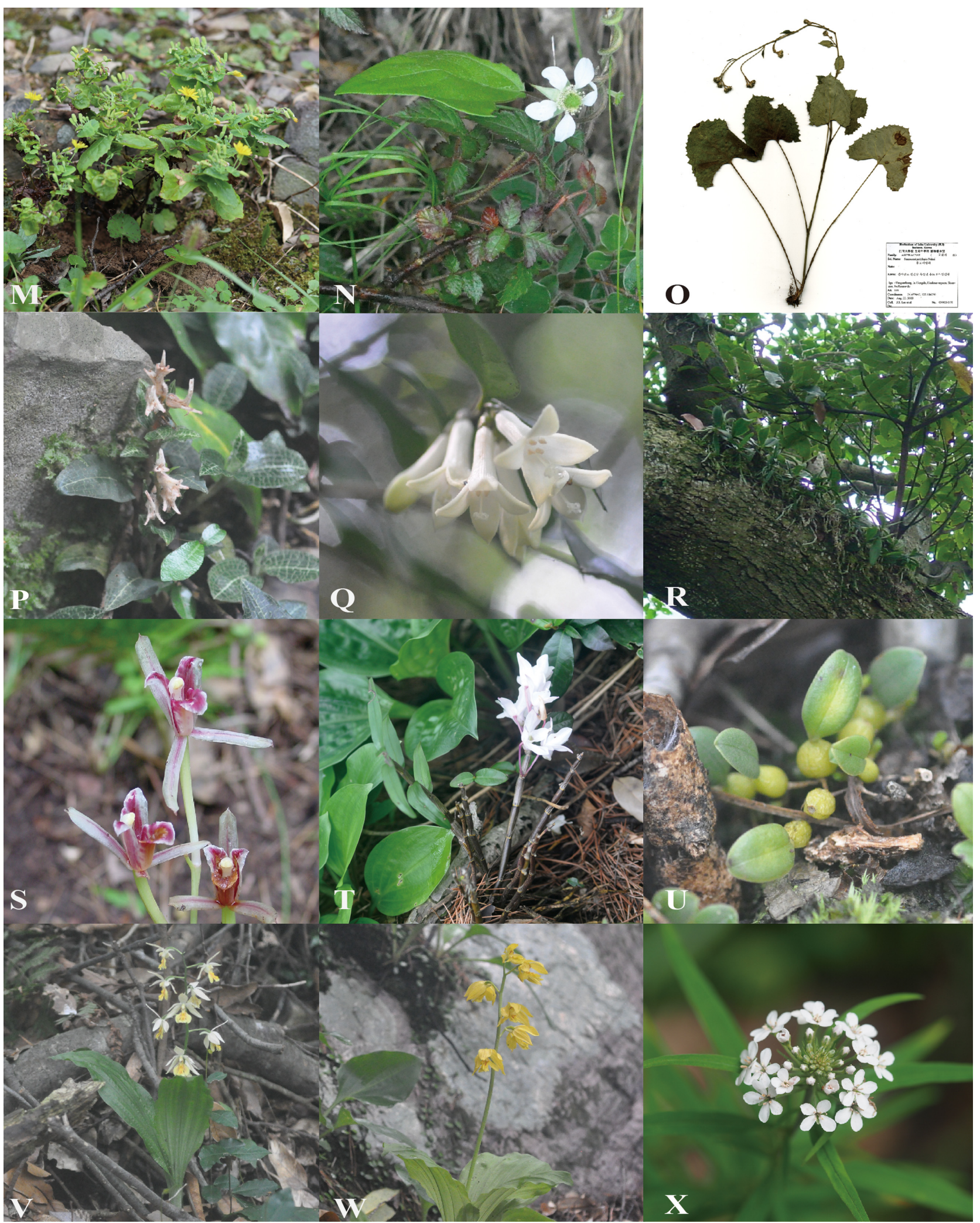

Fig. 2. Continued. 
보기도 하나(Lee, 2018), 본 논문에서는 형태 및 분자계통 에서 꼬마은난초를 독립된 종으로 본 Shin et al. (2019)의 견해에 따랐다.

\section{Platanthera neglecta Schltr. 하늘산제비란}

Platanthera mandarinorum var. neglecta (Schltr.) F. Maek.

홍도산은 산제비란과 함께 생육하며 각기 형태적인 독 립성을 유지하고 있으며(Lee and Choi, 2005), 잎이 장타원 형에서 선상 장타원형이고, 거가 현저히 위로 올라가며, 기부에서 약 $3 / 4$ 지점까지 두꺼워지다가 얇아지는 점에서 하늘산제비산으로 동정된다. 기존 홍도식물상에서는 보 고되지 않았으며, Lee and Choi (2005)에 의해 홍도 분포가 알려졌다. 하늘산제비란은 산제비란(P. mandarinorum Rchb. f.)의 종내분류군으로 보거나(Inoue, 1982, 1983; Lee, 2011), 산제비란의 이명(Chen et al., 2009) 또는 독립된 종 으로 보기도 한다(Lee and Choi, 2005; Efimov, 2016). 본 논 문에서는 형태 및 분포에서 독립된 종으로 본 Efimov (2016)의 견해에 따랐다.

9. Hemerocallis hongdoensis M. G. Chung \& S. S. Kang 홍도원추리(Fig. 2J)

홍도에 분포하는 원추리에 대해, 기존 홍도식물상에서 원추리(H. aurantiaca Backer) (Lee and Lee, 1959), 골잎원추 리(H. coreana Nakai) (Lee and Kim, 1968) 또는 원추리[H. fulva (L.) L.]와 홍도원추리(Lee, 2014) 등으로 서로 다르게 보고되었다. 또한, 기존 표본(T. B. Lee s.n. SNUA:101528) 은 애기원추리(H. minor Mill.)로 동정되어 있다. 홍도산을 관찰한 결과 지하경이 없고, 뿌리 끝에 방추상 덩이뿌리 가 있으며, 화서는 1 회 차상분지하고, 꽃은 오렌지빛 황색 으로 낮에 개화하며, 꽃 길이는 10-15 cm로 큰 특징에서 홍도원추리로 판단된다. 깃대봉 남서쪽 사면 초지와 능선 부, 해안가 암벽까지 홍도 전역에 생육하였다.

\section{Hosta yingeri S. B. Jones 흑산도비비추(Fig. $2 \mathrm{~K}$ )}

홍도에 분포하는 비비추에 대해, 기존 홍도식물상 보고 에서 비비추[H. longipes (Franch. \& Sav.) Matsum.] (Lee and Lee, 1959; Lee and Kim, 1968) 또는 흑산도비비추(Lee, 2014)로 다르게 기록하고 있다. 기존 표본들을 보면 Ishidoya, T. \& T. H. Chung 3374 (SNU)은 H. japonica Ascherson.로 동정되었다가 이후 M. G. Chung에 의해 흑산 도비비추로 재동정된 바 있으며(Schmid, 2010), 그 외에 표 본들은 비비추(T. B. Lee 4354 SNUA:101629), 주걱비비추 (H. clausa Nakai) (T. B. Lee s.n. SNUA:101569), 좀비비추 $[H$. minor (Baker) Nakai] (T. B. Lee 4355 SNUA:101581), 옥잠화 [H. plantaginea (Lam.) Asch.] (T. B. Lee s.n. SNUA:101584) 로 동정되어 있었다. 비비추, 주걱비비추, 좀비비추, 옥잠 화로 동정되어있던 기존 표본과 이번조사 표본을 관찰한 결과, 잎은 타원형으로 끝은 예첨두로 뾰족하고 밑부분은
원저 또는 유저로 잎자루에 날개가 있으며, 포는 녹색 또 는 연갈색으로 숙존하고, 근생화경은 표면에 세로줄이 없 고 평활하며, 꽃이 화경에 나선상으로 배열되고, 꽃은 깔 때기형으로 화피편이 거미 모양(spider shaped)로 갈라지 며, 수술이 3 개는 길고 3 개는 짧은 특징을 가져 흑산도비 비추로 재동정되었다. 양산봉 북동쪽 사면과 깃대봉 능선 부의 소사나무 군락에 여러 개체수가 생육하였다.

11. Polygonatum cryptanthum H. Lév. \& Vaniot 목포용둥굴레 기존 홍도식물상에서 용둥굴레[P. involucratum (Franch. \& Sav.) Maxim.] (Lee and Lee, 1959; Lee and Kim, 1968) 또 는 용둥굴레와 목포용둥굴레(Lee, 2014)가 기록되었다. 또 한 기존 표본(T. B. Lee s.n. SNUA:101908)은 용둥굴레로 동 정되어 있다. 하지만 기존 표본과 본인들의 표본을 관찰 한 결과, 홍도산은 화경, 소화경, 포와 잎에 유두상 돌기가 있으며, 포엽과 꽃이 2장 이상이 달리며, 암술은 수술보다 짧으며, 근경은 지름이 $5 \mathrm{~mm}$ 이상으로 두꺼운 점에서 모 두 목포용동굴레로 동정된다. 구실잣밤나무림의 그늘진 곳에 생육하였다.

\section{Hepatica insularis Nakai 새끼노루귀(Fig. 2L)}

기존 홍도식물상에서 노루귀 (H. asiatica Nakai) (Lee and Lee, 1959; Lee and Kim, 1968) 또는 노루귀와 새끼노루귀 두 종이 분포(Lee, 2014)한다고 보고되었다. 한편 기존 표 본(T. B. Lee s.n. SNUA:83258)은 노루귀로 동정되어 있다. 새끼노루귀는 노루귀와 형태적으로 매우 유사하여 혼동 이 있을 수 있다. 기존 표본과 현지조사 결과, 홍도산은 암 술과 수과에 털이 있고, 인편엽은 대개 $3 \mathrm{~cm}$ 미만으로 잎 열편은 대개 둔두이며, 잎과 꽃이 동시에 피는 점에서 새 끼노루귀 한 종으로 동정된다.

13. Hylotelephium spectabile (Boreau) H. Ohba 큰뀡의비름 기존 홍도식물상에서 꿩의비름[Sedum alboroseum Baker (=H. erythrostictu (Miq.) H. Ohba)]이 보고되었다(Lee and Lee, 1959; Lee and Kim, 1968; Lee, 2014). 기존 표본 (Ishidoya, T. \& T. H. Chung $3503 \mathrm{KWUN}$ )은 자주꿩의비름 $[S$. telephium L. (=H. pallescens (Freyn) H.Ohba)]으로 동정 되어 있다. 홍도산 표본들을 관찰한 결과 잎은 3-5장씩 윤 생하며, 줄기는 녹색이고, 화판은 자색으로, 꽃잎이 수술 보다 짧은 특징에서 큰꿩의비름으로 판단된다. 깃대봉 능 선부 초지에 다정큼나무, 예덕나무, 진달래, 산국, 억새, 도 깨비바늘와 함께 생육하였다.

\section{Indigofera koreana Ohwi 좀땅비싸리}

기존 홍도식물상에서 땅비싸리(I. kirilowii Maxim. ex Palib.) (Lee and Lee, 1959) 또는 땅비싸리와 좀땅비싸리 두 종이 분포(Lee, 2014)한다고 보고되었다. 한국의 남서부를 제외한 한반도 전역에 분포하는 땅비싸리와 달리, 좀땅비 
싸리는 충남의 해안지방으로부터 전북, 전남에 제한적으 로 분포하는 특산종으로써(Cho et al., 1997), 지리적으로 홍도에는 좀땅비싸리가 분포할 가능성이 높다. 현지조사 표본을 관찰한 결과, 홍도산은 소엽 하면에 털이 없고 꽃 의 크기가 $1.2 \mathrm{~cm}$ 이하 인 점에서 좀땅비싸리로 동정된다. 양산봉과 깃대봉 능선부와 양산봉 전망대에서 송전탑 가 는 길목 소사나무-쇠물푸레림의 건조한 사면에 주로 생육 하였다.

15. Lespedeza inschanica (Maxim.) Schindl. 청비수리

기존 홍도식물상에서 비수리[L. cuneata (Dum.Cours.) G. Don가 보고되었다(Lee and Kim, 1968; Lee, 2014). 현지조 사 표본을 관찰한 결과 홍도산은 소엽에 망상맥이 뚜렷하 고 소엽이 좁은 타원형 내지 타원형이며, 소화경이 1$2 \mathrm{~mm}$ 로 짧은 점에서 청비수리로 판단된다. 기존 보고에 서 형태적인 유사성으로 인해 청비수리를 비수리로 동정 했을 가능성이 높다. 깃대봉 구실잣밤나무림 무덤가에서 이고들빼기, 엉겅퀴, 고사리와 함께 생육하였다.

16. Vicia nipponica Matsum. 네잎갈퀴나물

기존 홍도식물상에서 광릉갈퀴( $V$. venosa var. cuspidata Maxim.)가 보고되었으며(Lee and Kim, 1968), 기존 표본(T. B. Lee 1861 SNUA:86871)은 큰네잎갈퀴[V. ramuliflora (Maxim.) Ohwi]로 동정되어 있다. 하지만 기존 표본과 현 지조사 표본을 관찰한 결과, 홍도산은 화서가 분지하며, 소엽의 중앙부가 가장 넓은 점에서 네잎갈퀴나물로 동정 된다. 2 구 구실잣밤나무림 묘지 부근 초지에서 이대, 장딸 기, 산꿩의다리, 이고들빼기와 함께 생육하였다.

\section{Potentilla chinensis Ser. 딱지꽃}

기존 홍도식물상에서는 잎 표면에 털이 많은 형태인 털 딱지꽃(P. chinensis var. concolor Franch. \& Sav. $)$ 이 보고되 었다(Lee and Lee, 1959; Lee and Kim, 1968). 그러나 기존 표본(T. B. Lee s.n. SNUA:85942)과 현지조사 표본을 관찰 한 결과, 홍도산은 잎 표면이 무모이거나 약간의 털이 산 생하여 딱지꽃으로 동정되었다.

\section{Prunus jamasakura Siebold ex Koidz. 벚나무}

기존 홍도식물상에서 벚나무(Lee and Lee, 1959) 또는 산 벚나무(P. sargentii Rehder) (Lee and Kim, 1968; Lee, 2014) 가 보고되었다. 기존 표본(Ishidoya, T. \& T. H. Chung 5956 $\mathrm{SNU})$ 은 산벚나무로 동정되어 있으나, 생식형질이 없어 벚나무와 구분하기 어렵다. 현지조사 표본을 관찰한 결과, 홍도산은 화서가 산방화서이며, 꽃자루가 $2-3 \mathrm{~cm}$ 으로 긴 점에서 대부분 벚나무로 확인되었다. 또한, 일부 표본(J. S. Lee et al. 030613-413 IUI; J. S. Lee et al. 030405-44 IUI; Y. J. Jang 200422-55 HIBR)은 꽃자루와 잎자루 및 잎 뒷면에 털이 있는 잔털벚나무형 $[P$. serrulata var. pubescens
(Makino) Nakai]이 관찰되었다.

19. Rhamnus rugulosa Hemsl. 털갈매나무 Rhamnus koraiensis C. K. Schneid.

기존 홍도식물상 보고에서 목록에는 학명 R. koraiensis C. K. Schneid에 국명을 돌갈매나무로 보고하고 본문에는 털갈매나무로 국명을 적는 등 혼동된다(Lee and Kim, 1968). 현지조사 표본을 관찰한 결과, 홍도산은 대부분 잎 은 호생하며, 털이 있고, 크기는 $3 \mathrm{~cm}$ 이상인 점에서 털갈 매나무로 확인되었다.

\section{Celtis bungeana Blume 좀풍게나무}

기존 홍도식물상 보고에서 풍게나무(C. jessoensis Koidz.) 로 보고되었으나(Lee and Lee, 1959; Lee, 2014), 기존 표본 (T. B. Lee s.n. SNUA)은 좀풍게나무로 동정되어 있다. 기존 표본과 현지조사 표본을 관찰한 결과, 홍도산은 열매자루 가 $10 \mathrm{~mm}$ 이상으로 길고, 열매는 검은색(드물게 노란색) 이며, 잎의 톱니가 극히 일부 발달하고, 잎자루가 $15 \mathrm{~mm}$ 이하로 비교적 짧은 특징에서 좀풍게나무로 동정된다.

21. Boehmeria nivea var. tenacissima (Gaudich.) Miq 섬모시풀 기존 홍도식물상에서 모시풀 [B. nivea (L.) Gaudich.] (Lee and Lee, 1959, 섬모시풀(Lee and Kim, 1968) 또는 두 종 모두 분포(Lee, 2014)한다고 보고되었다. 기존 표본(T. B. Lee s.n. SNUA:81207; T. B. Lee $4320 \mathrm{SNUA)}$ 과 현지조사 표 본을 관찰한 결과, 홍도산은 탁엽이 기부에서 유합하고 줄기와 잎자루에 압착된 거친 털이 밀생하는 점에서 섬모 시풀로 판단되었다.

22. Viola grypoceras A. Gray 낚시제비꽃

기존 홍도식물상에서 낚시제비꽃과 졸방제비꽃 $(V$. acuminata Ledeb.)이 보고되었으나(Lee and Lee, 1959; Lee and Kim, 1968; Lee, 2014), 두 종 모두 표본이 확인되지 않 았다. 한편 기존표본(T. B. Lee s.n. SNUA:88165)은 왜졸방 제비꽃(V. sacchalinensis H. Boissieu)으로 동정되어 있다. 기존 표본과 현지조사 표본을 검토한 결과, 꽃잎 안쪽에 털이 없고, 암술대 상부에 돌기모가 없는 점에서 낚시제 비꽃으로 판단된다. 또한, 일부 기존표본(Y.J.Jang 200421-14 IUI)은 줄기잎이 점첨두인 점에서 졸방제비꽃 과 유사하나, 근생엽이 있고, 꽃잎 안쪽에 털이 없으며, 암 술대 상부에 돌기모가 없는 점에서 낚시제비꽃으로 동정 되었다.

\section{Viola japonica (Langsd.) DC. 왜제비꽃}

기존 홍도식물상에서 태백제비꽃(V.albida Palib.) (Lee and Lee, 1959) 또는 왜제비꽃(Lee, 2014)이 보고되었고, 기 존 결실기 표본(T. B. Lee $116 \mathrm{SNUA:87719)은} \mathrm{태백제비꽃}$ 으로 동정되어 있었다. 현지조사 결과, 엽연은 둔한 톱니 
이며, 꽃색이 자주색 또는 옅은 자주색이고, 꽃잎 안쪽에 털이 없는 점에서 왜제비꽃으로 판단된다.

\section{Rhododendron mucronulatum Turcz. 진달래}

Rhododendron mucromulatum var. lucidum Nakai, Rhododendron mucronulatum var. ciliatum Nakai

기존 홍도식물상에서 털진달래(var. ciliatum Nakai) (Lee and Kim, 1968) 또는 털진달래와 반들진달래(var. lucidum Nakai) (Lee, 2014)가 분포한다고 보고되었다. 반들진달래 는 홍도에서 채집된 표본(Miwa-Tosio s.n. TI; Holotype)을 기준으로 Nakai (1942)에 의해 기재되었다. 금번 관찰결과 홍도에는 잎 상면에 털이 있는 털진달래형과 잎 표면이 혁질성으로 두껍고 광택이 있는 반들진달래형이 관찰되 었다. 그러나 털이 없는 잎이 혼생하거나, 잎의 두께가 중 간형으로 보이는 개체가 관찰되어 이들을 진달래로부터 구별하는 데 어려움이 있다. 본 논문에서는 털진달래와 반들진달래를 진달래의 개체변이로 본 Chang et al. (1998, 2011)과 Hwang (1999)의 분류학적 견해에 따랐다.

25. Geranium thunbergii Siebold ex Lindl. \& Paxton 이질풀 기존 홍도식물상에서 쥐손이풀 $(G$ sibiricum L.)이 보고 되었으나(Lee and Lee, 1959), 기존 표본(T. B. Lee s.n. SNUA:87069)은 이질풀로 재동정되었다. 본인들의 현지 조사와 표본 관찰결과 홍도산은 꽃이 2 개씩 달리는 점 등 에서 이질풀로 확인되었다.

26. Adenophora triphylla (Thunb.) A. DC. 층층잔대 Adenophora verticillata var. angustifolia Regel; Adenophora verticillata Fisch.; Adenophora radiatifolia Nakai

기존 홍도식물상에서 잔대[A. triphylla var. tetraphylla (Thunb.) Makino (=A. triphylla var. japonica (Regel) H. Hara)] 가 보고되었고(Lee and Kim, 1968), 기존 표본(T. B. Lee s.n. SNUA:93538)은 잔대에서 층층잔대로 재동정되어있었다. 금번조사결과 악편이 피침형인 잔대와 달리 악편이 선형 인 특징 등에서 홍도산은 층층잔대로 판단되었다.

\section{Carpesium cernuum L. 좀담배풀}

기존 홍도식물상에서 천일담배풀(C. glossophyllum Maxim.)이 보고되었고(Kim, 1986, 1987), 기존 표본(Ishidoya, T. \& T. H. Chung 1370 SKK; Ishidoya, T. \& T. H. Chung 3732 $\mathrm{TI})$ 은 천일담배풀에서 좀담배풀로 재동정되어있었다. 현 지조사에서 홍도산은 개화기에 뿌리잎이 조락하며, 줄기 잎이 발달하는 특징 등에서 좀담배풀로 동정되었다.

28. Crepidiastrum $\times$ muratagenii $\mathrm{H}$. Ohashi \& K. Ohashi 홍도고들빼기(Fig. 2M)

C. denticulatum (Houtt.) J. H. Pak \& Kawano $\times C$. lanceolatum (Houtt.) Nakai. $\times$ Crepidiastrixeris denticulato- lanceolata Kitam. nom. illeg.

기존 문헌에서 홍도고들빼기의 학명은 $\times$ Crepidiastrixeris denticulato-platyphylla (Makino) Kitam.가 보고되었으나 (Lee, 1969; Lee, 1996), 이는 비합법명으로 새로운 학명은 Crepidiastrum ×nakaii H. Ohashi \& K. Ohashi이다(Ohashi and Ohashi, 2007). 기존 표본(Ishidoya, T. \& T. H. Chung 3741 $\mathrm{TI})$ 은 갯고들빼기와 이고들빼기의 잡종인 $\times$ Crepidiastrixeris denticulato-lanceolata Kitam. $[=\times$ Crepidiastrum $\times$ muratagenii H. Ohashi \& K. Ohashi]로 재동정된 것이 확인되었다 (Kitamura, 1955). 기존 표본과 현지조사 표본을 본인들이 검토한 결과, 홍도산은 목질화된 짧고 굵은 원줄기가 있 는 아관목 형태이며, 내총포편은 8개로 소화수가 10-12개 인 점에서는 갯고들빼기의 특성을 보이나, 개화기에 뿌리 잎이 조락하고, 줄기잎은 종이질로 예두 톱니가 있으며 수과에 부리가 있는 점에서는 이고들빼기의 특성을 보였 다. 즉 홍도산은 갯고들빼기 C. lanceolatum (Houtt.) Nakai 와 이고들빼기의 형태가 혼합되어 나타나, 이 두종 간의 잡종인 C. ×muratagenii로 판단되었다. 홍도고들빼기의 분 류학적 실체에 관해서는 별도의 논문에서 자세히 기술하 였다(Jang and Choi, 2021).

\section{Sanicula tuberculata Maxim. 애기참반디}

기존 홍도식물상에서 붉은참반디(S. rubriflora F. Schmidt ex Maxim.)이 보고되었고(Lee and Kim, 1968), 기존 표본(T. B. Lee s.n. SNUA:89369)은 애기참반디로 재동정되어있었 다. 본인들의 현지조사에서도 꽃은 백색이고 열매에 혹모 양의 돌기가 있는 점 등에서 애기참반디로 판단되었다.

\section{분포가 특이한 분류군}

홍도 및 인근 도서는 한반도의 최서남단에 있으며 중국, 대만, 일본, 제주도와 한반도 간에 식물의 분포 경로에 위 치해 식물지리학적으로 중요한 지역이다(Yang et al., 2013). 홍도에 자라는 식물 중 붉은사철란, 수정목, 신안새 우난초, 홍도원추리는 홍도 및 그 인근 도서가 분포의 북 방한계를 보이며, 흑산도비비추와 홍도서덜취는 홍도 및 그 인근 도서에만 분포하여 식물지리학적으로 특기할만 한 분류군들이다(Fig. 3). 한편 거지딸기(Rubus sumatranus Miq.)(Fig. 2N)는 제주도와 전남 일부 도서지방(홍도, 완도) 에 자생하는 것으로 알려져 있어 홍도가 북방한계로 판단 되나, 서해 도서까지 분포한다는 기록도 있어(Chang et al., 2011 ) 자생지에 대한 추가적인 조사가 필요하다.

1. Goodyera biflora (Lindl.) Hook. f. 붉은사철란(Fig. 2P) 붉은사철란(Fig. 3A)은 지리적으로 히말라야부터 인도, 네팔, 베트남 남부, 중국을 거쳐 한반도와 일본(규슈, 시코 쿠, 혼슈)까지 동아시아에 널리 분포한다(Chen et al., 2009; Yukawa, 2015). 한반도에서는 제주도와 전남(완도)에 분포 가 알려져 있다(Lee, 1984; Lee and Choi, 2006; Tae, 2018). 

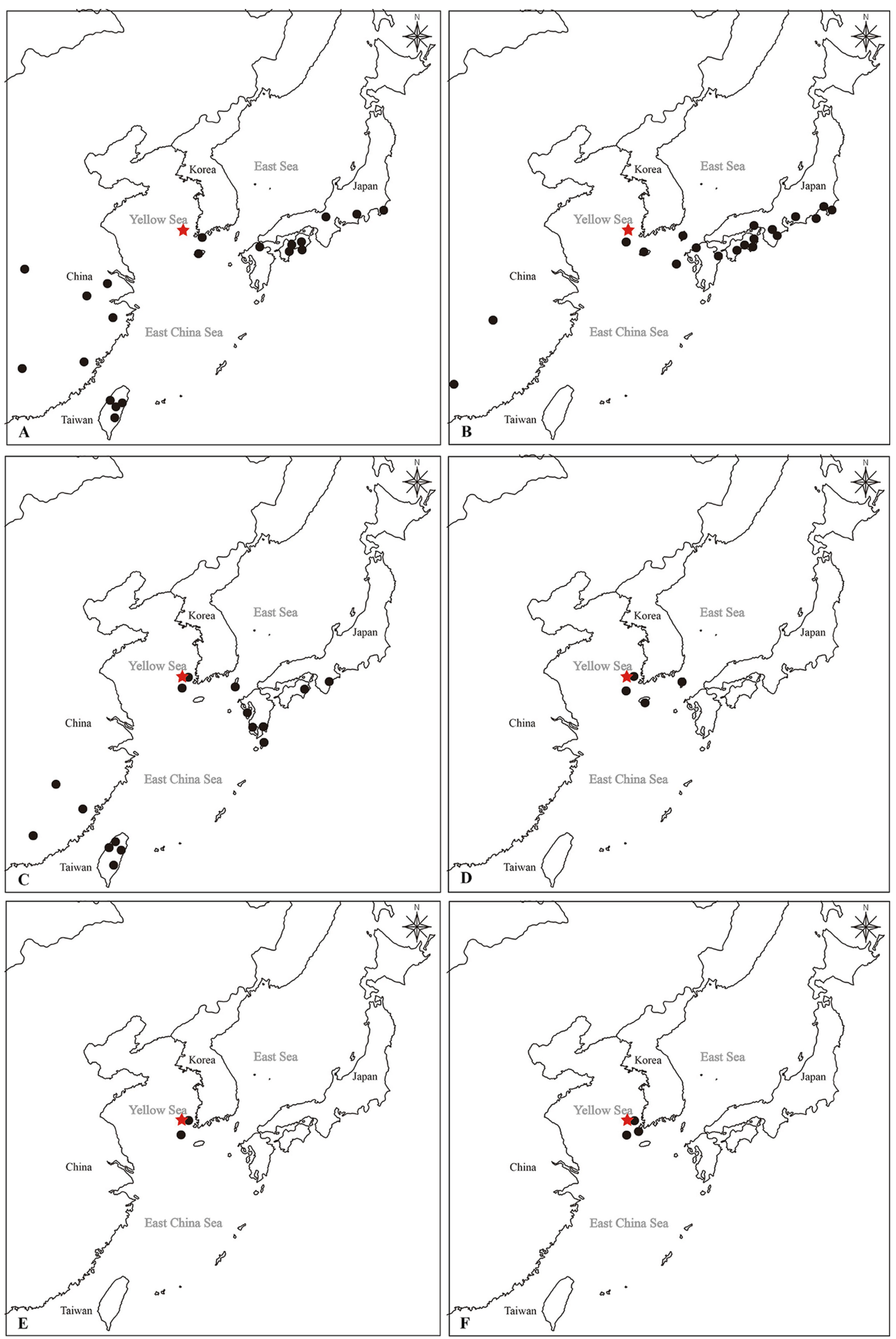

Fig. 3. Distribution maps of six Hongdo plants. A-D. Northern distributional limit in Korea. E, F. Endemic to Hongdo and nearby islands. A. Goodyera biflora. B. Damnacanthus major. C. Calanthe aristulifera. D. Hemerocallis hongdoensis. E. Hosta yingeri. F. Saussurea polylepis (Source: GBIF [http://www.gbif.org], The Korea National Biospecies Information System [http://www.nature.go.kr], Science Museum Net [http://science-net.kahaku.go.jp], the Chinese Virtual Herbarium [http://www.cvh.ac.cn]). 
홍도에서는 깃대봉 구실잣밤나무-붉가시나무림의 소수 개체가 생육하였으며, 국내 분포의 최북단으로 판단된다.

2. Damnacanthus major Siebold \& Zucc. 수정목(Fig. 2Q) 수정목(Fig. $3 \mathrm{~B}$ )은 지리적으로 인도, 태국, 중국(남부), 일본(혼슈 남부, 시코쿠, 큐슈), 한반도에 분포한다(Chen and Taylor, 2011; Uchi, 2017). 국내에서는 제주에 자라는데 (Lee et al., 2018), 추가적으로 전라남도의 신안군(가거도) 에 분포가 알려졌다(Yang, 2013). 기존 보고된 곳보다 북쪽 인 홍도의 깃대봉과 양산봉 구실잣밤나무림 사면과 암반 주변에서 생육하는 것이 확인되어 국내 최북단으로 판단 된다.

3. Calanthe aristulifera Rchb. f. 신안새우난초(Fig. 2E) 신안새우난초(Fig. $3 \mathrm{C}$ )는 지리적으로 중국 서남부(푸젠 성, 광둥성, 광시), 대만, 일본 (혼슈 이즈 반도와 와카야마 현, 시코쿠, 큐슈), 한국에 분포한다(Chen et al., 2009; Yukawa, 2015). 국내에서는 전라남도 흑산면(흑산도, 가거 도)에 분포가 알려져 있으며(Hong et al., 2009; Kim et al., 2012), 홍도가 국내 최북단 분포지로 보인다.

4. Hemerocallis hongdoensis M. G. Chung \& S. S. Kang 홍도원추리(Fig. 2J)

홍도원추리(Fig. 3D)는 홍도 및 그 인근 도서, 제주 섭섬, 대마도에 자라는 것으로 알려져 있으며(Kang and Chung, 2000), 홍도가 분포 북방한계로 판단된다. 홍도원추리의 기원으로 Kang and Chung (2000)은 allozyme 분석 결과와 형태적 유사성에 근거하여 한반도의 백운산원추리가 섬 으로 이주하여 홍도원추리로 분화하였다는 가설을 제안 한 바 있다.

5. Hosta yingeri S.B. Jones 흑산도비비추(Fig. $2 \mathrm{~K}$ )

흑산도비비추(Fig. $3 \mathrm{E}$ )는 흑산도에서 채집한 표본을 기 준으로 신종기재된 분류군으로, 홍도 및 그 인근 도서(대 흑산도, 가거도)에만 분포하는 특산식물이다(Schmid, 2010; Chung, 2018).

\section{Saussurea polylepis Nakai 홍도서덜취(Fig. 2O)}

홍도서덜취(Fig. $3 \mathrm{~F})$ 는 홍도에서 채집된 표본(Ishidoya, T. \& T. H. Chung 3735 TI; Holotype)을 기준으로 Nakai (1931)가 신종기재된 종이다. 홍도 및 그 인근 도서(대흑산 도, 가거도, 우이도, 관매도)에만 분포하는 특산식물이다 (Yun and Kim, 2021).

\section{법정보호종 및 희귀식물}

환경부의 멸종위기 야생식물(Ministry of Environment, 2017)에 따른 법정보호종은 총 7분류군이 확인되었다. I급 종에 풍란과 나도풍란 2 분류군, $\mathrm{II}$ 급에 대흥란, 새깃아재
Table 2. List of the protected species designated by the Ministry of Environment on Hongdo Island.

\begin{tabular}{clc}
\hline \hline Family & \multicolumn{1}{c}{ Species } & Criteria \\
\hline Orchidaceae & Neofinetia falcata 풍란 & I \\
Orchidaceae & Sedirea japonica 나도풍란 & I \\
Blechnaceae & Woodwardia japonica 새깃아재비 & II \\
Orchidaceae & Bulbophyllum inconspicuum 혹난초 & II \\
Orchidaceae & Calanthe aristulifera 신안새우난초 & II \\
Orchidaceae & Cymbidium macrorhizon 대흥란 & II \\
Orchidaceae & Dendrobium moniliforme 석곡 & II \\
\hline
\end{tabular}

Table 3. List of the red list plants designated by the National Institute of Biological Resources on Hongdo Island.

\begin{tabular}{clc}
\hline \hline Family & \multicolumn{1}{c}{ Species } & Criteria \\
\hline Orchidaceae & Neofinetia falcata 풍란 & $\mathrm{CR}$ \\
Orchidaceae & Sedirea japonica 나도풍란 & $\mathrm{CR}$ \\
Orchidaceae & Cymbidium macrorhizon 대흥란 & $\mathrm{EN}$ \\
Orchidaceae & Dendrobium moniliforme 석곡 & $\mathrm{EN}$ \\
Primulaceae & Lysimachia pentapetala 홍도까치수염 & $\mathrm{EN}$ \\
Asteraceae & Saussurea polylepis 홍도서덜취 & $\mathrm{VU}$ \\
Blechnaceae & Woodwardia japonica 새깃아재비 & $\mathrm{VU}$ \\
Orchidaceae & Bulbophyllum inconspicuum 혹난초 & $\mathrm{VU}$ \\
Orchidaceae & Calanthe sieboldii 금새우난초 & $\mathrm{VU}$ \\
Orchidaceae & Cephalanthera subaphylla 꼬마은난초 & $\mathrm{VU}$ \\
Orchidaceae & Goodyerabiflora 붉은사철란 & $\mathrm{NT}$ \\
\hline
\end{tabular}

$\overline{\mathrm{CR}}$, critically endangered; EN, endangered; VU, vulnerable; NT, near threatened.

비, 석곡, 신안새우난초, 혹난초 등 5 분류군이 각각 확인 되었다(Fig. 2, Table 2).

국립생물자원관에서 발간한 적색자료집(National Institute of Biological Resources, 2012)에 따른 희귀식물은 총 11분 류군이 확인되었다. 위급(critically endangered, CR) 종에 나 도풍란과 풍란 등 2분류군, 위기(endangered, $\mathrm{EN}$ ) 종에 대 흥란, 석곡, 홍도까치수염 등 3 분류군, 취약(vulnerable, $\mathrm{VU})$ 종에 금새우난초, 꼬마은난초, 새깃아재비, 혹난초, 홍도서덜취 등 5 분류군, 준위협(near threatened, NT) 종으 로 붉은사철란 1 분류군이 각각 확인되었다(Table 3). 추가 적으로 Oh et al. (2015)은 다도새우난초를 한국 남서부 도 서와 대마도에만 분포하는 점에서 위기(endangered, $\mathrm{EN}$ ) 종으로 평가한 바 있다.

1. Sedirea japonica (Linden \& Rchb. f.) Garay \& H. R. Sweet 나도풍란(Fig. 2R)

나도풍란은 홍도에서 Lee and Lee (1959), Lee and Kim 
(1968), Kim $(1986,1987)$ 에 의해 보고되었다. 그러나 Kim (1986, 1987)의 보고는 홍도관리사무소의 온실 속에 재배 개체를 목록에 포함한 것이다(Lee, 2014). 저자들의 2003 년 조사에서는 1 구 당산술 후박나무 고목 위에서 10 여 개 체가 확인되었다. 이들 개체는 복원을 위해 식재된 것으 로 판단되며, 2020년 조사에서는 확인되지 않아, 소멸된 것으로 판단된다. 나도풍란은 홍도 및 그 인근 섬(대흑산 도, 가거도, 보길도 등)과 제주도에서 최근 10 여 년간 관찰 기록이 없어, 국내에서는 남채 등으로 거의 절멸한 것으 로 간주되고 있다(National Institute of Biological Resources, 2012).

2. Neofinetia falcata (Thunb.) Hu. 풍란

풍란은 홍도에서 Lee and Lee (1959), Lee and Kim (1968), Lee (2014)에 의해 보고되었다. 주민청문에 의하면 깃대봉 서쪽 능선부 암석지대에 생육하고 있다고 하였으나, 금번 조사에서는 관찰하지 못하였다.

3. Cymbidium macrorhizon Lindl. 대흥란(Fig. 2S)

대흥란은 홍도에서 Lee and Choi (2006), Lee (2014)에 의 해 보고된 바 있으며, 금번 조사에서는 양산봉 남서쪽 사면 상록수림에서 10 여 개체가 생육하는 것이 관찰되었다.

4. Dendrobium moniliforme Sw. 석곡(Fig. 2T)

석곡은 홍도에서 Lee and Lee (1959), Lee and Kim (1968), $\operatorname{Kim}(1986,1987)$, Lee (2014)에 의해 보고된 바 있으며, 금 번 조사에서는 깃대봉에서 설풍여골로 가는 능선부의 암 석지대에서 여러 개체가 생육하는 것이 관찰되었다.

5. Bulbophyllum inconspicuum Maxim. 혹난초(Fig. 2U) 혹난초는 홍도에서 Lee and Lee (1959), Kim (1986, 1987), Lee (2014)에 의해 보고되었으며, 금번 조사에서는 깃대봉 에서 설풍여골으로 가는 능선부의 나무에 착생하여 생육 하는 것이 관찰되었다.

6. Calanthe insularis S. H. Oh, H. J. Suh \& C. W. Park 다 도새우난초(Fig. 2V)

다도새우난초는 홍도에서 Oh et al. (2015)에 의해 보고 되었으며, IUCN 기준에 따라 제한적인 분포를 보이는 점 에서 위기(EN)로 평가되었다(Oh et al., 2015). 금번 조사에 서는 구실잣밤나무의 그늘지고 습한 곳에 금새우난초 군 락과 신안새우난초 군락 주변에서 소수 개체가 생육하는 것이 관찰되었다.

7. Calanthe sieboldii Decne. ex Regel 금새우난초(Fig. 2W) Calanthe striata f. sieboldii (Decne. ex Regel) Ohwi

금새우난초는 홍도에서 Lee (2007), Lee (2014)에 의해 보고되었으며, 금번 조사에서는 홍도 전역의 구실잣밤나 무림에 많은 개체가 생육하는 것이 관찰되었다.
8. Lysimachia pentapetala Bunge 홍도까치수염(쇠까치수 염) (Fig. 2X)

홍도까치수염은 지리적으로 중국 동북부에서 동부까 지 넓게 분포하며, 한반도에서는 홍도의 길가 또는 숲 가 장자리에 분포한다고 알려져 있다. 최근에는 홍도뿐 아니 라, 내륙인 전남과 경북, 강원 일부 지역에서 분포한다고 알려져 자생지에 대한 정확한 조사가 요구된다. 홍도에서 는 Lee and Lee (1959), Lee and Kim (1968), Kim (1986, 1987), Lee (2014)에 의해 보고되었으며, 금번 조사에서는 깃대봉 탐방로와 숲 속 무덤가에서 소수 개체가 관찰되었다.

\section{귀화식물}

홍도에서 발견된 귀화식물은 40 분류군이었으며, 식물 상 목록에 N으로 표시하였다(Appendix 1). 조사지역의 귀 화율(Naturalized Index: 귀화식물의 종수/출현식물의 총 종 수 $\times 100=40 / 470 \times 100)$ 은 $8.51 \%$, 도시화지수(Urbanization Index: 귀화식물의 종수/남한 귀화식물 총 종수 $\times 100=40 /$ $405 \times 100)$ 은 $9.88 \%$ 이었다. 대부분의 귀화식물은 경작지, 등산로, 해수욕장 등 인위적으로 교란된 지역에서 출현하 였다.

홍도의 귀화식물은 면적이 크고 인구가 많은 흑산도(52 분류군)보다는 적게 나타났지만, 면적과 인구수가 인구가 유사한 가거도(28분류군)보다는 많이 나타났다(Yang et al., 2013; Jang et al., 2014). 이는 홍도가 가거도보다 관광객 의 왕래가 빈번한 것과 관광객의 증가로 1 구의 개발이 이 루어지면서 나타난 결과로 여겨진다. 이전 문헌에서 홍도 의 귀화식물은 Lee and Lee (1959)는 5 분류군, Lee and Kim (1968)은 6분류군, $\operatorname{Kim}(1986,1987)$ 은 15분류군, Lee (2014) 는 10 분류군을 보고하였으며, Kim and Oh (2010)는 다도해 귀화식물 연구에서 42 분류군을 보고하였다. 이러한 결과 는 외부 방문객과 물류의 급증과 더불어, 이번조사가 다 양한 경로와 시기에 이루어져 종수가 증가한 것으로 생각 된다. 이번 조사에서 좀명아주, 청비름, 유럽점나도나물, 개자리, 땅꽈리, 선개불알풀, 별꽃아재비, 비짜루국화, 주 걱개망초, 왕포아풀, 좀참새귀리가 새롭게 추가되었다.

ORCID: Young-Jong JANG https://orcid.org/0000-0001-62572424; Jong-Soo PARK https://orcid.org/0000-0001-5297-2926; Ji-Yeon LEE https://orcid.org/0000-0002-4930-6540; ByoungHee CHOI https://orcid.org/0000-0002-9234-9052

\section{Acknowledgments}

그동안 연구실에서 홍도 현지조사와 식물 동정에 도움 을 준 심현보(인천과학예술영재학교), 김원희(국립생물 자원관), 김소영, 이정현(전남대학교), 조원범(국립산림품 종관리센터), 이동혁(국립세종수목원), 최인수(Arizona State University), 진동필(국립생물자원관) 박사님들과 박 
종원(인하대학교 식물계통분류연구실)께 감사드립니다. 본 연구는 국립수목원(KNA1-1-18, 15-3)과 한국연구재단 (NRF-2018R1D1A1B07043030)의 홍도 현지조사 경비 지 원이 있었기에 가능했음을 밝힙니다.

\section{Conflict of Interest}

The authors declare that there are no conflicts of interest.

\section{Literature Cited}

Chang, C. S. 2020. Flora of the Korean Peninsula Phase II. Version 1.4. TB Lee Herbarium. Occurrence Dataset. GBIF.Org. Retrieved Dec. 31, 2020, available from https://oi.org/ 10.15468/0vevsq.

Chang, C.-S. and K. S. Chang. 2010. Reexamination of foreign collector's sites and exploration routes in Korea (IV) - with respect to T. Ishidoya. Korean Journal of Plant Taxonomy 40: 90-104. (in Korean)

Chang, C.-S., J. I. Jeon and W. K. Min. 1998. The distribution of the woody plants of South Korea based on herbarium (SNUA) materials of the arboretum (IV) Ericaceae. Bulletin of the Arboretum Seoul National University 18:1-21. (in Korean)

Chang, C. S., H. Kim and G. S. Chang. 2011. Illustrated Encyclopedia of Fauna and Flora of Korea, Vol. 43. Woody Plants. Ministry of Education, Seoul, 510 pp. (in Korean)

Chen, T. and C. M. Taylor. 2011. Damnacanthus. In Flora of China, Vol. 19. Cucurbitaceae through Valerianaceae, with Annonaceae and Berberidaceae. Wu, Z. Y., P. H. Raven and D. Y. Hong (eds.), Science Press, Beijing and Missouri Botanical Garden Press, St. Louis, MO. Pp. 94-97.

Chen, X., Z. Liu, G. Zhu, K. Y. Lang, Z. Ji, Y. B. Luo, X. Jin, P. J. Cribb, J. J. Wood, S. W. Gale, P. Ormerod, J. J. Vermeulen, H. P. Wood, D. Clayton and A. Bell. 2009. Orchidaceae. In Flora of China, Vol. 25. Wu, Z. Y., P. H. Raven and D. Y. Hong (eds.), Science Press, Beijing and Missouri Botanical Garden Press, St. Louis, MO. Pp. 45-54.

Choi, B. M. 1980. A research on plants in Hongdo island. Chongju National University Thesis Collection 17: 343-364. (in Korean)

Christenhusz, M. J. M., J. L. Reveal, A. Farjon, M. F. Gardner, R. R. Mill and M. W. Chase. 2011. A new classification and linear sequence of extant gymnosperms. Phytotaxa 19: 55-70.

Chung, G. Y., K. S. Chang, J.-M. Chung, H. J. Choi, W.-K. Paik and J.-O. Hyun. 2017. A checklist of endemic plants on the Korean Peninsula. Korean Journal of Plant Taxonomy 47: 264-288. (in Korean)

Chung, Y. C. 2018. Hosta. In The Genera of Vascular Plants of
Korea. Flora of Korea Editorial Committee (eds.), Hongneung Science Publishing Co., Seoul. Pp. 1734-1737. (in Korean)

Cultural Heritage Administration. 2012. Natural Monument. National Research Institute of Cultural Heritage, Daejeon. Pp. 216-221. (in Korean)

Efimov, P. G. 2016. A revision of Platanthera (Orchidaceae; Orchidoideae; Orchideae) in Asia. Phytotaxa 254: 1-233.

Flora of Korea Editorial Committee. 2018. The Genera of Vascular Plants of Korea. Hongneung Science Publishing Co., Seoul, 1950 pp. (in Korean)

Hong, H.-H., H.-T. Im, G.-H. Jang, G.-N. Ko, Y.-I. Lee, J.-K. Jung and J.-S. Kim. 2009. First record of Calanthe aristulifera (Orchidaceae) in Korea. Korean Journal of Plant Taxonomy 39: 292-295. (in Korean)

Hong, H.-H., J.-S. Kim, G.-H. Jang and H.-T. Im. 2010. First record of Calanthe $(C . \times$ kibanakirishima F. Maek., Orchidaceae) in Korea. Korean Journal of Plant Taxonomy 40: 183185. (in Korean)

Hong, S. J. and H. S. Yu. 1997. Geomorphological landscape in Hongdo-Heuksando. In 2nd National Ecosystem Survey Hongdo-Heuksando Natural Environment. Ministry of Environment (eds.), Ministry of Environment, Seoul. Pp. 2-32. (in Korean)

Hwang, H. J. 1999. Systematic study on the genus Rhododendron in Korea. PhD dissertation, Seoul National University, Seoul, Korea, 140 pp (in Korean)

Im, H. T., K. Choi, K. S. Chang, H. W. Kim, C. H. Ryu, J. Murata and H. Ikeda. 2017. Specimens Collected from Korea at the Herbarium of the University of Tokyo. Korea National Arboretum, Pocheon, 5178 pp.

Im, H. T., K. Choi, K. S. Chang, J. Murata and H. Ikeda. 2018. Specimens Collected from Korea at the Herbarium of the University of Tokyo. Korea National Arboretum, Pocheon, 4982 pp.

Inoue, K. 1982. Taxonomic notes on some species of Platanthera (Orchidaceae) in Japan. Journal of the Faculty of Science, University of Tokyo, Section III Botany 13: 175-202.

Inoue, K. 1983. Systematics of the genus Platanthera (Orchidaceae) in Japan and adjacent regions with special reference to pollination. Journal of the Faculty of Science, University of Tokyo, Section III Botany 13: 285-374.

Ishidoya, T. 1920. The forest flora of Daeheuksan-do and Maegado islands. Chosen 8: 35-55. (in Japanese)

Jang, C.-S., S.-G. Yang, H.-D. Jang, R.-Y. Lee, M.-S. Park, K.-H. Kim and B.-U. Oh. 2014. Floristic study of Daeheuksando in Korea. Korean Journal of Plant Resources 27: 518-533. (in Korean)

Jang, Y. J. and B. H. Choi. 2021. Taxonomic identity of Crepidiastrum $\times$ nakaii recorded on Hongdo Island. Korean Journal of Plant Taxonomy 51: 198-204. 
Jeollanam-do Education Association. 1940. Plants in Jeollanamdo. Jeollanam-do Education Association, Seoul, 340 pp. (in Japanese)

Kang, E. S., S.-R. Lee, S. H. Oh, D.-K. Kim, S.-Y. Jung and D. C. Son. 2020. Comprehensive review about alien plants in Korea. Korean Journal of Plant Taxonomy 50: 89-119. (in Korean)

Kang, S. S. and M. G. Chung. 2000. High levels of allozyme variation within populations and low allozyme divergence within and among species of Hemerocallis (Liliaceae). American Journal of Botany 87: 1634-1646.

Kim, C. S. 1986. Studies on the flora and vegetation of Hongdo island. Bulletin of Institute of Littoral Biota. Mokpo National College 3: 1-36. (in Korean)

Kim, C. S. 1987. Studies on the flora and vegetation of Hong-do. In The Report for Natural Conservation of Hong-do. Sinan. Pp. 89-174. (in Korean)

Kim, H. 2020. T.B. Lee Herbarium Vascular Plant Collection. Version 1.19. TB Lee Herbarium. Occurrence Dataset. GBIF.Org. Retrieved Dec. 31, 2020, available from https://doi.org/ 10.15468/3lchvw.

Kim, H. and C. S. Chang. 2020. TB Lee Herbarium Vascular Plant Collection Phase II. Version 1.3. TB Lee Herbarium. Occurrence Dataset. GBIF.Org. Retrieved Dec. 31, 2020, available from https://doi.org/10.15468/htq2vm.

Kim, H. H., D. B. Kim, H. H. Song, G. Y. Hwang and W. S. Kong. 2018. Phytogeographical characteristics of outermost islands in the Korean Peninsula. Journal of the Korean Geographical Society 53: 117-132. (in Korean)

Kim, H. S. 1996. On the natural ecology and conservation counterplan in the Kagŏ-do. Journal of Korean Island 7: 173-185. (in Korean)

Kim, H. S. and J. G. Oh. 2010. Distribution of naturalized plants in Dadohae National Marine Park. Korean Journal of Plant Resources 23: 187-196. (in Korean)

Kim, J.-H., G.-H. Nam and J.-S. Kim. 2012. The vascular plants in Is. Gageo (Jeollanam-do). Journal of the Environmental Sciences 21: 437-450. (in Korean)

Kim, J. S. and T. Y. Kim. 2018. Woody Plants of Korean Peninsula: A revised edition. Dolbegae, Paju, 715 pp. (in Korean)

Kim, K.-J. and S.-M. Yun. 2012. A new species of Melampyrum (Orobanchaceae) from Southern Korea. Phytotaxa 42: 48-50.

Kitamura, S. 1955. Compositae Japonicae. Pars Quarta. Memoirs of the College of Science, Kyoto Imperial University, Series B 22: $77-126$

Korea Meteorological Administration. 2020. Climate Statistical Analysis. Retrieved Jan. 20, 2021, available from https:// www.kma.go.kr/eng/index.jsp.

Kwon, J. H., J. G. An, Y. H. Cho, S. S. Kim, M. O. Moon and S.
H. Hwang. 2018. Vscular plant. In Dadohaehaesang National Park Nature Resource Survey: Land. Korea National Park National Park Research Institute (eds.), Korea National Park Service, Wonju. Pp. 259-448. (in Korean)

Lee, B. Y., J. W. Park and E. B. Lee. 2018. Rubiaceae. In The Genera of Vascular Plants of Korea. Flora of Korea Editorial Committee (eds.), Hongneung Science Publishing Co., Seoul. Pp. 1223-1240. (in Korean)

Lee, I. K. and T. B. Lee. 1959. Flora of Hongdo. Gobongji 3: 5874. (in Korean)

Lee, J.-H. 2014. A study of the characteristics of the vegetation of the Hongdo Natural Preserve: Species and vegetation composition of natural heritage No. 170. PhD dissertation, Chungnam National University, Daejeon, Korea, 184 pp. (in Korean)

Lee, J.-H., M.-S. Do and H.-K. Song. 2013. Vegetation structure of Hongdo island. Korean Journal of Environment and Ecology 27: 592-613. (in Korean)

Lee, J. S. 1984. Studies on species of wild orchid and their geographical distribution in Korea. Cheju National University Journal 19: 31-54. (in Korean)

Lee, J. S. 2007. Taxonomy of Orchideae and distribution of Orchidaceae in Korea. PhD. dissertation, Inha University, Incheon, Korea. 198 pp. (in Korean)

Lee, J.-S. and B.-H. Choi. 2005. A taxonomic study of Korean Platanthera with a special reference to external morphology. Korean Journal of Plant Taxonomy 35: 25-46. (in Korean)

Lee, J. S. and B. H. Choi. 2006. Distributions and red data of wild orchids in the Korean Peninsula. Korean Journal of Plant Taxonomy 36: 335-360. (in Korean)

Lee, J. S. and Y.-J. Kim. 1978. Investigation of vegetation in Soheuksan-do and Hong-do. Korean Journal of Agricultural Science 5: 145-148. (in Korean)

Lee, K. H. 2000. Studies on Juniperus sargentii (Henry) Takeda varieties in Korea. MS dissertation. Konkuk University, Seoul, Korea, 43 pp. (in Korean)

Lee, N. S. 2011. Illustrated Flora of Korean Orchids. Ewha Womans University Press, Seoul. 345 pp. (in Korean)

Lee, S. M. 1999. Vascular Plant Flora of the Dadohae Haesang National Park in Korea. In The Report of the National Science Museum. National Science Museum (eds.), Seoul. Pp. 118-175. (in Korean)

Lee, T. B. 1969. Plant resources in Korea. Bulletin of Seoul National University (Biological Agriculture) 20: 158--159. (in Korean)

Lee, T. B. and T. W. Kim. 1968. Land Plants of Hongdo. In Report of the Academic Survey of Mt. Hanlasan and Hongdo Natural Conservatory Area: Natural Monument No. 182 and 170. Cul- 
ture and Public Information, Seoul. Pp. 308-359. (in Korean)

Lee, W. B. 2018. Cephalanthera. In The Genera of Vascular Plants of Korea. Flora of Korea Editorial Committee (eds.), Hongneung Science Publishing Co., Seoul. Pp. 1800-1801. (in Korean)

Lee, W. T. 1996. Lineamenta Florae Koreae. Academy Publishing Co., Seoul, 1688 pp. (in Korean)

Lee, W. T. 2012. The phototype speciemens of Korean vascular plants. Retrieved Jan. 20, 2021, available from http:// www.nature.go.kr/kbi/lvbng/clssc/selectBmbRsrmList1.do.

Lee, W. T. and Y. J. Yim. 1978. Studies on the distribution of vascular plants in the Korean Peninsula. Korean Journal of Plant Taxonomy 8: 1-33 (Appendix 1). (in Korean)

Ministry of Environment. 2017. Wildlife Protection and Management. Retrieved Dec. 31, 2020, available from http:// www.me.go.kr.

Nakai, T. 1931. Contributio Ad Cognitionem Generis Saussureae Japono-Koreanae. Botanical Magazine, Tokyo 45: 513-524.

Nakai, T. 1942. Notulae plantas Asiae orientalis (XXIX). Journal of Japanese Botany 19: 374-375.

National Institute of Biological Resources. 2012. Red Data Book of Endangered Vascular Plants in Korea. National Institute of Biological Resources, Incheon, 391 pp. (in Korean)

National Institute of Ecology. 2018. Floristic Target Species (FT Species) in Korea. National Institute of Ecology, Seocheon, 728 pp. (in Korean)

Oh, B. U. 2008. A taxonomic review of Korean Asarum (Aristolochiaceae). Korean Journal of Plant Taxonomy 38: 251-270. (in Korean)

Oh, B. U., S. C. Ko, S. H. Kang, W. K. Baik, K. O. Yoo, H. T. Im, C. G. Jang, G. Y. Chung, B. H. Choi, H. J. Choi, Y. M. Lee, C. H. Shin, K. Choi, J. H. Han, S. H. Park, H. J. Kim, G. S. Chang, J. C. Yang, S. Y. Jeong, C. H. Lee, S. H. Oh and D. G. Jo. 2016. Distribution Maps of Vascular Plants in Korea. Korea National Arboretum, Pocheon, 809 pp. (in Korean)

Oh, S.-H., H.-J. Suh and C.-W. Park. 2015. Two new species of Calanthe (Orchidaceae: Epidendroideae) from Korea. Phytotaxa 218: 69-76.

Ohashi, H. and K. Ohashi. 2007. Hybrids in Crepidiastrum (Asteraceae). Journal of Japanese Botany 82: 337-347.

Park, Y. K. 2003. Flora of islands in west and south regions of Korea. MS dissertation, Honam University, Gwangju, Korea, 121 pp. (in Korean)
Schmid, W. G. 2010. Hosta Species Update. HostaLibrary.Org/ Species/.

Shin, H. W., C. S. Lee, S. A. Choi, S. M. Eum and N. S. Lee. 2019. Taxonomic status of three controversial species of Cephalanthera (Orchidaceae) from Korea based on morphological and molecular data. Phytotaxa 415: 105-112.

Suh, H.-J., J.-H. Kim, J.-E. Choi, W. Lee, J.-S. Kim and S. Kim. 2020. A new distribution record of Sedum kiangnanense (Crassulaceae) in Korea. Korean Journal of Plant Taxonomy 50: 247-251.

Sun, B. Y. 2018. Cupressaceae. In The Genera of Vascular Plants of Korea. Flora of Korea Editorial Committee (eds.), Hongneung Science Publishing Co., Seoul. Pp. 165-174. (in Korean)

Tae, K. H. 2018. Goodyera. In The Genera of Vascular Plants of Korea. Flora of Korea Editorial Committee (eds.), Hongneung Science Publishing Co., Seoul. Pp. 1811-1813. (in Korean)

The Angiosperm Phylogeny Group, M. W. Chase, M. J. M. Christenhusz, M. F. Fay, J. W. Byng, W. S. Judd, D. E. Soltis, D. J. Mabberley, A. N. Sennikov, P. S. Soltis and P. F. Stevens. 2016. An update of the Angiosperm Phylogeny Group classification for the orders and families of flowering plants: APG IV. Botanical Journal of the Linnean Society 181: 1-20.

The Pteridophyte Phylogeny Group. 2016. A community-derived classification for extant lycophytes and ferns. Journal of Systematics and Evolution 54: 563-603.

Uchi, T. 2017. Rubiaceae. In Wild Flowers of Japan, Vol. 4. Ohashi, H., Y. Kadota, H. Kihara, J. Murata and K. Yonekura (eds.), Heibonsha, Tokyo. Pp. 266-293. (in Japanease)

Yang, S.-G., C.-S. Jang, H.-D. Jang, R.-Y. Lee, M.-S. Park, K.-H. Kim and B.-U. Oh. 2013. Floristic study of Gageodo in Korea. Korean Journal of Plant Resources 26: 597-612. (in Korean)

Yukawa, T. 2015. Orchidacea. In Wild Flowers of Japan, Vol. 1. Ohashi, H., Y. Kadota, H. Kihara, J. Murata and K. Yonekura (eds.), Heibonsha, Tokyo. Pp. 178-231. (in Japanease)

Yun, K.-W., Y. Hwang, S. So and M. Kim. 2012. Flora of island Gageo in Jellonamdo, Korea. Korean Journal of Environment and Ecology 26: 139-155. (in Korean)

Yun, S. A. and S.-C. Kim. 2021. Genetic diversity and structure of Saussurea polylepis (Asteraceae) on continental islands of Korea: Implications for conservation strategies and management. PLoS ONE 16: e0249752. 


\section{홍도 관속식물상 재검토}

\section{장영종 $\cdot$ 박종수 ${ }^{1} \cdot$ 이진실 ${ }^{2} \cdot$ 이지연 $^{3} \cdot$ 최병희 ${ }^{*}$}

인하대학교 생명과학과, ${ }^{1}$ 국립호남권생물자원관 식물자원연구부, ${ }^{2}$ 연수고등학교, ${ }^{3}$ 국립생물자원관

적 요: 전라남도 신안군에 위치한 홍도의 관속식물상을 연구하였다. 생물다양성 데이터베이스를 통해 과거 홍도 식물상 연구들에서 수집된 표본 검토와 함께, 본인들이 2003년 4월부터 2020년 10월까지 22회에 걸쳐 현지조사를 수행하였다. 과거에 채집된 것과 금번조사 표본을 종합검토한 결과, 홍도의 관속식물은 102 과 296속 425종 6아종 41변종으로 총 472분류군의 분포를 확인하였다. 이들 중 111 분류군은 이번 조사에서 새 로이 분포가 확인되었으며, 특히 6 분류군의 형태적 특징과 생육지를 기록하였다. 또한, 분류학적으로 재검토 및 재동정된 29분류군에 대한 분류학적 주석을 기술하였다. 이번 조사에서 붉은사철란, 수정목, 신안새우난 초, 홍도원추리 등 4 분류군은 홍도가 국내에서 분포 북한계지임이 밝혀졌다. 한편 흑산도비비추와 홍도서덜 취의 분포는 국내에서 홍도와 인근 섬에만 분포가 한정되었다. 이들에 대한 분포도를 기재하였다. 환경부 지 정 멸종위기 야생식물은 I급에 나도풍란과 풍란 2분류군, II급에 대흥란, 새깃아재비, 석곡, 신안새우난초, 혹 난초 등 5 분류군으로 총 7 분류군이 확인되었으며, 국립생물자원관에서 발간한 적색자료집에 따른 희귀식물 은 11 분류군이 확인되었다. 귀화식물은 40 분류군이 보고되었다.

주요어: 홍도 식물상, 관속식물, 증거표본, 생물다양성 데이터베이스 
Appendix 1. List of vascular plants on Hongdo Island including voucher specimens, arranged by PPG I (Pteridophytes), Christenhusz et al. (Gymnosperms) and APG IV (Angiosperms). Source: GBIF.org (01 May 2021) GBIF Occurrence Download https://doi.org/10.15468/ dl.ztmz8g, The Korea National Biospecies Information System (www.nature.go.kr). [Abbreviation] Previous studies (Lee and Lee, 1959; Lee and Kim, 1968; Kim, 1986, 1987; Lee, 2014), E (endemic plants), CR (critical endangered plants), VU (vulnerable plants), NT (near threatened), Class I-II (protected species designated by ministry of environment), III-V (degree of floristic target species), N (naturalized alien plants), $\star$ (newly recorded plant in this study), *(cultivated plants), ○ (list only without voucher specimens), (with voucher specimens), Misid (misidentification)

Taxa $\quad \begin{gathered}\text { Previous } \\ \text { studies }\end{gathered} \quad$ This study and voucher specimens

\section{LYCOPODIACEAE 석송과}

1. Huperzia serrata (Thunb.) Trevis. 뱀톱

\section{SELAGINELLACEAE 부처손과}

2. Selaginella tamariscina (P.Beauv.) Spring 바위손

3. Selaginella involvens (Sw.) Spring 부처손

\section{OPHIOGLOSSACEAE 고사리삼과}

4. Botrychium ternatum (Thunb.) Sw. 고사리삼

5. Botrychium virginianum (L.) Sw. 늦고사리삼

\section{OSMUNDACEAE 고비과}

6. Osmunda japonica Thunb. 고비

HYMENOPHYLLACEAE 처녀이끼과

7. Crepidomanes minutum (Blume) K. Iwats. 부채괴불이끼

\section{LINDSAEACEAE 비고사리과}

8. Odontosoria chinensis (L.) J. Sm. 바위고사리

PTERIDACEAE 고사리과

9. Pteris cretica L. 큰봉의꼬리(III)

10. Pteris multifida Poir. 봉의꼬리

T. B. Lee 923 (SNUA); J. S. Lee et al. 030615-664 (IUI)

DENNSTAEDTIACEAE 잔고사리과

11. Hypolepis punctata (Thunb.) Mett. ex Kuhn 점고사리

12. Microlepia strigosa (Thunb.) C.Presl 돌토끼고사리

13. Pteridium aquilinum var. latiusculum (Desv.) Underw. ex A. Heller 고사리

ASPLENIACEAE 꼬리고사리과

$\star$ 14. Asplenium incisum Thunb. 꼬리고사리

J. S. Park \& Y. J. Jang 190730-34 (IUI)

\section{WOODSIACEAE 우드풀과}

15. Woodsia manchuriensis Hook. 만주우드풀

\section{BLECHNACEAE 새깃아재비과}

$\star$ 16. Woodwardia japonica (L. f.) Sm. 새깃아재비(VU, Class II, V)

ATHYRIACEAE 개고사리과

$\star$ 17. Athyrium niponicum (Mett.) Hance 개고사리

18. Athyrium yokoscense (Franch. \& Sav.) Christ 뱀고사리

19. Deparia conilii (Franch. \& Sav.) M.Kato 좀진고사리

$\star 20$. Deparia japonica (Thunb.) M. Kato 진고사리

J. S. Lee et al. 030510-312 (IUI)

Ishidoya, T. \& T. H. Chung 3308 (TI); Y. J.

Jang 200602-34 (IUI)

Ishidoya, T. \& T. H. Chung 3328 (TI); J. S. Park \& Y. J. Jang 190729-13 (IUI)

J. S. Park \& Y. J. Jang 190928-81 (IUI)

$\bigcirc$

J. S. Park \& Y. J. Jang 190928-79 (IUI)

J. S. Park \& Y. J. Jang 191102-29 (IUI)

Observation!

J. S. Lee et al. 030714-996 (IUI)

$$
\Rightarrow \text { D. japonica (Misid) }
$$

T. B. Lee s.n. (SNUA:82612); Y. J. Jang 200702-28 (IUI)

THELYPTERIDACEAE 처녀고사리과 
Appendix 1. Continued

\begin{tabular}{ccc}
\hline \hline Taxa & $\begin{array}{c}\text { Previous } \\
\text { studies }\end{array}$ & This study and voucher specimens \\
\hline
\end{tabular}

21. Cyclosorus acuminatus (Houtt.) Nakai ex H.Itô 별고사리

22. Phegopteris decursive-pinnata (H.C.Hall) Fée 설설고사리

$\star 23$. Thelypteris angustifrons (Miq.) Ching 탐라사다리고사리(IV)

$\star 24$. Thelypteris glanduligera (Kunze) Ching 사다리고사리

\section{DRYOPTERIDACEAE 관중과}

25. Arachniodes amabilis (Blume) Tindale 쇠고사리

26. Arachniodes aristata (G. Forst.) Tindale 가는쇠고사리(III)

27. Arachniodes simplicior (Makino) Ohwi 낫쇠고사리(꼬리쇠고사리) (III)

28. Cyrtomium caryotideum var. coreanum Nakai 참쇠고비

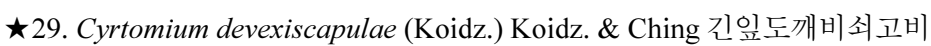

30. Cyrtomium falcatum (L. f.) C.Presl 도깨비고비(도깨비쇠고비)

31. Cyrtomium fortunei J.Sm. 쇠고비

32. Dryopteris bissetiana (Baker) C. Chr. 산족제비고사리

^33. Dryopteris caudipinna Nakai 가는홍지네고사리

34. Dryopteris chinensis (Baker) Koidz. 가는잎족제비고사리

35. Dryopteris crassirhizoma Nakai 관중

36. Dryopteris erythrosora (D.C. Eaton) Kunze 홍지네고사리

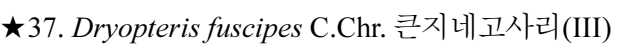

38. Dryopteris lacera (Thunb.) Kunze 비늘고사리

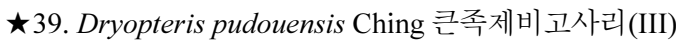

40. Dryopteris sacrosancta Koidz. 애기족제비고사리

41. Dryopteris uniformis (Makino) Makino 곰비늘고사리

42. Dryopteris varia (L.) Kuntze 족제비고사리

43. Polystichum polyblepharum (Roem.) Kunze ex C.Pres1 나도히초미

DAVALLIACEAE 넉줄고사리

44. Davallia mariesii T. Moore ex Baker 넉줄고사리

\section{POLYPODIACEAE 고란초과}

45. Lemmaphyllum microphyllum C.Presl 콩짜개덩굴

46. Lepisorus onoei (Franch. \& Sav.) Ching 애기일엽초(III)

47. Lepisorus thunbergianus (Kaulf.) Ching 일엽초
Y. J. Jang 200319-44 (IUI)

Y. J. Jang 200818-22 (IUI)

$\Rightarrow$ A. aristate (Misid)

Y. J. Jang 200703-45 (IUI)

- T. B. Lee 4314 (SNUA:81560); T. B. Lee s.n. (SNUA:81555); Y. J. Jang 190730-24 (IUI) $\Rightarrow$ C. falcatum (Synonym)

Y. J. Jang 200702-33 (IUI)

- T. B. Lee 122 (SNUA:81598); J. S. Park \& Y. J. Jang 191103-71 (IUI)

$\bigcirc$

Ishidoya, T. \& T. H. Chung 3315 (TI); T. B. Lee s.n. (SNUA:81866); J. S. Park \& Y. J. Jang 190928-71 (IUI)

Y. J. Jang 200702-36 (IUI)

Y. J. Jang 200603-44 (IUI)

$\bigcirc$

T. B. Lee 140 (SNUA:81717); Y. J. Jang 200702-35 (IUI)

Y. J. Jang 200601-20 (IUI)

- T. B. Lee s.n. (SNUA:81764); T. B. Lee s.n. (SNUA:81765); J. S. Park \& Y. J. Jang 191103-58 (IUI)

T. B. Lee 149 (SNUA:81823); T. B. Lee s.n. (SNUA:81833); Y. J. Jang 200818-25 (IUI)

- $\Rightarrow$ D. bissetiana (Misid)

Y. J. Jang 200601-18 (IUI)

T. B. Lee s.n. (SNUA:81506); T. B. Lee 82 (SNUA:82055); Y. J. Jang 200601-16 (IUI)

- Ishidoya, T. \& T. H. Chung 3324 (TI); T. B. Lee s.n. (SNUA:82126); J. H. Lee et al. 090320-93086 (IUI)

- T. B. Lee 237 (SNUA); Y. J. Jang 200319-49 (IUI)

- Ishidoya, T. \& T. H. Chung 3319 (TI); T. B. Lee 69 (SNUA:82144); T. B. Lee 238 (SNUA:82149); Y. J. Jang 200421-33 (IUI) 
Appendix 1. Continued

\begin{tabular}{|c|c|c|}
\hline Taxa & $\begin{array}{l}\text { Previous } \\
\text { studies }\end{array}$ & This study and voucher specimens \\
\hline 48. Lepisorus ussuriensis (Regel \& Maack) Ching 산일엽초 & ○ & $\begin{array}{l}\text { Ishidoya, T. \& T. H. Chung } 3318 \text { (TI); T. B. } \\
\text { Lee s.n. (SNUA) }\end{array}$ \\
\hline 49. Pyrrosia lingua (Thunb.) Farw. 석위(III) & ○ & $\begin{array}{l}\text { T. B. Lee } 4274 \text { (SNUA:82231); J. S. Lee et } \\
\text { al. 030510-4283 (IUI) }\end{array}$ \\
\hline 50. Pyrrosia petiolosa (Christ) Ching 애기석위 & $\bigcirc$ & J. S. Lee et al. 030712-877 (IUI) \\
\hline 51. Pyrrosia hastata (Houtt.) Ching 세뿔석위 & $\bigcirc$ & \\
\hline 52. Selliguea hastata (Thunb.) Fraser-Jenk. 고란초 & $\bigcirc$ & \\
\hline \multicolumn{3}{|l|}{ GINKGOACEAE 은행나무과 } \\
\hline 53. Ginkgo biloba L. 은행나무* & $\bigcirc$ & \\
\hline \multicolumn{3}{|l|}{ PINACEAE 소나무과 } \\
\hline 54. Pinus densiflora Siebold \& Zucc. 소나무 & $\bigcirc$ & J. S. Park \& Y. J. Jang 190730-27 (IUI) \\
\hline 55. Pinus rigida Mill. 리기다소나무* & ○ & \\
\hline 56. Pinus thunbergii Parl. 곰솔 & $\bigcirc$ & J. S. Lee et al. 030510-258 (IUI) \\
\hline \multicolumn{3}{|l|}{ CUPRESSACEAE 측백나무과 } \\
\hline 57. Cryptomeria japonica (Thunb. ex L. f.) D.Don 삼나무* & $\bigcirc$ & Y. J. Jang 200318-39 (IUI) \\
\hline 58. Juniperus chinensis var. procumbens Siebold ex Endl. 섬향나무(V) & 0 & $\begin{array}{l}\text { T. B. Lee } 332 \text { (SNUA); J. S. Park \& Y. J. } \\
\text { Jang 190927-65 (IUI) }\end{array}$ \\
\hline 59. Juniperus rigida Siebold \& Zucc. 노간주나무 & O & T. B. Lee 3033 (SNUA:26994) \\
\hline 60. Platycladus orientalis (L.) Franco 측백나무* & $\bigcirc$ & Y. J. Jang 200917-25 (IUI) \\
\hline \multicolumn{3}{|l|}{ SCHISANDRACEAE 오미자과 } \\
\hline 61. Kadsura japonica (L.) Dunal 남오미자(III) & ○ & $\begin{array}{l}\text { T. B. Lee s.n. (SNUA:56917); T. B. Lee s.n. } \\
\text { (SNUA:56919); T. B. Lee 4304 } \\
\text { (SNUA:56912); J. S. Lee et al. 031025-? } \\
\text { (IUI) }\end{array}$ \\
\hline 62. Schisandra chinensis (Turcz.) Baill. 오미자 & $\bigcirc$ & \\
\hline \multicolumn{3}{|l|}{ PIPERACEAE 후추과 } \\
\hline 63. Piper kadsura (Choisy) Ohwi 후추등 & $\bigcirc$ & \\
\hline \multicolumn{3}{|l|}{ ARISTOLOCHIACEAE 쥐방울덩굴과 } \\
\hline 64. Aristolochia contorta Bunge 쥐방울덩굴 & $\bigcirc$ & \\
\hline 65. Asarum heterotropoides var. seoulense (Nakai) F.Maekawa 서울족도리풀 & $\bigcirc$ & \\
\hline 66. Asarum maculatum Nakai 개족도리풀 (E, III) & $\bigcirc$ & $\begin{array}{l}\text { T. B. Lee s.n. (SNUA:80160); Y. J. Jang } \\
\text { 200421-13 (IUI) }\end{array}$ \\
\hline 67. Asarum sieboldii Miq. 족도리풀 & ○ & $\Rightarrow$ A. maculatum (Misid) \\
\hline \multicolumn{3}{|l|}{ LAURACEAE 녹나무과 } \\
\hline 68. Actinodaphne lancifolia (Blume) Meisn. 육박나무(III) & & $\begin{array}{l}\text { T. B. Lee s.n. (SNUA:57991); J. S. Lee et al. } \\
\text { 030821-2032 (IUI) }\end{array}$ \\
\hline 69. Cinnamomum yabunikkei H. Ohba 생달나무(III) & $\bigcirc$ & J. S. Park \& Y. J. Jang 190729-9 (IUI) \\
\hline 70. Lindera erythrocarpa Makino 비목나무 & $\bigcirc$ & J. S. Park \& Y. J. Jang 191102-38 (IUI) \\
\hline 71. Lindera obtusiloba Blume 생강나무 & O & $\begin{array}{l}\text { T. B. Lee s.n. (SNUA); J. S. Lee et al. } \\
\text { 030614-540 (IUI) }\end{array}$ \\
\hline 72. Litsea japonica (Thunb.) Juss. 까마귀쪽나무(III) & $\bigcirc$ & J. H. Lee et al. 090320-93081 (IUI) \\
\hline 73. Machilus japonica Siebold \& Zucc. ex Blume 센달나무(III) & $\bigcirc$ & J. S. Park \& Y. J. Jang 190927-42 (IUI) \\
\hline
\end{tabular}


Appendix 1. Continued

\begin{tabular}{|c|c|c|}
\hline Taxa & $\begin{array}{l}\text { Previous } \\
\text { studies }\end{array}$ & This study and voucher specimens \\
\hline 74. Machilus thunbergii Siebold \& Zucc. 후박나무 & O & $\begin{array}{l}\text { T. B. Lee s.n. (SNUA:58061); T. B. Lee s.n. } \\
\text { (SNUA:58037); T. B. Lee 1128 } \\
\text { (SNUA:58097); J. H. Lee et al. 090320- } \\
\text { 93051 (IUI) }\end{array}$ \\
\hline 75. Neolitsea aciculata (Blume) Koidz. 새덕이(III) & $\bigcirc$ & J. S. Park \& Y. J. Jang 190928-77 (IUI) \\
\hline 76. Neolitsea sericea (Blume) Koidz. 참식나무 & ○ & $\begin{array}{l}\text { T. B. Lee } 4287 \text { (SNUA:58181); J. H. Lee et } \\
\text { al. 090320-93053 (IUI) }\end{array}$ \\
\hline \multicolumn{3}{|l|}{ ARACEAE 천남성과 } \\
\hline 77. Arisaema amurense Maxim. 둥근잎천남성 & $\bigcirc$ & Y. J. Jang 200317-28 (IUI) \\
\hline 78. Arisaema amurense f. serratum (Nakai) Kitag. 천남성 & O & Y. J. Jang 200512-46 (IUI) \\
\hline 79. Arisaema ringens (Thunb.) Schott 큰천남성 & 0 & $\begin{array}{l}\text { T. B. Lee s.n. (SNUA:100642); J. S. Lee et al. } \\
\text { 030614-601 (IUI) }\end{array}$ \\
\hline 80. Pinellia ternata (Thunb.) Makino 반하 & $\bigcirc$ & Y. J. Jang 200918-34 (IUI) \\
\hline \multicolumn{3}{|l|}{ DIOSCOREACEAE 마과 } \\
\hline 81. Dioscorea bulfifera L. 둥근마 & $\bigcirc$ & \\
\hline 82. Dioscorea japonica Thunb. 참마 & $\bigcirc$ & \\
\hline 83. Dioscorea polystachya Turcz. 마 & $\bigcirc$ & J. S. Lee et al. 030713-925 (IUI) \\
\hline 84. Dioscorea quinquelobata Thunb. 단풍마 & $\bigcirc$ & $\begin{array}{l}\text { T. B. Lee s.n. (SNUA:102507); J. S. Lee et al. } \\
\text { 031025-? (IUI) }\end{array}$ \\
\hline 85. Dioscorea septemloba Thunb. 국화마 & ○ & $\Rightarrow$ D. quinquelobate (Misid) \\
\hline \multicolumn{3}{|l|}{ MELANTHIACEA 여로과 } \\
\hline 86. Heloniopsis koreana Fuse, N.S.Lee \& M.N.Tamura 처녀치마 & O & \\
\hline 87. Veratrum maackii var. japonicum (Baker) Shimizu 여로 & $\bigcirc$ & \\
\hline$\star$ 88. Veratrum maackii var. Parviflorum (Maxim. ex Miq.) H.Har & & J. S. Park \& Y. J. Jang 190729-12 (IUI) \\
\hline
\end{tabular}

\section{COLCHICACEAE 애기나리과}

89. Disporum sessile (Thunb.) D.Don ex Schult. \& Schult. f. 윤판나물아재비(III)

90. Disporum smilacinum A. Gray 애기나리

T. B. Lee 4328 (SNUA:101383); Y. J. Jang 200422-42 (IUI)

\section{SMILACACEAE 청미래덩굴과}

91. Smilax china $\mathrm{L}$. 청미래덩굴

J. S. Lee et al. 030510-270 (IUI)

92. Smilax sieboldii Miq. 청가시덩굴

93. Smilax sieboldii f. inermis (Nakai ex T.Mori) H.Hara 민청가시덩굴

\section{LILIACEAE 백합과}

94. Lilium amabile Palib. 털중나리

J. S. Lee et al. 060313-414 (IUI)

95. Lilium concolor Salisb. 하늘나리

$\bigcirc$

96. Lilium lancifolium Thunb. 참나리

J. S. Lee et al. 030713-932 (IUI)

97. Lilium leichtlinii var. maximowiczii (Regel) Baker 중나리

J. S. Lee et al. 030613-453 (IUI)

Y. J. Jang 200603-41 (IUI)

$$
\Rightarrow \text { S. sieboldii (Synonym) }
$$

\section{ORCHIDACEAE 난초과}

98. Amitostigma gracile 병아리난초

T. B. Lee 4508 (SNUA:102726); J. S. Lee et al. 030822-179 (IUI)

99. Bulbophyllum drymoglossum Maxim. ex Ökubo 콩짜개란

100. Bulbophyllum inconspicuum Maxim. 혹난초(VU, Class II, V)

Observation! 
Appendix 1. Continued

Taxa Previous studies

101. Calanthe aristulifera Rchb. f. 신안새우난초(Class II, V)

102. Calanthe discolor Lindl. 새우난초(III)

103. Calanthe insularis S. H. Oh, H. J. Suh \& C.-W. Park 다도새우난초

104. Calanthe sieboldii Decne. ex Regel 금새우난초(VU, III)

105. Cephalanthera erecta (Thunb.) Blume 은난초

106. Cephalanthera longibracteata Blume 은대난초

$\star$ 107. Cephalanthera subaphylla Miyabe \& Kudô 꼬마은난초(VU)

108. Cymbidium goeringii (Rchb. f.) Rchb. f. 보춘화

109. Cymbidium macrorhizon Lindl. 대흥란(EN, Class II, V)

110. Dendrobium moniliforme $\mathrm{Sw}$. 석곡(EN, Class II, V)

111. Goodyera biflora (Lindl.) Hook. f. 붉은사철란(NT)

112. Goodyera repens (L.) R.Br. 애기사철란

113. Goodyera schlechtendal Rchb. f. 사철란

114. Lecanorchis japonica Blume 무엽란

115. Liparis makinoana Schltr. 나리난초

116. Liparis krameri Franch. \& Sav. 나나벌이난초

117. Liparis kumokiri F.Maek. 옥잠난초

118. Neofinetia falcata (Thunb.) Hu. 풍란(CR, Class I, V)

119. Platanthera komarovii Schltr. 산제비란

120. Platanthera neglecta Schltr. 하늘산제비란

121. Ponerorchis graminifolia Rchb.f. 나비난초

122. Sedirea japonica (Linden \& Rchb. f.) Garay \& H. R. Sweet 나도풍란(CR, Class I, V)

123. Spiranthes sinensis (Pers.) Ames 타래난초

\section{AIRIDACEAE 붓꽃과}

124. Iris koreana Nakai 노랑붓꽃

125. Iris rossii Baker 각시붓꽃

126. Iris sanguinea Donn ex Hornem. 붓꽃

127. Sisyrinchium angustifolium Mill. 등심붓꽃

\section{ASPHODELACEAE 아스포델과}

128. Hemerocallis coreana Nakai 골잎원추리

129. Hemerocallis fulva (L.) L. 원추리

130. Hemerocallis hongdoensis M.G. Chung \& S.S. Kang 홍도원추리(E, III)

\section{AMARYLLIDACEAE 수선화과}

131. Allium macrostemon Bunge 산달래

132. Allium monanthum Maxim. 달래
This study and voucher specimens

Observation!

T. B. Lee s.n. (SNUA:102713); T. B. Lee s.n. (SNUA:102715)

- Y. J. Jang 200602-33 (IUI)

J. S. Lee 050416-01 (IUI)

J. S. Lee et al. 030614-11 (IUI)

J. S. Lee et al. 030510-284 (IUI)

J. S. Lee et al. 030405-68 (IUI)

Observation!

Observation!

J. S. Park \& Y. J. Jang 190927-36 (IUI)

Ishidoya, T. \& T. H. Chung s.n. (SNU); T. B. Lee 200818-9 (IUI); Y. J. Jang 200818-9 (IUI)

T. B. Lee 75048 (SNUA); J. S. Lee et al 030714-962 (IUI)

T. B. Lee s.n. (SNUA:102936)

J. S. Lee et al. 030615-684 (IUI)

J. S. Lee et al. 030615-680 (IUI)

Misidentification

Ishidoya, T. \& T. H. Chung s.n. (TI)

$\bigcirc \quad$ J. S. Lee et al. 030822-050961 (IUI)
$\Rightarrow H$. hongdoensis (Misid)

$\Rightarrow H$. hongdoensis (Misid)

T. B. Lee s.n. (SNUA:101528); J. S. Lee et al. 030714-975 (IUI)

Y. J. Jang 200702-13 (IUI) 
Appendix 1. Continued

\begin{tabular}{|c|c|c|}
\hline Taxa & $\begin{array}{l}\text { Previous } \\
\text { studies }\end{array}$ & This study and voucher specimens \\
\hline 133. Allium thunbergii G. Don 산부추 & $\bigcirc$ & Y. J. Jang 200917-17 (IUI) \\
\hline \multicolumn{3}{|l|}{ ASPARAGACEAE 비짜루과 } \\
\hline 134. Asparagus oligoclonos Maxim. 방울비짜루 & $\bigcirc$ & \\
\hline 135. Asparagus schoberioides Kunth 비짜루 & $\bigcirc$ & J. S. Lee et al. 030713-936 (IUI) \\
\hline \multicolumn{3}{|l|}{ 136. Hosta capitata (Koidz.) Nakai 일월비비추 } \\
\hline 137. Hosta longipes (Franch. \& Sav.) Matsum. 비비추 & ○ & $\Rightarrow H$. yingeri (Misid) \\
\hline 138. Hosta yingeri S.B. Jones 흑산도비비추(E) & $\bigcirc$ & $\begin{array}{l}\text { Ishidoya, T. \& T. H. Chung } 3374 \text { (SNU); T. } \\
\text { B. Lee 4354 (SNUA:101629); T. B. Lee } \\
\text { 4314 (SNUA:101569); T. B. Lee } 4355 \\
\text { (SNUA:101581); T. B. Lee s.n. } \\
\text { (SNUA:101584); Y. J. Jang 200918-39 } \\
\text { (IUI) }\end{array}$ \\
\hline 139. Liriope platyphylla F.T. Wang \& Tang 맥문동 & ○ & $\begin{array}{l}\text { T. B. Lee s.n. (SNUA:101799); Y. J. Jang } \\
\text { 200818-26 (IUI) }\end{array}$ \\
\hline \multicolumn{3}{|l|}{ 140. Liriope spicata (Thunb.) Lour. 개맥문동 } \\
\hline 141. Ophiopogon jaburan (Siebold) G. Lodd. 맥문아재비(III) & 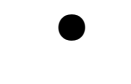 & $\begin{array}{l}\text { T. B. Lee } 4387 \text { (SNUA:101793); J. S. Park \& } \\
\text { Y. J. Jang 190730-30 (IUI) }\end{array}$ \\
\hline 142. Ophiopogon japonicus (Thunb.) Ker Gawl. 소엽맥문동 & ○ & $\begin{array}{l}\text { T. B. Lee } 4388 \text { (SNUA:101950); J. S. Lee et } \\
\text { al. 030714-965 (IUI) }\end{array}$ \\
\hline 143. Ophiopogon japonicus var. umbrosus Maxim. 실맥문동 & $\bigcirc$ & $\Rightarrow$ O. japonicus (Synonym) \\
\hline 144. Polygonatum cryptanthum H.Lév. \& Vaniot 목포용둥굴레 & $\bigcirc$ & $\begin{array}{l}\text { T. B. Lee s.n., (SNUA:101908); Y. J. Jang } \\
\text { 200512-36 (IUI) }\end{array}$ \\
\hline 145. Polygonatum involucratum (Franch. \& Sav.) Maxim. 용둥굴레 & 0 & $\Rightarrow$ P. cryptanthum (Misid) \\
\hline$\star$ 146. Polygonatum lasianthum Maxim. 죽대 & $\bigcirc$ & Y. J. Jang 200603-47 (IUI) \\
\hline 147. Polygonatum odoratum var. pluriflorum (Miq.) Ohwi 둥굴레 & $\bigcirc$ & \\
\hline 148. Scilla scilloides (Lindl.) Druce 무릇 & ○ & $\begin{array}{l}\text { T. B. Lee } 4411 \text { (SNUA:102053); J. S. Lee et } \\
\text { al. 030821-2027 (IUI) }\end{array}$ \\
\hline \multicolumn{3}{|l|}{ COMMELINACEAE 닭의장풀과 } \\
\hline 149. Commelina communis L. 닭의장풀 & 0 & $\begin{array}{l}\text { T. B. Lee } 4242 \text { (SNUA:100717); J. S. Lee et } \\
\text { al. 030713-9211 (IUI) }\end{array}$ \\
\hline \multicolumn{3}{|l|}{ ZINGIBERACEAE 생강과 } \\
\hline 150. Zingiber mioga (Thunb.) Roscoe 양하* & $\bigcirc$ & \\
\hline \multicolumn{3}{|l|}{ JUNCACEAE 골풀과 } \\
\hline 151. Juncus decipiens (Buchenau) Nakai 골풀 & O & J. S. Lee et al. 030713-923 (IUI) \\
\hline 152. Juncus leschenaultii Gay ex Laharpe 참비녀골풀 & $\bigcirc$ & \\
\hline 153. Luzula capitata (Miq. ex Franch. \& Sav.) Kom. 뀡의밥 & O & J. S. Lee et al. 030404-29 (IUI) \\
\hline \multicolumn{3}{|l|}{ CYPERACEAE 사초과 } \\
\hline 154. Bulbostylis densa (Wall.) Hand.-Mazz. 꽃하늘지기 & $\bigcirc$ & \\
\hline 155. Carex boottiana Hook. \& Arn. 밀사초(갯사초) & $\bigcirc$ & J. S. Lee et al. 030510-263 (IUI) \\
\hline 156. Carex breviculmis R.Br. 청사초 & $\bigcirc$ & J. S. Lee et al. 030404-42 (IUI) \\
\hline 157. Carex ciliato-marginata Nakai 털대사초 & $\bigcirc$ & \\
\hline 158. Carex dispalata Boott 삿갓사초 & $\bigcirc$ & \\
\hline ^159. Carex gibba Wahlenb. 나도별사초 & & J. S. Lee et al. 030615-675 (IUI) \\
\hline
\end{tabular}


Appendix 1. Continued

Taxa Previous
studies

This study and voucher specimens

160. Carex jackiana var. macroglossa (Franch. \& Sav.) Kük. ex Matsum. 보리사 초(애기염주사초)

161. Carex lanceolata Boott 삿갓사초

$\star$ 162. Carex lenta D.Don 줄사초

163. Carex lithophila Turcz. 바위사초

$\star$ 164. Carex planiculmis Kom. 그늘흰사초

$\star$ 165. Carex polyschoena H. Lév. \& Vaniot 가지청사초

166. Carex siderosticta Hance 대사초

167. Cyperus amuricus Maxim. 방동사니

168. Cyperus difformis L. 알방동사니

$\star 169$. Cyperus iria $\mathrm{L}$. 참방동사니

$\star$ 170. Cyperus polystachyos Rottb. 중방동사니(갯방동사니)

171. Fimbristylis littoralis Gaudich. 바람하늘지기

172. Fimbristylis tristachya var. subbispicata (Nees) T.Koyama 꼴하늘지기

173. Kyllinga brevifolia Rottb. 가시파대가리

\section{POACEAE 벼과}

174. Agrostis clavata Trin. 겨이삭(산겨이삭)

175. Arundinella hirta (Thunb.) Tanaka 털새

176. Arundinella hirta var. ciliata (Thunb.) Koidz. 새

177. Arundinella hirta var. glauca (Koidz.) Honda 흰새

$\star$ 178. Arundo donax L. 왕갈대(물대)

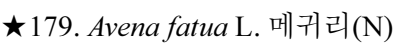

180. Brachypodium sylvaticum (Huds.) P.Beauv. 숲개밀

$\star$ 181. Bromus catharticus Vahl. 큰이삭풀 $(\mathrm{N})$

$\star$ 182. Bromus inermis Leyss. 좀참새귀리 $(\mathrm{N})$

183. Bromus japonicus Houtt. 참새귀리

$\star$ 184. Calamagrostis arundinacea (L.) Roth 실새풀

185. Calamagrostis purpurea (Trin.) Trin. 산새풀

186. Cleistogenes hackelii (Honda) Honda 대새풀

187. Cymbopogon tortilis var. goeringii (Steud.) Hand.-Mazz. 개솔새

$\star$ 188. Dactylis glomerata L. 오리새(N)

189. Diarrhena japonica (Franch. \& Sav.) Franch. \& Sav 용수염풀

190. Digitaria ciliaris (Retz.) Koeler 바랭이

191. Eleusine indica (L.) Gaertn. 왕바랭이

$\star$ 192. Elymus ciliare (Trin. ex Bunge) Tzvelev 속털개밀

193. Elymus dahuricus (Turcz.) Griseb. 갯보리

194. Elymus mollis Trin. 갯그령
J. S. Park \& Y. J. Jang 191103-70 (IUI)

T. B. Lee 4059 (SNUA:99929)

Y. J. Jang 200423-65 (IUI)

$\bigcirc$

$\bigcirc \quad$ J. S. Lee et al. 030823-2204 (IUI)

J. S. Lee et al. 030823-2210 (IUI)

J. S. Lee et al. 030823-2205 (IUI)

T. B. Lee s.n. (SNUA:100372); J. S. Park \& Y. J. Jang 190927-53 (IUI)

J. S. Lee et al. 030823-2214 (IUI)

J. S. Park \& Y. J. Jang 190927-25 (IUI)

J. S. Lee et al. 030821-2020 (IUI)

J. S. Lee et al. 030823-2251 (IUI)

$\Rightarrow A$. hirta (Synonym)

J. S. Lee et al. 031024-? (IUI)

J. S. Lee et al. 030509-215 (IUI)

- T. B. Lee 3730 (SNUA:97484); T. B. Lee s.n. (SNUA:97483); T. B. Lee 3730 (SNUA); $J$. S. Lee et al. 030712-881 (IUI)

J. S. Lee et al. 030510-260 (IUI)

J. S. Lee et al. 030511-356 (IUI)

$\bigcirc \quad$ J. S. Lee et al. 030509-240 (IUI)

J. S. Park \& Y. J. Jang 190927-40 (IUI)

$\bigcirc$

$\bigcirc \quad$ J. S. Lee et al. 030821-2062 (IUI)

J. S. Lee et al. 030511-352 (IUI)

J. S. Lee et al. 030821-2038 (IUI)

Y. J. Jang 200512-61 (IUI)

- T. B. Lee s.n. (SNUA:89369); Y. J. Jang 200601-4 (IUI)

Y. J. Jang 200512-59 (IUI) 
Appendix 1. Continued

Taxa Previous studies

195. Elymus tsukushiensis var. transiens (Hack.) T. Osada 개밀

196. Eragrostis ferruginea (Thunb.) P.Beauv. 그령

$\star$ 197. Eulalia speciosa (Debeaux) Kuntze 개억새

198. Festuca ovina L. 김의털

199. Festuca parvigluma Steud. 김의털아재비

200. Festuca rubra L. 왕김의털

201. Imperata cylindrica var. koenigii (Retz.) Pilg. 띠

202. Ischaemum anthephoroides (Steud.) Miq. 갯쇠보리

203. Leymus chinensis (Trin.) Tzvelev 개밀아재비

$\star$ 204. Lolium perenne L. 호밀풀(N)

205. Lophatherum gracile Brongn. 조릿대풀(III)

^206. Microstegium japonicum (Miq.) Koidz. 민바랭이새

207. Misidcanthus sinensis Andersson 억새

208. Misidcanthus sinensis var. purpurascens (Andersson) Matsum. 참억새

209. Molinia japonica Hack. 진퍼리새

210. Oplismenus undulatifoliu (Ard.) P.Beauv. 주름조개풀

211. Oplismenus undulatifolius var. japonicus (Steud.) Koidz. 민주름조개풀

212. Paspalum thunbergii Kunth ex Steud. 참새피

213. Pennisetum alopecuroides (L.) Spreng. 수크령

214. Phaenosperma globosa Munro ex Benth. 산기장

215. Poa acroleuca Steud. 실포아풀

$\star 216$. Poa annua L. 새포아풀

$\star 217$. Poa pratensis L 왕포아풀(N)

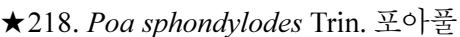

219. Pseudosasa japonica (Siebold \& Zucc. ex Steud.) Makino ex Nakai 이대

220. Sasa borealis (Hack.) Makino \& Shibata 조릿대

$\star 221$. Setaria chondrachne (Steud.) Honda 조아재비

$\star 222$. Setaria pallide-fusca (Schumach.) Stapf ex C.E. Hubb. 가는금강아지풀

223. Setaria viridis (L.) P.Beauv. 강아지풀

$\star 224$. Setaria viridis var. pachystachys (Franch. \& Sav.) Masamura \& Nemoto 갯 강아지풀

$\star 225$. Setaria faberi R.A.W. Herrm. 가을강아지풀

226. Sorghum nitidum (Vahl) Pers. 수수새

227. Spodiopogon cotulifer (Thunb.) Hack. 기름새
This study and voucher specimens

Y. J. Jang 200603-53 (IUI)

- T. B. Lee 3888 (SNUA:98560)

T. B. Lee 4315 (SNUA:98118)

- T. B. Lee 3786 (SNUA:97775); Y. J. Jang 200531-2 (IUI)

Y. J. Jang 200512-37 (IUI)

$\bigcirc$

J. S. Lee et al. 030615-671 (IUI)

O

Y. J. Jang 200513-81 (IUI)

- Ishidoya, T. \& T. H. Chung s.n. (TI); T. B. Lee 3822 (SNUA:97611); J. S. Park \& Y. J. Jang 190928-80 (IUI)

T. B. Lee 4306 (SNUA:97960)

- T. B. Lee 4315 (SNUA:98263); J. S. Park \& Y. J. Jang 190927-15 (IUI)

$\bigcirc \quad$ J. S. Park \& Y. J. Jang 190927-23 (IUI)

$\bigcirc$

Y. J. Jang 200918-37 (IUI)

J. S. Park \& Y. J. Jang 190927-18(IUI)

$\bigcirc \quad$ J. S. Lee et al. 030821-2063 (IUI)

$\bigcirc \quad$ J.S. Park \& Y. J. Jang 190926-3 (IUI)

- Ishidoya, T. \& T. H. Chung s.n. (TI); J. S. Lee et al. 030712-890 (IUI)

$\bigcirc$

Y. J. Jang 200316-6 (IUI)

T. B. Lee 3885 (SNUA); J. S. Lee et al. 030510-286 (IUI)

T. B. Lee 3888 (SNUA:98575); J. S. Lee et al. 030614-624 (IUI)

$\bigcirc \quad$ J. S. Lee et al. 030511-330 (IUI)

- T. B. Lee s.n. (SNUA:38555); T. B. Lee 3696 (SNUA:97182)

J. S. Lee et al. 030821-4028 (IUI)

J. S. Lee et al. 030823-2201 (IUI)

$\bigcirc$

J. S. Lee et al. 030822-2089 (IUI)

Y. J. Jang 200818-5 (IUI)

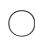

0 
Appendix 1. Continued

Taxa Previous studies

This study and voucher specimens

228. Sporobolus fertilis (Steud.) Clayton 쥐꼬리새풀

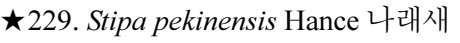

230. Themeda triandra subsp. japonica (Andersson) T. Koyama 솔새

$\star$ 231. Trisetum bifidum (Thunb.) Ohwi 잠자리피

232. Zoysia japonica Steud. 잔디

$\star 233$. Zoysia sinica Hance 갯잔디

PAPAVERACEAE 양귀비과

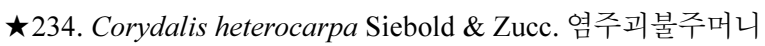

235. Corydalis incisa (Thunb.) Pers. 자주괴불주머니

236. Corydalis remota Fisch. ex Maxim. 현호색

237. Corydalis speciosa Maxim. 산괴불주머니

\section{LARDIZABALACEAE 으름덩굴과}

238. Stauntonia hexaphylla (Thunb.) Decne. 멀꿀(III)

\section{MENISPERMACEAE 방기과}

239. Cocculus orbiculatus (L.) DC. 댕댕이덩굴

240. Menispermum dauricum DC. 새모래덩굴

241. Sinomenium acutum (Thunb.) Rehder \& E.H. Wilson 방기(III)

242. Stephania japonica (Thunb.) Miers 함박이

\section{BERBERIDACEAE 매자나무과}

243. Berberis amurensis Rupr. 매발톱나무

RANUNCULACEAE 미나리아재비과

244. Clematis apiifolia DC. 사위질빵

245. Clematis patens C. Morren \& Decne. 큰꽃으아리

246. Clematis terniflora DC. 참으아리

247. Clematis terniflora var. mandshurica (Rupr.) Ohwi 으아리

248. Hepatica asiatica Nakai 노루귀

249. Hepatica insularis Nakai 새끼노루귀(E)

250. Ranunculus acris L. 산미나리아재비

251. Ranunculus chinensis Bunge 젓가락나물

252. Thalictrum acteaifolium var. brevistylum Nakai 은뀡의다리(E)

253. Thalictrum aquilegiifolium var. sibiricum Regel \& Tiling 뀡의다리

254. Thalictrum tuberiferum Maxim. 산꿩의다리

\section{BUXACEAE 회양목과}

$\star 255$. Buxus microphylla var. koreana Nakai ex Rehder 회양목

DAPHNIPHYLLACEAE 굴거리나무과
J. S. Lee et al. 030822-2246 (IUI)

$\bigcirc \quad$ J. S. Lee et al. 030821-2005 (IUI)

J. S. Lee et al. 030615-638(IUI)

J. S. Lee et al. 030614-628 (IUI)

T. B. Lee 3934 (SNUA:98735)

J. S. Lee et al. 030614-619 (IUI)

Y. J. Jang 200317-12 (IUI)

Y. J. Jang 200422-38 (IUI)

T. B. Lee s.n. (SNUA:21926); J. H. Lee et al. 090321-93099 (IUI)

J. S. Lee et al. 030822-2103 (IUI)

$\bigcirc$

T. B. Lee s.n. (SNUA:56875); J. S. Park \& Y. J. Jang 191101-4 (IUI)

$\bigcirc$ 
Appendix 1. Continued

Taxa $\quad$ Previous

studies This study and voucher specimens

256. Daphniphyllum macropodum Miq. 굴거리나무(III)

J.S. Lee et al. 030510-299 (IUI)

257. Daphniphyllum teiysmannii Zoll. ex Teijsm. \& Binn. 좀굴거리(IV)

J. S. Lee et 030511-328 (IUI)

\section{SAXIFRAGACEAE 범의귀과}

258. Astilbe chinensis (Maxim.) Franch. \& Sav. 노루오줌

\section{CRASSULACEAE 돌나물과}

259. Hylotelephium erythrostictum (Miq.) H.Ohba 뀡의비름

$\star 260$. Hylotelephium spectabile (Boreau) H. Ohba 큰꿩의비름(III)

261. Orostachys japonica (Maxim.) A. Berger 바위솔

262. Orostachys minuta (Kom.) A.Berger 좀바위솔

263. Sedum kamtschaticum Fisch. \& C.A. Mey. 기린초

$\star 264$. Sedum kiangnanense D. Q. Wang \& Z. F. Wu 잎꽃돌나물

265. Sedum oryzifolium Makino 땅채송화

266. Sedum polytrichoide Hemsl. 바위채송화

\section{HALORAGACEAE 개미탑과}

267. Haloragis micrantha (Thunb.) R.Br. ex Siebold \& Zucc. 개미탑

\section{VITACEAE 포도과}

268. Ampelopsis brevipedunculata (Maxim.) Trautv. 개머루

269. Cayratia japonica (Thunb.) Gagnep. 거지덩굴

270. Parthenocissus tricuspidata (Siebold \& Zucc.) Planch. 담쟁이덩굴

271. Vitis amurensis Rupr. 왕머루

272. Vitis ficifolia var. sinuata (Regel) H.Hara 까마귀머루

273. Vitis flexuosa Thunb. 새머루

\section{FABACEAE 콩과}

274. Aeschynomene indica L. 자귀풀

275. Albizia julibrissin Durazz. 자귀나무

$\star 276$. Amphicarpaea bracteata subsp. edgeworthii (Benth.) H. Ohashi 새콩

277. Caesalpinia decapetala (Roth) Alston 실거리나무(III)

278. Chamaecrista nomame (Makino) H.Ohashi 차풀

279. Dunbaria villosa (Thunb.) Makino 여우팥

$\star 280$. Hylodesmum podocarpum (DC.) H. Ohashi \& R.R. Mill 개도둑놈의갈고 리

$\star 281$. Hylodesmum podocarpum subsp fallax (Schindl.) H. Ohashi \& R.R. Mill 긴도둑놈의갈고리

282. Hylodesmum podocarpum var. mandshuricum (Maxim.) H. Ohashi \& R.R. Mill 애기도둑놈의갈고리

283. Hylodesmum podocarpum subsp oxyphyllum (DC.) H. Ohashi \& R.R. Mill 도 둑놈의갈고리

284. Indigofera kirilowii Maxim. ex Palib. 땅비싸리

$$
\Rightarrow \text { H. spectabile (Misid) }
$$

Ishidoya, T. \& T. H. Chung 3503 (KWUN); J. S. Lee et al. 031024-? (IUI)

J. S. Park \& Y. J. Jang 191101-9 (IUI)

J. S. Lee et al. 030713-947 (IUI)

Suh et al. (2020)

Y. J. Jang 200701-1 (IUI)

T. B. Lee 1277 (SNUA:85276); J. S. Lee et al. 030712-872 (IUI)

J. S. Lee et al 030822-2083 (IUI)

T. B. Lee 4308 (SNUA:33225); Y. J. Jang 200423-70 (IUI)

$\bigcirc \quad$ J. S. Lee et al. 030713-924 (IUI)

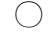

$\bigcirc$

T. B. Lee s.n. (SNUA:13592); J. S. Lee et al. 030822-2079 (IUI)

Y.J. Jang 200601-12 (IUI)

$\bigcirc \quad$ J. S. Lee et al. 030714-999 (IUI)

Y. J. Jang 200917-18 (IUI)

T. B. Lee s.n. (SNUA:79984); J. S. Lee et al. 030613-445 (IUI)

$\bigcirc \quad$ J. S. Lee et al. 030822-2084 (IUI)

J. S. Lee et al. 030822-2108(IUI)

Ishidoya, T. \& T. H. Chung 3546 (TI)

J. S. Lee et al. 030823-2242 (IUI)

T. B. Lee s.n. (SNUA:86407); J. S. Lee et al. 030822-2110 (IUI)

$\Rightarrow$ I. koreana (Misid) 
Appendix 1. Continued

\section{Taxa}

285. Indigofera koreana Ohwi 좀땅비싸리(E)

286. Kummerowia striata (Thunb.) Schindl. 매듭풀

287. Lathyrus japonicus Willd. 갯완두

288. Lespedeza bicolor Turcz. 싸리

289. Lespedeza bicolor var. sericea Nakai 털싸리

290. Lespedeza cuneata (Dum.Cours.) G.Don 비수리

291. Lespedeza cyrtobotrya Miq. 참싸리

Ł292. Lespedeza inschanica (Maxim.) Schindl. 청비수리

293. Lespedeza maximowiczii C.K. 조록싸리

294. Lespedeza maximowiczii var. tomentella (Nakai) Nakai 털조록싸리 295. Lespedeza pilosa (Thunb.) Siebold \& Zucc. 괭이싸리

$\star 296$. Medicago polymorpha L. 개자리(N)

297. Pueraria lobata (Willd.) Ohwi 칡

298. Rhynchosia volubilis Lour. 여우콩

299. Vicia angustifolia L. 가는살갈퀴

$\star 300$. Vicia hirsuta (L.) Gray 새완두

$\star 301$. Vicia nipponica Matsum. 네잎갈퀴나물

302. Vicia unijuga A. Braun 나비나물

303. Vicia venosa var. cuspidata Maxim. 광릉갈퀴

$\star$ 304. Vigna angularis var. nipponensis (Ohwi) Ohwi \& H. Ohashi 새팥

\section{ROSACEAE 장미과}

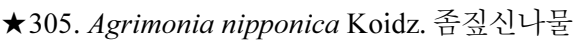

306. Agrimonia pilosa Ledeb. 짚신나물

307. Aria alnifolia (Siebold \& Zucc.) Decne. 팥배나무

308. Duchesnea chrysantha (Zoll. \& Moritzi) Miq. 뱀딸기

$\star$ 309. Potentilla chinensis Ser. 딱지꽃

310. Potentilla chinensis var. concolor Franch. \& Sav. 털딱지꽃

311. Potentilla fragarioides L. 양지꽃

312. Pourthiaea villosa (Thunb.) Decne. 윤노리나무

313. Pourthiaea villosa var. laevis (Thunb.) Stapf 민윤노리나무

314. Pourthiaea villosa var. brunnea (H.Lév.) Nakai 떡윤노리나무

315. Prunus jamasakura Siebold ex Koidz. 벚나무

316. Prunus sargentii Rehder 산벚나무

$\begin{gathered}\text { Previous } \\ \text { studies }\end{gathered} \quad$ This study and voucher specimens
.

J. S. Lee et al. 030509-232 (IUI)

J. S. Lee et al. 030821-2007 (IUI)

Y. J. Jang 200512-58 (IUI)

J. S. Lee et al. 030821-2048 (IUI)

$\Rightarrow$ L. bicolor (Synonym)

$\Rightarrow$ L. inschanica (Misid)

Y. J. Jang 200918-42 (IUI)

- T. B. Lee 1773 (SNUA); J. S. Lee et al. 030714-968 (IUI)

$\Rightarrow$ L. maximowiczii (Synonym)

J. S. Park \& Y. J. Jang 190927-24 (IUI)

J. S. Lee et al. 030509-216 (IUI)

J. S. Lee et al. 030823-2260 (IUI)

- T. B. Lee s.n. (SNUA:86623); J. S. Lee et al. 030821-2013 (IUI)

$\bigcirc \quad$ J. S. Lee et al. 030613-426 (IUI)

J. S. Lee et al. 030509-242 (IUI)

T. B. Lee 1861 (SNUA:86871); Y. J. Jang 200919-47 (IUI)

$\bigcirc \quad$ J. S. Lee et al. 030614-575 (IUI)

$$
\Rightarrow \text { V. nipponica (Misid) }
$$

Y. J. Jang 200819-33 (IUI)

J. S. Lee et al. 030825-2256 (IUI)

- T. B. Lee s.n. (SNUA:85630); J. S. Lee et al. 030712-864 (IUI)

T. B. Lee s.n. (SNUA:29903); T. B. Lee 1477 (SNUA:38487); Y. J. Jang 200512-64 (IUI)

$\bigcirc \quad$ J. S. Lee et al. 030509-212 (IUI)

T. B. Lee s.n. (SNUA:85942); J. S. Lee et al. 030823-2269 (IUI)

- $\Rightarrow$ P. chinensis (Misid)

Y. J. Jang 200421-30 (IUI)

- T. B. Lee s.n. (SNUA:71470); Y. J. Jang 200603-38 (IUI)

$$
\Rightarrow \text { P. villosa (Synonym) }
$$

Ishidoya, T. \& T. H. Chung 5956 (SNU); J. S. Lee et al. 030405-44 (IUI)

$\Rightarrow$ P. jamasakura (Misid) 
Appendix 1. Continued

Taxa Previous

studies This study and voucher specimens

317. Rhaphiolepis indica var. umbellata (Thunb.) H. Ohashi 다정큼나무(III)

318. Rosa lucieae Franch. \& Rochebr. ex Crép. 돌가시나무

319. Rosa multiflora Thunb. 찔레나무

320. Rosa rugosa Thunb. 해당화

321. Rubus buergeri Miq. 겨울딸기

322. Rubus corchorifoliu L. f. 수리딸기

323. Rubus coreanus Miq. 복분자딸기

324. Rubus crataegifolius Bunge 산딸기

325. Rubus hirsutus Thunb. 장딸기(III)

326. Rubus parvifolius L. 멍석딸기

327. Rubus phoenicolasius Maxim. 곰딸기

328. Rubus schizostylus H.Lév. 가시복분자딸기

329. Rubus sumatranus Miq. 거지딸기(IV)

330. Rubus tozawae Nakai ex J.Y.Yang 거제딸기

331. Sanguisorba longifolia Bertol. 긴오이풀

332. Sanguisorba officinalis L. 오이풀

333. Sanguisorba tenuifolia Fisch. ex Link 가는오이풀

334. Sanguisorba tenuifolia var. purpurea Trautv. \& C.A.Mey. 자주가는오이풀 335. Stephanandra incisa (Thunb.) Zabel 국수나무

\section{ELAEAGNACEAE 보리수나무과}

336. Elaeagnus glabra Thunb. 보리장나무(III)

337. Elaeagnus glabra var. oxyphylla (Servett.) Nakai 좁은잎보리장

338. Elaeagnus macrophylla Thunb. 보리밥나무

339. Elaeagnus $\times$ maritima Koidz. 녹보리똥나무

340. Elaeagnus submacrophylla Servett. 큰보리장나무

341. Elaeagnus umbellata Thunb. 보리수나무

342. Elaeagnus umbellata var. coreana (H.Lév.) H.Lév. 왕보리수나무

\section{RHAMNACEAE 갈매나무과}

343. Rhamnella franguloides (Maxim.) Weberb. 까마귀베개

344. Rhamnus rugulosa Hemsl. 털갈매나무

345. Rhamnus parvifolia Bunge 돌갈매나무

346. Sageretia thea (Osbeck) M.C. Johnst. 상동나무(III)

347. Sageretia thea var. tomentosa C.K.Schneid. 털상동나무

\section{CANNABACEAE 삼과}

348. Celtis biondii Pamp. 폭나무
Y. J. Jang 200702-11 (IUI)

Y. J. Jang 200513-76 (IUI)

J. S. Park \& Y. J. Jang 190730-39 (IUI)

Y. J. Jang 200422-52 (IUI)

T. B. Lee 1335 (KNKA); Y. J. Jang 20051385 (IUI)

Y. J. Jang 200603-55 (IUI)

Y. J. Jang 200513-84 (IUI)

1. J. Jang 200513-84 (IU1)

(1)

T. B. Lee 4307 (SNUA:32580); J. S. Lee et al. 030613-486 (IUI)

J. S. Lee et al. 030822-2168 (IUI)

T. B. Lee 26323 (SNUA)

$\Rightarrow$ S. tenuifolia (Synonym)

Y. J. Jang 200603-37 (IUI)

J. S. Lee et al. 030511-326 (IUI)

0

- T. B. Lee 4283 (SNUA:13879); J. S. Park \& Y. J. Jang 190927-51 (IUI)

$\bigcirc$ 
Appendix 1. Continued

Taxa $\quad$ Previous

studies This study and voucher specimens

^349. Celtis bungeana Blume 좀풍게나무

350. Celtis jessoensis Koidz. 풍게나무

351. Celtis sinensis Pers. 팽나무

352. Humulus scandens (Lour.) Merr. 환삼덩굴

\section{MORACEAE 뽛나무과}

353. Broussonetia kazinoki Siebold ex Siebold \& Zucc. 닥나무

354. Broussonetia kazinoki var. humilis Uyeki nom. nud. 애기닥나무

355. Ficus carica L. 무화과나무*

356. Ficus erecta Thunb. 천선과나무(III)

357. Ficus erecta var. sieboldii (Miq.) King 천선과나무(III)

358. Ficus sarmentosa var. nipponica (Franch. \& Sav.) Corner 모람

359. Morus alba L. 뽕나무*

360. Morus australis Poir. 산뽕나무

361. Morus bombycis f. dissecta Nakai 가새뽕나무

362. Morus bombycis var. maritima Koidz. 섬뽕나무

363. Maclura tricuspidata Carriére 꾸지뽕나무

\section{URTICACEAE 쐐기풀과}

364. Boehmeria nivea (L.) Gaudich. 모시풀

365. Boehmeria nivea var. tenacissima (Gaudich.) Miq. 섬모시풀

366. Boehmeria pannosa Nakai \& Satake ex Oka 왕모시풀(III)

367. Boehmeria spicata (Thunb.) Thunb. 좀깨잎나무

$\star$ 368. Pilea japonica (Maxim.) Hand.-Mazz. 산물통이

369. Pilea peploides (Gaudich.) Hook. \& Arn. 물통이

\section{FAGACEAE 참나무과}

370. Castanopsis crenata Siebold \& Zucc, 밤나무*

371. Castanopsis cuspidata (Thunb.) Schottky 모밀잣밤나무(III)

372. Castanopsis sieboldii (Makino) Hatus. 구실잣밤나무(III)

373. Quercus acuta Thunb. 붉가시나무(III)

374. Quercus aliena Blume 갈참나무

375. Quercus dentata Thunb. 떡갈나무
T. B. Lee s.n. (SNUA); J. S. Lee et al. 030823-2215 (IUI)

$$
\Rightarrow \text { C. bungeana (Misid) }
$$

J. S. Lee et al. 030613-454 (IUI)

J. S. Lee et al. 030823-2264 (IUI)

T. B. Lee s.n. (SNUA); T. B. Lee 572 (SNUA); Y. J. Jang 200603-43 (IUI)

$$
\Rightarrow \text { B. kazinoki (Synonym) }
$$

Y. J. Jang 200819-35 (IUI)

Ishidoya, T. \& T. H. Chung 3434 (TI); T. B. Lee s.n. (SNUA); T. B. Lee s.n. (SNUA); Y. J. Jang 200512-29 (IUI)

$\bigcirc F$. erecta (Synonym)

T. B. Lee s.n. (SNUA:23246); T. B. Lee s.n. (SNUA:23245); T. B. Lee 582

(SNUA:53717); Y. J. Jang 200818-19 (IUI)

$\bigcirc$

T. B. Lee 4318 (SNUA); Y. J. Jang 20060226 (IUI)

\section{J. S. Park \& Y. J. Jang 190730-37 (IUI)}

$\Rightarrow$ B. nivea var. tenacissima (Misid)

T. B. Lee s.n. (SNUA:81207); T. B. Lee 4320 (SNUA); J. S. Lee et al. 030822-2112 (IUI)

T. B. Lee 11321 (SNUA); J. S. Lee et al. 031024-1305 (IUI)

$\bigcirc \quad$ J.S. Lee et al. 030714-997 (IUI)

T. B. Lee 590 (SNUA)

$\bigcirc \quad$ J. S. Lee et al. 030823-2267 (IUI)

$\bigcirc$ J. H. Lee et al. 090320-93079 (IUI)

T. B. Lee 11321 (SNUA:26884); T. B. Lee 509 (SNUA:9147); J. S. Lee et al. 030823701 (IUI)

Ishidoya, T. \& T. H. Chung s.n. (TI); T. B. Lee s.n. (SNUA:7614); T. B. Lee 4328 (SNUA:8847); J. S. Lee et al. 030614-554 (IUI)

J. S. Lee et al. 030510-262 (IUI) 
Appendix 1. Continued

Taxa Previous

studies This study and voucher specimens

376. Quercus $\times$ dentato-mongolica Nakai 떡신갈나무

377. Quercus $\times$ faberi Hance 떡속소리나무

378. Quercus glauca Thunb. 종가시나무

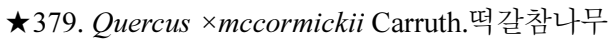

T. B. Lee 4369, T. B. Lee 4370 (SNUA)

380. Quercus mongolica Fisch. ex Ledeb. 신갈나무

381. Quercus mongolica var. crispula (Blume) H.Ohashi 물참나무

382. Quercus serrata Murray 졸참나무

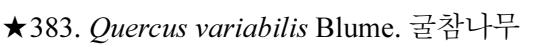

384. Quercus $\times$ urticifolia Blume 갈졸참나무

$\bigcirc$

\section{BETULACEAE 자작나무과}

385. Carpinus turczaninowii Hance 소사나무

$$
\begin{aligned}
& \text { T. B. Lee s.n. (SNUA:75924); T. B. Lee } 455 . \\
& \text { (SNUA:75946); T. B. Lee s.n } \\
& \text { (SNUA:75947); J. S. Lee et al. 030613- } \\
& 448 \text { (IUI) }
\end{aligned}
$$

386. Corylus sieboldiana var. mandshurica (Maxim.) C.K.Schneid. 물개암나무

\section{CUCURBITACEAE 박과}

387. Gynostemma pentaphylla (Thunb.) Makino 돌외

388. Trichosanthes kirilowii Maxim. 하늘타리

389. Trichosanthes kirilowii var. japonica Kitam. 노랑하늘타리(III)

\section{CELASTRACEAE 노박덩굴과}

390. Celastrus orbiculatus Thunb. 노박덩굴

391. Euonymus alatus (Thunb.) Siebold 화살나무

392. Euonymus fortunei var. radicans (Siebold ex Miq.) Rehder 줄사철나무

393. Euonymus japonicus Thunb. 사철나무

394. Euonymus macropterus Rupr. 나래회나무

395. Euonymus japonicus Thunb. 참회나무

\section{OXALIDACEAE 괭이밥과}

396. Oxalis corniculata L. 괭이밥 $(\mathrm{N})$

$\star$ 397. Oxalis debilis var. corymbosa (DC.) Lourteig 자주괭이밥*(N)

398. Oxalis stricta L. 선괭이밥

$\bigcirc \quad$ J. S. Lee et al. 030822-2099 (IUI)

$\Rightarrow$ T. kirilowii var. japonica (Misid)

J. S. Lee et al. 030822-2078 (IUI)

\section{HYPERICACEAE 물레나물과}

399. Hypericum ascyron L. 물레나물

400. Hypericum attenuatum var. confertissium (Nakai) T.B.Lee nom. Ileg. 큰고추 나물

401. Hypericum erectum Thunb. 고추나물

$\Rightarrow$ H. erectum (Invalid)

T. B. Lee 72 (SNUA:87563); J. S. Lee et al. 030822-2107 (IUI)

402. Hypericum japonicum Thunb. 애기고추나물

VIOLACEAE 제비꽃과

403. Viola acuminata Ledeb. 졸방제비꽃

$\Rightarrow$ V. grypoceras (Misid) 
Appendix 1. Continued

Taxa Previous studies

404. Viola albida Palib. 태백제비꽃

405. Viola albida var. chaerophylloides (Regel) F. Maek. ex H.Hara 남산제비꽃 406. Viola collina Besser 둥근털제비꽃

407. Viola grypoceras A. Gray 낚시제비꽃

408. Viola japonica (Langsd.) DC. 왜제비꽃

409. Viola keiskei Miq. 잔털제비꽃

410. Viola mandshurica W. Becker 제비꽃

$\star 411$. Viola ovato-oblonga (Miq.) Makino 긴잎제비꽃(III)

412. Viola rossii Hemsl. 고깔제비꽃

\section{SALICACEAE 버드나무과}

413. Idesia polycarpa Maxim. 이나무(III)

414. Populus deltoides Marsh 미류나무

415. Populus $\times$ tomentiglandulosa T.B.Lee ex M.Kim 은사시나무

416. Xylosma congesta (Lour.) Merr. 산유자나무(III)

\section{EUPHORBIACEAE 대극과}

417. Acalypha australis L. 깨풀

418. Euphorbia helioscopia L. 등대풀

$\star$ 419. Euphorbia humifusa Willd. 땅빈대

420. Euphorbia pekinensis Rupr. 대극

421. Mallotus japonicus (L. f.) Mull. Arg. 예덕나무

422. Ricinus communis L. 피마자*

\section{GERANIACEAE 쥐손이풀과}

423. Geranium sibiricum L. 쥐손이풀

424. Geranium thunbergii Siebold ex Lindl. \& Paxton 이질풀

\section{LYTHRACEAE 부처꽃과}

425. Lagerstroemia indica L. 배롱나무*

\section{ONAGRACEAE 바늘꽃과}

426. Oenothera odorata L. 달맞이꽃(N)

\section{STAPHYLEACEAE 고추나무과}

427. Euscaphis japonica (Thunb.) Kanitz 말오줌때

428. Staphylea bumalda DC. 고추나무

\section{ANACARDIACEAE 옻나무과}

429. Rhus javanica var. chinensis (Mill.) T. Yamaz. 붉나무

430. Toxicodendron succedaneum (L.) Kuntze 검양옻나무(IV)
This study and voucher specimens

$$
\Rightarrow \text { V. japonica (Misid) }
$$

J. S. Lee et al. 030404-25 (IUI)

- T. B. Lee s.n. (SNUA:87769)

T. B. Lee s.n. (SNUA:87769); Y. J. Jang 200423-68 (IUI)

T. B. Lee 116 (SNUA:87719); J. S. Lee et al. 030405-100 (IUI)

J. S. Lee et al. 030404-27 (IUI)

J. S. Lee et al. 030822-2127 (IUI)

Y. J. Jang 200422-49 (IUI)

- T. B. Lee 2266 (SNUA:73458); J. S. Lee et al. 030823-22502 (IUI)

T. B. Lee s.n. (SNUA:30018); J. S. Park \& Y. J. Jang 191102-45 (IUI)

J. S. Lee et al. 030821-2002 (IUI)

Y. J. Jang 200601-7 (IUI)

J. S. Lee et al. 030823-2219 (IUI)

J. S. Lee et al. 030712-865 (IUI)

$$
\Rightarrow \text { G. thunbergii (Misid) }
$$

T. B. Lee s.n. (SNUA:87069); J. S. Lee et al. 030823-221 (IUI)

J. S. Lee et al. 030822-2037 (IUI)

T. B. Lee s.n. (SNUA:29947); T. B. Lee 305 (SNUA:63855); T. B. Lee 2037 (SNUA:38517); Y. J. Jang 200602-27 (IUI)

$\bigcirc$

J. S. Lee et al. 030822-2080 (IUI)

- T. B. Lee 1996 (SNUA); Y. J. Jang 20070456 (IUI) 
Appendix 1. Continued

\section{Taxa}

\section{SAPINDACEAE 무환자나무과}

431. Acer mono var. savatieri (Pax) Nakai 왕고로쇠나무

432. Acer pictum var. mono (Maxim.) Maxim. ex Franch 고로쇠나무

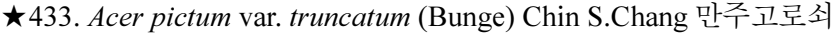

^434. Acer pseudosiebold (Pax) Kom. 당단풍나무

435. Acer tataricum subsp. ginnala (Maxim.) Wesm. 신나무

\section{RUTACEAE 운향과}

436. Citrus junos Siebold ex Tanaka 유자나무*

437. Zanthoxylum ailanthoides Siebold \& Zucc. 머귀나무(III)

438. Zanthoxylum piperitum (L.) DC. 초피나무

439. Zanthoxylum planispinum DC. 개산초

440. Zanthoxylum schinifolium Siebold \& Zucc. 산초나무

\section{SIMAROUBACEAE 소태나무과}

441. Picrasma quassioides (D.Don) Benn. 소태나무

\section{MELIACEAE 멀구슬나무과}

442. Melia azedarach L. 멀구슬나무(III, N)

\section{MALVACEAE 아욱과}

443. Abutilon theophrasti Medik. 어저귀*

444. Corchoropsis crenata Siebold \& Zucc. 수까치깨

445. Corchoropsis psilocarpa Harms \& Loes. ex Gilg \& Loes. 까치깨

446. Grewia biloba G.Don 장구밥나무

447. Hibiscus syriacus L. 무궁화*

448. Tilia mandshurica Rupr. \& Maxim. 찰피나무

449. Tilia taquetii C.K.Schneid. 뽕잎피나무

\section{BRASSICACEAE 십자화과}

^450. Arabis hirsuta (L.) Scop. 털장대

^451. Berteroella maximowiczii (Palib.) O.E. Schulz 장대냉이

$\star 452$. Brassica juncea (L.) Czern. 갓(N)

^453. Capsella bursa-pastori (L.) Medik. 냉이

$\star$ 454. Cardamine flexuosa With. 황새냉이

455. Cardamine impatiens L. 싸리냉이

456. Draba nemorosa L. 싸리냉이

457. Lepidium apetalum Willd. 다닥냉이
Previous studies

This study and voucher specimens

$\Rightarrow$ A. pictum var. mono, A. pictum var. truncatum (Misid)

T. B. Lee 2053 (SNUA:64865); J. S. Lee et al. 030510-289 (IUI)

T. B. Lee 2053 (SNUA:64907); J. S. Lee et al. 030510-289-2 (IUI)

J. S. Lee et al. 030510-283 (IUI)

T. B. Lee 1932 (SNUA:27959); J. S. Lee et al. 030823-2216 (IUI)

T. B. Lee 1936 (SNUA:75514); T. B. Lee 1936 (SNUA:75514); J. S. Lee et al. 030614-611 (IUI)

T. B. Lee s.n. (SNUA:29853); T. B. Lee s.n. (SNUA:29854); J. S. Lee et al. 031025-? (IUI)

J. S. Lee et al. 030712-902 (IUI)

Y. J. Jang 200603-40 (IUI)

Y. J. Jang 200701-9 (IUI)

J. S. Lee et al. 030821-2022 (IUI)

T. B. Lee s.n. (SNUA:30046); J. S. Lee et al. 030712-859 (IUI)

$\bigcirc$ J. S. Park \& Y. J. Jang 190730-35 (IUI)

J. S. Park \& Y. J. Jang 191103-75 (IUI)

J. S. Lee et al. 030510-311 (IUI)

J. S. Lee et al. 030713-940 (IUI)

J. S. Lee et al. 030509-203 (IUI)

J. S. Lee et al. 030404-16 (IUI)

J. S. Lee et al. 030509-233 (IUI)

J. S. Lee et al. 030614-4006 (IUI)

○

$\Rightarrow$ L. virginicum (Misid) 
Appendix 1. Continued

\begin{tabular}{|c|c|c|}
\hline Taxa & $\begin{array}{l}\text { Previous } \\
\text { studies }\end{array}$ & This study and voucher specimens \\
\hline 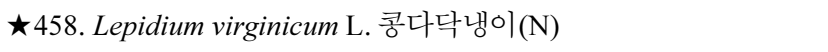 & & J. S. Lee et al. 030614-549 (IUI) \\
\hline 459. Raphanus sativus var. hortensis f. raphanistroides Makino 갯무 & O & \\
\hline 460. Rorippa indica (L.) Hiern 개갓냉이 & $\bigcirc$ & \\
\hline ^461. Turritis glabra L. 장대나물 & & Y. J. Jang 200703-43 (IUI) \\
\hline \multicolumn{3}{|l|}{ SANTALACEAE 단향과 } \\
\hline 462. Korthalsella japonica (Thunb.) Engl. 동백나무겨우살이(III) & 0 & $\begin{array}{l}\text { T. B. Lee s.n. (SNUA:54175); T. B. Lee s.n. } \\
\text { (SNUA:54199); T. B. Lee } 4289 \\
\text { (SNUA:54196); J. S. Lee et al. 030613-422 } \\
\text { (IUI) }\end{array}$ \\
\hline
\end{tabular}

\section{PLUMBAGINACEAE 갯질경과}

463. Limonium tetragonum (Thunb.) Bullock 갯질경

\section{POLYGONACEAE 마디풀과}

464. Aconogonon alpinum (All.) Schur 싱아

$\star$ 465. Fallopia dumetorum (L.) Holub 닭의덩굴

466. Polygonum aviculare L. 마디풀

467. Polygonum hydropiper L. 여뀌

468. Polygonum japonicum Meisn 흰꽃여뀌

469. Polygonum longisetum Bruijn 개여뀌

470. Polygonum perfoliatum L. 며느리배꼽

$\star 471$. Polygonum persicaria L. 봄여뀌

472. Polygonum senticosum (Meisn.) Franch. \& Sav. 며느리배꼽

473. Rumex crispus $\mathrm{L}$. 소리쟁이 $(\mathrm{N})$

$\star$ 474. Rumex japonicus Houtt. 참소리쟁이

\section{CARYOPHYLLACEAE 석죽과}

^475. Cerastium glomeratum Thuill. 유럽점나도나물(양점나도나물)

$\star$ 476. Cerastium holosteoides var. Hallaisanense (Nakai) M. Mizush. 점나도나 물

477. Dianthus chinensis L. 패랭이꽃

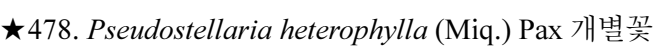

479. Pseudostellaria palibiniana (Takeda) Ohwi 큰개별꽃

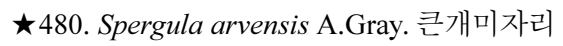

$\star$ 481. Sagina japonica (Sw.) Ohwi 개미자리

$\star$ 482. Sagina maxima L. 들개미자리 $(\mathrm{N})$

483. Silene aprica var. oldhamiana (Miq.) C.Y. Wu 갯장구채

484. Spergularia marina (L.) Besser 갯개미자리

485. Stellaria media (L.) Vill. 별꽃(N)

J. S. Lee et al. 030822-2095 (IUI)

J. S. Lee et al. 030822-2085 (IUI)

$\bigcirc$ 
Appendix 1. Continued

\section{Taxa}

487. Amaranthus mangostanus L. 비름

488. Amaranthus reteroflexus L. 털비름

$\star$ 489. Amaranthus viridis $\mathrm{L}$. 청비름 $(\mathrm{N})$

490. Atriplex gmelinii C.A.Mey. ex Bong. 가는갯는쟁이

491. Chenopodium album L. 명아주(흰명아주)(N)

$\star$ 492. Chenopodium ficifolium Sm. 좀명아주(N)

$\star$ 493. Salsola komarovii Iljin 수송나물

494. Suaeda japonica Makino 칠면초

AIZOACEAE 번행초과

495. Tetragonia tetragonoides (Pall.) Kuntze 번행초

\section{PHYTOLACCACEAE 자리공과}

496. Phytolacca acinosa Roxb. 자리공

$\star$ 497. Phytolacca americana L. 미국자리공 $(\mathrm{N})$

\section{NYCTAGINACEAE 분꽃과}

498. Mirabilis jalapa L. 분꽃*

\section{PORTULACACEAE 쇠비름과}

499. Portulaca oleracea L. 쇠비름

\section{CACTACEAE 선인장과}

500. Opuntia ficus-indica (L.) Mill. 선인장

\section{CORNACEAE 충층나무과}

501. Alangium platanifolium (Siebold \& Zucc.) Harms 박쥐나무

\section{BALSAMINACEAE 봉선화과}

502. Impatiens balsamina L. 봉선화

\section{PENTAPHYLACACEAE 펜타필락스과}

^503. Cleyera japonica Thunb. 비쭈기나무(IV)

504. Eurya emarginata (Thunb.) Makino 우묵사스레피나무(III)

505. Eurya japonica Thunb. 사스레피나무

\section{EBENACEAE 감나무과}

506. Diospyros kaki Thunb. 감나무*

507. Diospyros lotus L. 고욤나무

\section{PRIMULACEAE 앵초과}

508. Ardisia crenata Sims 백량금(III)

509. Ardisia japonica (Thunb.) Blume 자금우

510. Ardisia pusilla A.DC. 산호수

511. Lysimachia fortunei Maxim. 진퍼리까치수염

512. Lysimachia japonica Thunb. 좀가지풀

Previous
studies $\quad$ This study and voucher specimens

J. S. Lee et al. 030823-2213 (IUI)

J. S. Park \& Y. J. Jang 190927-47 (IUI)

J. S. Park \& Y. J. Jang 190927-50 (IUI)

Y. J. Jang 200916-1 (IUI)

T. B. Lee 793 (SNUA:80087); J. S. Lee et al. 030713-935 (IUI)

J. S. Lee et al. 030822-2082 (IUI)

Y. J. Jang 200703-51 (IUI)

J. S. Lee et al. 030823-2035 (IUI)

Observation!

J. S. Lee et al. 030825-2268 (IUI)

\section{T. B. Lee 2174 (SNUA:38541)}

T. B. Lee 4284 (SNUA:73328); J. S. Lee et al. 030823-2212 (IUI)

T. B. Lee 4301 (SNUA:78753); J. S. Lee et al. 030404-21 (IUI)

T. B. Lee 2519 (SNUA:5074); D. P. Jin \& Y. J. Jang 200111-30 (IUI)

T. B. Lee s.n. (SNUA:30143); J. H. Lee et al. 090320-93057 (IUI)

$\bigcirc$

$\Rightarrow$ L. pentapetala (Misid)

J. S. Lee et al. 030405-99 (IUI) 
Appendix 1. Continued

Taxa Previous studies

513. Lysimachia mauritiana Lam. 갯까치수염

514. Lysimachia pentapetala Bunge 홍도까치수염(쇠까치수염) (EN, IV)

515. Trientalis europaea $\mathrm{L}$. 참기생꽃

THEACEAE 차나무과

516. Camellia japonica L. 동백나무

517. Camellia japonica f. albipetala H.T.Chang 흰동백나무

\section{SYMPLOCACEAE 노린재나무과}

$\star 518$. Symplocos tanakana Nakai 검노린재

\section{STYRACACEAE 때죽나무과}

519. Styrax japonicus Siebold \& Zucc. 때죽나무

\section{ACTINIDIACEAE 다래나무과}

520. Actinidia arguta (Siebold \& Zucc.) Planch. ex Miq. 다래

\section{ERICACEAE 진달래과}

521. Chimaphila japonica Miq. 매화노루발

522. Pyrola japonica Klenze ex Alef. 노루발

^523. Rhododendron mucronulatum Turcz. 진달래

524. Rhododendron mucronulatum var. ciliatum Nakai 털진달래

525. Rhododendron mucronulatum var. lucidum Nakai 반들진달래

526. Rhododendron yedoense f. poukhanense (H.Lév.) Sugim. ex T.Yamaz. 산철 叒

527. Vaccinium bracteatum Thunb. 모새나무(III)

528. Vaccinium oldhamii Miq. 정금나무

\section{EUCOMMIACEAE 두충과}

$\star 529$. Eucommia ulmoides Oliv. 두충*

\section{GARRYACEAE 가리아과}

530. Aucuba japonica Thunb. 식나무(III)

\section{RUBIACEAE 꼭두선이과}

531. Damnacanthus indicus C.F. Gaertn. 호자나무(III)

532. Damnacanthus major Siebold \& Zucc. 수정목(IV)
This study and voucher specimens

Ishidoya, T. \& T. H. Chung 3663 (TI); J. S.

Lee et al. 030614-576 (IUI)

- Ishidoya, T. \& T. H. Chung 3664 (TI); T. B. Lee 2538 (SNUA:89772); T. B. Lee 2542 (SNUA:89773); T. B. Lee 2542

(SNUA:89774); Y. J. Jang 200916-6 (IUI)

○

T. B. Lee 2618 (SNUA:79900); T. B. Lee 42 (SNUA:79915); T. B. Lee s.n. (SNUA:79903); T. B. Lee s.n. (SNUA:79909); J. S. Lee et al. 030404-19 (IUI)

$$
\Rightarrow \text { C. japonica (Synonym) }
$$

T. B. Lee s.n. (SNUA:71348)

Y. J. Jang 200602-32 (IUI)

$\bigcirc \quad$ J. S. Lee et al. 030614-513 (IUI)

- T. B. Lee s.n. (SNUA:89497); J. S. Lee et al. 030713-922 (IUI)

Miwa-Tosio s.n. (TI; Holotype); J. S. Lee et al. 030615-662 (IUI)

$\bigcirc \quad \Rightarrow$ R. mucronulatum (Synonym)

$\Rightarrow$ R. mucronulatum (Synonym)

$\bigcirc$

- Ishidoya, T. \& T. H. Chung 3650 (TI); T. B. Lee 2497 (SNUA:13612); T. B. Lee 2497 (SNUA:4219); J. S. Lee et al. 030822-2102 (IUI)

Y. J. Jang 200603-54 (IUI)

T. B. Lee 1380 (SNUA)

- T. B. Lee s.n. (SNUA:70853); T. B. Lee 4280 (SNUA:70865); T. B. Lee 2448 (SNUA); $J$. S. Lee et al. 030510

Y. J. Jang 200318-38 (IUI)

Y. J. Jang 200601-11 (IUI) 
Appendix 1. Continued

Taxa Previous
studies

This study and voucher specimens

533. Galium dahuricum Turcz. ex Ledeb. 큰잎갈퀴

534. Galium gracilens (A. Gray) Makino 좀네잎갈퀴

535. Galium kinuta Nakai \& H.Hara 민둥갈퀴

536. Galium pogonanthum Franch. \& Sav. 산갈퀴

537. Galium spurium var. echinospermum (Wallr.) Hayek 갈퀴덩굴

538. Galium trachyspermum A. Gray 네잎갈퀴

539. Mitchella undulata Siebold \& Zucc. 호자덩굴(III)

540. Paederia foetida L. 계요등

541. Paederia foetida var. angustifolia (Nakai) S.S.Ying 좁은잎계요등

542. Rubia argyi (H. Lév. \& Vaniot) H.Hara ex Lauener 꼭두선이

543. Rubia chinensis Regel \& Maack 큰꼭두선이

544. Rubia cordifolia var. pratensis Maxim. 갈퀴꼭두선이

\section{GENTIANACEAE 용담과}

545. Gentiana zollingeri Fawc. 큰구슬붕이

LOGANIACEAE 마전과

546. Gardneria insularis Nakai 영주치자(III)

\section{APOCYNACEAE 협죽도과}

547. Cynanchum wilfordii (Maxim.) Maxim. ex Hook. f. 큰조롱

548. Metaplexis japonica (Thunb.) Makino 박주가리

549. Trachelospermum asiaticum (Siebold \& Zucc.) Nakai 마삭줄

\section{BORAGINACEAE 지치과}

550. Argusia sibirica (L.) Dandy 모래지치

551. Bothriospermum zeylanicum (J. Jacq.) Druce 꽃받이

552. Lithospermum zollingeri A. DC. 반디지치

$\star$ 553. Trigonotis peduncularis (Trevis.) Benth. ex Baker \& S. Moore 꽃마리

\section{CONVOLVULACEAE 메꽃과}

554. Calystegia sepium var. japonica (Choisy) Makino 메꽃

555. Calystegia soldanella (L.) R.Br. 갯메꽃

556. Quamoclit coccinea Moench 둥근잎유홍초*

\section{SOLANACEAE 가지과}

557. Lycium chinense Mill. 구기자나무(N)

558. Physalis alkekengi L. 꽈리

560. Solanum lyratum Thunb. 배풍등

561. Solanum nigrum L. 까마중 $(\mathrm{N})$

562. Tubocapsicum anomalum (Franch. \& Sav.) Makino 알꽈리
J. S. Lee et al. 030511-353 (IUI)

$\Rightarrow R$. chinensis (Misid)

J. S. Lee et al. 030613-436 (IUI)

Y. J. Jang 200602-25 (IUI)

J. S. Lee et al. 030615-648 (IUI)

J. S. Lee et al. 030822-2093 (IUI)

J. S. Lee et al. 030821-2057 (IUI)

Y. J. Jang 200512-48 (IUI)

J. S. Lee et al. 030821-2072 (IUI)

Y. J. Jang 200421-29 (IUI)

D. P. Jin \& Y. J. Jang 200110-12 (IUI)

T. B. Lee 2666 (SNUA:91173); J. S. Lee et al. 030822-2087 (IUI)

T. B. Lee 2666 (SNUA:91079); J. S. Lee et al. 030615-677 (IUI)

Y. J. Jang 200511-23 (IUI)

$\bigcirc$ J.S. Lee et al. 030510-256 (IUI)

$\bigcirc \quad$ J. S. Lee et al. 030405-85 (IUI)

J. S. Lee et al. 030509-222 (IUI)

J. S. Lee et al. 030712-887 (IUI)

J. S. Lee et al. 030614-617 (IUI)

$\bigcirc$

Y. J. Jang 200918-35 (IUI)

T. B. Lee 2868 (SNUA:91173)

T. B. Lee s.n. (SNUA:92795); T. B. Lee 2874 (SNUA:92777); J. S. Lee et al. 0308222169 (IUI)

$\bigcirc \quad$ J. S. Lee et al. 030713-939 (IUI)

Ishidoya, T. \& T. H. Chung 3785 (TI); T. B. Lee s.n. (SNUA:92815); T. B. Lee s.n. (SNUA:92816); T. B. Lee 4235 (SNUA:92814); T. B. Lee 2880 (SNUA:92813); J. S. Lee et al. 0308232039 (IUI)
J. S. Lee et al. 030510-317 (IUI) 
Appendix 1. Continued

Taxa

\section{OLEACEAE 물푸레나무과}

563. Forsythia koreana (Rehder) Nakai 개나리*

564. Fraxinus rhynchophylla Hance 물푸레나무

565. Fraxinus sieboldiana Blume 쇠물푸레

566. Ligustrum japonicum Thunb. 광나무

567. Ligustrum obtusifolium Siebold \& Zucc. 쥐똥나무

568. Ligustrum ovalifolium Hassk. 왕쥐똥나무

569. Syringa patula var. kamibayashii (Nakai) M.Kim 정향나무

PLANTAGINACEAE 질경이과

570. Callitriche japonica Engelm. ex Hegelm. 별이끼

571. Plantago asiatica L. 질경이

572. Plantago camtschatica Cham. ex Link 개질경이

$\star$ 573. Plantago depressa Willd. 털질경이

574. Plantago major var. japonica (Franch. \& Sav.) Kuntze 왕질경이

$\star 575$. Veronica arvensis L. 선개불알풀 $(\mathrm{N})$

576. Veronica persica Poir. 큰개불알풀(N)

577. Veronica polita subsp. lilacina (H. Hara ex T. Yamaz.) T. Yamaz. 개불알풀

\section{ACANTHACEAE 쥐꼬리망초과}

578. Justicia procumbens L. 쥐꼬리망초

\section{LAMIACEAE 꿀풀과}

579. Callicarpa japonica Thunb. 작살나무

580. Callicarpa japonica var. luxurians Rehder 왕작살나무

581. Caryopteris incana (Thunb. ex Houtt.) Miq. 층꽃나무

582. Clerodendrum trichotomum Thunb. 누리장나무

583. Clinopodium chinense (Benth.) Kuntze 층층이꽃

584. Clinopodium multicaule (Maxim.) Kuntze 탑꽃

585. Elsholtzia ciliata (Thunb.) Hyl. 향유

586. Isodon inflexus (Thunb.) Kudô 산박하

$\star 587$. Isodon inflexus var. canescens (Nakai) Kudô 털산박하(E)

588. Isodon japonicus (Burm.f.) H.Hara 방아풀

589. Lamium amplexicaule L. 광대나물

590. Leonurus japonicus Houtt. 익모초 \begin{tabular}{c}
$\begin{array}{c}\text { Previous } \\
\text { studies }\end{array} \quad$ This study and voucher specimens \\
\hline
\end{tabular} 
Appendix 1. Continued

Taxa Previous

studies This study and voucher specimens

591. Meehania urticifolia (Miq.) Makino 벌깨덩굴

592. Mosla dianthera (Buch.-Ham. ex Roxb.) Maxim. 쥐깨풀

593. Mosla japonica (Benth.) Maxim. f. thymolifera (Makino) T.Yamaz. \& Murata 섬쥐깨풀

594. Mosla scabra (Thunb.) C.Y.Wu \& H.W.Li 들깨풀

595. Salvia plebeia R.Br. 배암차즈기

596. Scutellaria fauriei H.Lév. \& Vaniot 그늘골무꽃

597. Scutellaria indica L. 골무꽃

598. Scutellaria pekinensis var. transitra (Makino) H.Hara 산골무꽃

$\star$ 599. Teucrium veronicoides Maxim. 곽향(III)

600. Vitex negundo var. heterophylla (Franch.) Rehder 좀목형(III)

601. Vitex rotundifolia L. f. 순비기나무

$\bigcirc$

MAZACEAE 주름잎과

602. Mazus pumilus (Burm. f.) Steenis 주름잎

\section{PHRYMACEAE 파리풀과}

603. Phryma leptostachya var. oblongifolia (Koidz.) Honda 파리풀

\section{OROBANCHACEAE 열당과}

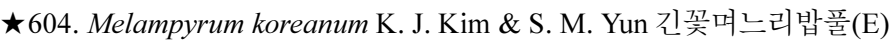

605. Melampyrum roseum Maxim. 꽃며느리밥풀

606. Melampyrum roseum var. ovalifolium (Nakai) Nakai ex Beauverd 알며느리 밥풀

607. Melampyrum setaceum (Maxim. ex Palib.) Nakai 애기며느리밥풀(III)

608. Paulownia coreana Uyeki 오동나무*

609. Pseudolysimachion linariifolium (Pall. ex Link) Holub 꼬리풀

610. Siphonostegia chinensis Benth. 절국대

\section{AQUIFOLIACEAE 감탕나무과}

611. Ilex crenata Thunb. 꽝꽝나무

612. Ilex integra Thunb. 감탕나무(III)

614. Ilex rotunda Thunb. 먼나무

\section{CAMPANULACEAE 초롱꽃과}

615. Adenophora divaricata Franch. \& Sav. 넓은잔대

616. Adenophora stricta Miq. 당잔대

617. Adenophora triphylla var. japonica (Regel) H.Hara 잔대

618. Adenophora triphylla (Thunb.) A. DC. 층층잔대

T. B. Lee 2004 (SNUA:28469); T. B. Lee 2031 (SNUA:38469); J. S. Lee et al. 030405-62 (IUI)

J. S. Lee et al. 030613-4002 (IUI)

- T. B. Lee 2842 (SNUA:92459); Y. J. Jang 200601-6 (IUI)

T. B. Lee 3027 (SNUA:92586)

$\bigcirc \quad$ J. S. Lee et al. 030821-2026 (IUI)

J. S. Park \& Y. J. Jang 190729-17 (IUI)

Y. J. Jang 200512-53 (IUI)

- T. B. Lee s.n. (SNUA:90373); Y. J. Jang 200702-24 (IUI)

T. B. Lee 2904 (SNUA); Y. J. Jang 20091840 (IUI)

Y. J. Jang 200818-14 (IUI)

Y. J. Jang 200818-14 (IUI)

T. B. Lee s.n. (SNUA); J. S. Park \& Y. J. Jang 190926-2 (IUI)

$\bigcirc$

- T. B. Lee s.n. (SNUA:90799, SNUA:90800); J. S. Lee et al. 030821-2042 (IUI)

$\bigcirc$

- Ishidoya, T. \& T. H. Chung 3729 (TI); J. S.

Park \& Y. J. Jang 191101-14 (IUI)

$\Rightarrow$ A. triphylla (Misid)

T. B. Lee s.n. (SNUA:93538); J. S. Lee et al. 030822-2138 (IUI) 
Appendix 1. Continued

Taxa Previous studies

619. Adenophora triphylla var. angustifolia (Regel) Kitam. 가는층층잔대

620. Codonopsis lanceolata (Siebold \& Zucc.) Benth. \& Hook. f. ex Trautv. 더덕

621. Codonopsis ussuriensis (Rupr. \& Maxim.) Hemsl. 소경불알

622. Platycodon grandiflorus (Jacq.) A.DC. 도라지

\section{ASTERACEAE 국화과}

623. Ainsliaea apiculata Sch. Bip. 좀딱취

624. Artemisia capillaris Thunb. 사철쑥

$\star 625$. Artemisia feddei H. Lév. \& Vaniot 뺑쑥

626. Artemisia fukudo Makino 큰비쑥:

627. Artemisia japonica Thunb. 제비쑥

628. Artemisia keiskeana Miq. 맑은대쑥

629. Artemisia littoricola Kitam. 갯제비쑥

630. Artemisia princeps Pamp. 쑥

631. Artemisia scoparia Waldst. \& Kit. 비쑥

632. Artemisia stolonifera (Maxim.) Kom. 넓은잎외잎쑥

633. Aster ageratoides Turcz. 까실쑥부쟁이

634. Aster hispidus Thunb. 갯쑥부쟁이

635. Aster scaber Thunb. 참취

636. Aster spathulifoliu Maxim. 해국

$\star 637$. Aster subulatus Michx. 비짜루국화(N)

638. Aster yomena (Kitam.) Honda 쑥부쟁이

639. Atractylodes ovata Thunb.DC. 삽주

640. Bidens bipinnata L. 도깨비바늘

$\star$ 641. Bidens biternata (Lour.) Merr. ex Sherff 털도깨비바늘

642. Calendula arvensis $\mathrm{L}$. 금잔화

643. Carduus crispus L. 지느러미엉겅퀴

644. Carpesium abrotanoides L. 담배풀

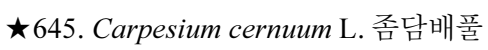

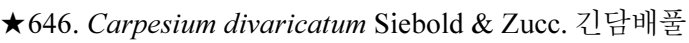

647. Carpesium glossophyllum Maxim. 천일담배풀
This study and voucher specimens

$\Rightarrow$ A. triphylla (Synonym)

J. S. Lee et al. 030822-2125 (IUI)

Y. J. Jang 200818-23 (IUI)

0

- Ishidoya, T. \& T. H. Chung s.n. (TI); T. B. Lee 4286 (SNUA:32973); J. S. Lee et al. 030822-2139 (IUI)

$\bigcirc \quad$ Y. J. Jang 200917-19 (IUI)

Y. J. Jang 200917-29 (IUI)

$\bigcirc \quad$ J. S. Lee et al. 030712-901 (IUI)

$\bigcirc \quad$ J. S. Lee et al. 030822-2161 (IUI)

Y. J. Jang 200818-11 (IUI)

Misidentification

T. B. Lee 3301 (SNUA:94244); J. S. Lee et al. 030822-2158 (IUI)

$$
\Rightarrow \text { A. capillaris (Misid) }
$$

○

- Ishidoya, T. \& T. H. Chung 3762 (TI); J. S. Lee et al. 030823-2257 (IUI)

- Ishidoya, T. \& T. H. Chung 3756, 3765 (TI); J. S. Lee et al. 030823-2203 (IUI)

- T. B. Lee 3336 (SNUA:94591); T. B. Lee 3336 (SNUA:94598); J. S. Lee et al. 030822-2136 (IUI)

- T. B. Lee 4316 (SNUA:94682); J. S. Park \& Y. J. Jang 190927-54 (IUI)

J. S. Lee et al. 030823-2202 (IUI)

T. B. Lee 3343 (SNUA:94784); J. S. Lee et al. 030822-2173 (IUI)

J. S. Lee et al. 030821-2262 (IUI)

$\bigcirc$

- Ishidoya, T. \& T. H. Chung 3734 (TI); J. S. Lee et al. 031025-? (IUI)

Ishidoya, T. \& T. H. Chung 1370 (SKK); Ishidoya, T. \& T. H. Chung 3732 (TI); J. S. Lee et al. 030821-2009 (IUI)

Ishidoya, T. \& T. H. Chung 3731 (TI); T. B. Lee s.n. (SNUA:94945)

$\Rightarrow$ C. cernuum (Misid) 
Appendix 1. Continued

Taxa Previous studies
This study and voucher specimens

648. Chrysanthemum boreale (Makino) Makino 산국

649. Chrysanthemum indicum L. 감국

650. Chrysanthemum zawadskii var. latilobum (Maxim.) Kitam. 구절초

651. Cirsium japonicum var. maackii (Maxim.) Matsum. 엉겅퀴

652. Cirsium japonicum var. spinossimum Kitam. 가시엉겅퀴

$\star$ 653. Conyza bonariensis (L.) Cronquist 실망초(N)

654. Conyza canadensis (L.) Cronquist 망초(N)

$\star$ 655. Conyza sumatrensis E.Walker 큰망초(N)

656. Coreopsis lanceolata L. 큰금계국(N)

657. Coreopsis tinctoria Nutt. 기생초(N)

658. Cosmos bipinnatus Cav. 코스모스*

659. Crepidiastrum denticulatum (Houtt.) J. H. Pak \& Kawano 이고들 빼기

660. Crepidiastrum lanceolatum (Houtt.) Nakai 갯고들 빼기

661. Crepidiastrum $\times$ muratagenii H. Ohashi \& K. Ohashi 홍도고들빼기

662. Crepidiastrum sonchifolium (Maxim.) J.H.Pak \& Kawano 고들 빼기

663. Eclipta prostrata (L.) L. 한련초(N)

664. Erigeron annuus (L.) Pers. 개망초(N)

^665. Erigeron strigosus Muhl. ex Willd. 주걱개망초(N)

666. Euchiton japonicus (Thunb.) Holub 풀솜나물

667. Eupatorium fortunei Turcz. 새등골나물

668. Eupatorium japonicum Thunb. 등골나물

669. Eupatorium lindleyanum DC. 골등골나물

$\star 670$. Eupatorium tripartitum (Makino) Murata \& H.Koyama 향등골나물

671. Farfugium japonicum (L.) Kitam. 털머위(III)

^672. Galinsoga parviflora Cav. 별꽃아재비(N)

673. Ixeridium dentatum (Thunb.) Tzvelev 씀바귀

674. Lactuca indica L. 왕고들 빼기

675. Ligularia fischeri (Ledeb.) Turcz. 곰취

676. Ligularia intermedia Nakai 어리곤달비

677. Ligularia stenocephala (Maxim.) Matsum. \& Koidz. 곤달비(III)

$\star$ 678. Petasites japonicus (Siebold \& Zucc.) Maxim. 머위

679. Prenanthes ochroleuca (Maxim.) Hemsl. 왕씀배

680. Pseudognaphalium affine (D.Don) Anderb. 떡쑥

681. Pseudognaphalium hypoleucum (DC.) Hilliard \& B.L.Burtt 금떡쑥

Y. J. Jang 201028-3 (IUI)

J. S. Park \& Y. J. Jang 190927-59 (IUI)

T. B. Lee 3407 (SNUA:95157); J. S. Lee et al. 030614-500 (IUI)

T. B. Lee 3409 (SNUA:95213)

J. S. Lee et al. 030821-2069 (IUI)

J. S. Park \& Y. J. Jang 191101-3 (IUI)

J. S. Lee et al. 030821-20091 (IUI)

$\bigcirc \quad$ J. S. Lee et al. 030713-949 (IUI)

$\bigcirc \quad$ J. S. Lee et al. 030713-950 (IUI)

$\bigcirc$

Y. J. Jang 201029-4 (IUI)

Ishidoya, T. \& T. H. Chung 3741 (TI); Y. J. Jang 201029-3 (IUI)

J. S. Lee et al. 030822-2094 (IUI)

$\bigcirc$ J.S. Park \& Y. J. Jang 190927-32 (IUI)

J. S. Park \& Y. J. Jang 190730-29 (IUI)

$\bigcirc$ J.S. Lee et al. 030615-691 (IUI)

$\bigcirc$

T. B. Lee s.n. (SNUA:95475); J. S. Park \& Y. J. Jang 190926-5 (IUI)

$\bigcirc \quad$ J. S. Lee et al. 030822-2081 (IUI)

T. B. Lee 3446 (SNUA:95420); T. B. Lee 3448 (SNUA: 95421); J. S. Lee et al. 030713-928 (IUI)

T. B. Lee 4285 (SNUA:95563); J. S. Lee et al. 031024-1312 (IUI)

J. S. Park \& Y. J. Jang 191103-55 (IUI)

Misidentification

Ishidoya, T. \& T. H. Chung 1431 (SKK); J. S. Lee et al. 030823-2031 (IUI)

Y. J. Jang 200317-21 (IUI)

J. S. Lee et al. 030613-438(IUI) 
Appendix 1. Continued

Taxa Previous studies

682. Saussurea gracilis Maxim. 은분취(가야산은분취)

683. Saussurea maximowiczii Herder 버들분취

684. Saussurea polylepis Nakai 홍도서덜취(VU, E)

685. Saussurea seoulensis Nakai 분취

$\star 686$. Senecio vulgaris L. 개쑥갓 $(\mathrm{N})$

687. Serratula coronata subsp insularis (Iljin) Kitam. 산비장이

688. Sigesbeckia glabrescens (Makino) Makino 진득찰

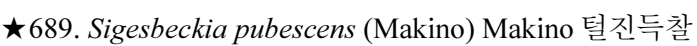

690. Solidago virgaurea subsp asiatica (Nakai ex H.Hara) Kitam. ex H.Hara 미역 취

691. Sonchus asper (L.) Hill 큰방가지똥(N)

692. Sonchus oleraceus L. 방가지똥(N)

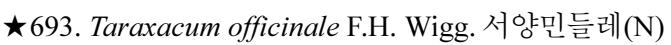

694. Taraxacum mongolicum Hand.-Mazz. 털민들레(민들레)

695. Xanthium strumarium L. 도꼬마리(N)

696. Youngia japonica (L.) DC. 뽀리뱅이

VIBURNACEAE 산분꽃나무과

697. Viburnum carlesii Hemsl. 분꽃나무

698. Viburnum dilatatum Thunb. 가막살나무

699. Viburnum erosum Thunb. 덜뀡나무

700. Viburnum wrightii Miq. 산가막살나무

\section{CAPRIFOLIACEAE 인동과}

701. Lonicera japonica Thunb. 인동

702. Sambucus racemosa L. subsp. pendula (Nakai) H.I.Lim \& Chin S.Chang 말 오줌나무

703. Sambucus williamsii Hance 딱총나무

704. Patrinia villosa (Thunb.) Dufr. 뚝갈

705. Valeriana fauriei Briq. 쥐오줌풀

706. Weigela subsessilis (Nakai) L.H.Bailey 병꽃나무

\section{PITTOSPORACEAE 돈나무과}

707. Pittosporum tobira (Thunb.) W.T. Aiton 돈나무(III)

\section{ARALIACEAE 두릅나무과}

708. Aralia elata (Miq.) Seem. 두릅나무
This study and voucher specimens

T. B. Lee s.n. (SNUA:95963)

Ishidoya, T. \& T. H. Chung 3735 (TI;

Holotype); T. B. Lee s.n. (SNUA); J. S. Lee et al. 030822-2170 (IUI)

Misidentification

J. S. Lee et al. 030405-109 (IUI)

- Ishidoya, T. \& T. H. Chung 3739 (TI); J. S.

Lee et al. 031024-1307 (IUI)

J. S. Lee et al. 030821-2061 (IUI)

J. S. Park \& Y. J. Jang 191102-28 (IUI)

Y. J. Jang 200601-8 (IUI)

J. S. Park \& Y. J. Jang 191103-51 (IUI)

Y. J. Jang 200318-30 (IUI)

J. S. Lee et al. 030821-2053 (IUI)

Y. J. Jang 200512-49 (IUI)

T. B. Lee 3135 (SNUA:68085, SNUA:68096, SNUA:68098); J. S. Lee et al. 030614-538 (IUI)

J. S. Lee et al. 030822-2150 (IUI)

- Ishidoya, T. \& T. H. Chung 3715 (TI); T. B. Lee 3138 (SNUA:68674); J. S. Lee et al. 030509-224 (IUI)

J. S. Lee et al. 030823-2207 (IUI)

$\bigcirc \quad$ Misidentification

T. B. Lee 3166 (SNUA:93284); J. S. Park \& Y. J. Jang 190926-11 (IUI)

Ishidoya, T. \& T. H. Chung 3507 (TI); T. B. Lee s.n. (SNUA:59804); T. B. Lee 4279 (SNUA:59836); Y. J. Jang 200511-4 (IUI)

- T. B. Lee 2349 (SNUA:75978); J. S. Lee et al. 030822-2086 (IUI) 
Appendix 1. Continued

Taxa Previous studies

709. Dendropanax trifidus (Thunb.) Makino ex H.Hara 황칠나무(III)

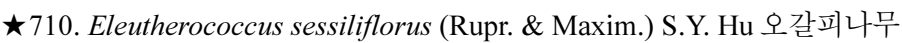

711. Hedera rhombea (Miq.) Siebold \& Zucc. ex Bean 송악

712. Hydrocotyle maritima Honda 선피막이

713. Kalopanax septemlobus (Thunb.) Koidz. 음나무

APIACEAE 미나리과

714. Angelica japonica A. Gray 갯강활(IV)

$\star 715$. Anthriscus sylvestris (L.) Hoffm. 전호

716. Bupleurum komarovianum Lincz. 시호

717. Centella asiatica (L.) Urb. 병풀(III)

718. Cryptotaenia japonica Hassk. 파드득나물

719. Heracleum moellendorffii Hance 어수리

720. Ostericum grosseserratum (Maxim.) Kitag. 신감채

721. Ostericum sieboldii (Miq.) Nakai 묏미나리

722. Peucedanum japonicum Thunb. 갯기름나물

723. Peucedanum terebinthaceum (Fisch. ex Trevir.) Fisch. ex Turcz. 기름나물

724. Peucedanum terebinthaceum var. deltoideum (Makino ex K.Yabe) Makino 산 기름나물

725. Sanicula chinensis Bunge 참반디

726. Sanicula rubriflora F.Schmidt ex Maxim. 붉은참반디

$\star$ 727. Sanicula tuberculata Maxim. 애기참반디(III)

728. Torilis japonica (Houtt.) DC. 사상자

^729. Torilis scabra (Thunb.) DC. 큰사상자(개사상자)
This study and voucher specimens

T. B. Lee 41032 (SNUA); T. B. Lee 4290 (SNUA:33105); J. S. Lee et al. 030405-88 (IUI)

Y. J. Jang 200819-30 (IUI)

$\bigcirc \quad$ J. S. Lee et al. 030404-131 (IUI)

$\bigcirc \quad$ J. S. Lee et al. 030510-2211 (IUI)

Y. J. Jang 200512-30 (IUI)

J. S. Park \& Y. J. Jang 190729-14 (IUI)

J. S. Lee et al. 030509-210 (IUI)

$\bigcirc$

J. S. Lee et al. 030823-2218 (IUI)

$\bigcirc$

T. B. Lee 2868 (SNUA:88889)

J. S. Lee et al. 030822-2121 (IUI)

$\bigcirc$

- T. B. Lee s.n. (SNUA:89137); J. S. Lee et al. 030712-8511 (IUI)

Y. J.Jang 200819-28 (IUI)

$\bigcirc$

- T. B. Lee s.n, (SNUA:89327); J. S. Lee et al. 030823-2036 (IUI)

- $\Rightarrow$ S. tuberculata (Misid)

T. B. Lee s.n (SNUA:89369); J. S. Lee et al. 030614-509 (IUI)

J. S. Lee et al. 030712-882 (IUI)

J. S. Lee et al. 030615-688 (IUI) 